Nova Southeastern University

Florida

\title{
Lived Experience of Adolescents with Chronic Pain: A Phenomenological Study
}

Ryan Christopher Suder

Nova Southeastern University

This document is a product of extensive research conducted at the Nova Southeastern University College of Health Care Sciences. For more information on research and degree programs at the NSU College of Health Care Sciences, please click here.

Follow this and additional works at: https://nsuworks.nova.edu/hpd_ot_student_dissertations

Part of the Occupational Therapy Commons

All rights reserved. This publication is intended for use solely by faculty, students, and staff of Nova Southeastern University. No part of this publication may be reproduced, distributed, or transmitted in any form or by any means, now known or later developed, including but not limited to photocopying, recording, or other electronic or mechanical methods, without the prior written permission of the author or the publisher.

\section{NSUWorks Citation}

Ryan Christopher Suder. 2016. Lived Experience of Adolescents with Chronic Pain: A Phenomenological Study. Doctoral dissertation. Nova Southeastern University. Retrieved from NSUWorks, College of Health Care Sciences - Occupational Therapy Department. (53)

https://nsuworks.nova.edu/hpd_ot_student_dissertations/53. 
THE LIVED EXPERIENCE OF ADOLESCENTS WITH CHRONIC PAIN: A PHENOMENOLOGICAL STUDY

\author{
by \\ Ryan Suder \\ Submitted in partial fulfillment of the requirements for the degree of \\ Doctor of Philosophy in Occupational Therapy \\ Occupational Therapy Department \\ College of Allied Health and Nursing \\ Nova Southeastern University \\ Fort Lauderdale, Florida 33328
}

June 2016 
ProQuest Number: 10190679

All rights reserved

INFORMATION TO ALL USERS

The quality of this reproduction is dependent upon the quality of the copy submitted.

In the unlikely event that the author did not send a complete manuscript and there are missing pages, these will be noted. Also, if material had to be removed, a note will indicate the deletion.

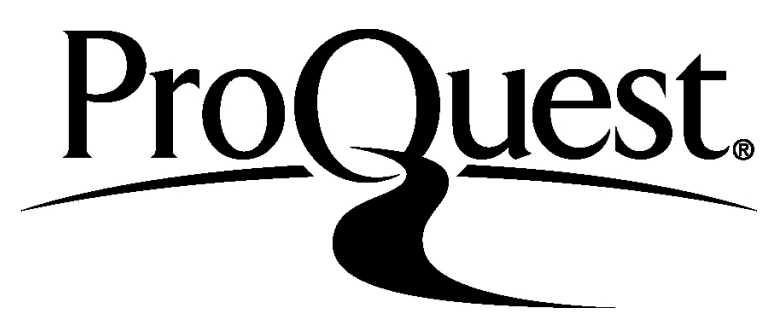

ProQuest 10190679

Published by ProQuest LLC (2016). Copyright of the Dissertation is held by the Author.

All rights reserved.

This work is protected against unauthorized copying under Title 17, United States Code Microform Edition (c) ProQuest LLC.

ProQuest LLC.

789 East Eisenhower Parkway

P.O. Box 1346

Ann Arbor, Ml 48106 - 1346 


\section{NOVA SOUTHEASTERN UNIVERSITY HEALTH PROFESSIONS DIVISION COLLEGE OF HEALTH CARE SCIENCES OCCUPATIONAL THERAPY DEPARTMENT FORT LAUDERDALE, FL 33328}

This dissertation, written by Ryan Suder under direction of his Dissertation Committee, and approved by all its members, has been presented and accepted in partial fulfillment of requirements for the degree of

DOCTOR OF PHILOSOPHY

DISSERTATION COMMITTEE

Cathy Peirce, Ph.D., OTR/L

Date

Chairperson of Dissertation Committee

Kristin Winston, Ph.D., OTR/L

Date

Dissertation Committee Member

Susan Bazyk, Ph.D., OTR/L, FAOTA

Date

Dissertation Committee Member 


\section{NOVA SOUTHEASTERN UNIVERSITY HEALTH PROFESSIONS DIVISION COLLEGE OF HEALTH CARE SCIENCES FORT LAUDERDALE, FL 33328}

\section{Certification}

We hereby certify that this dissertation, submitted by Ryan Suder, conforms to acceptable standards and is fully adequate in scope and quality to fulfill the dissertation requirement for the Doctor of Philosophy degree.

\section{Approved}

Kristin Winston, Ph.D., OTR/L

Date

Ph.D. in Occupational Therapy Program Director

Wendy Stav, Ph.D., OTR/L, FAOTA

Date

Managing Director of Fort Lauderdale Occupational Therapy Programs

Peter Taylor, Ph.D.

Date

Associate Dean of Academic Affairs

Stanley Wilson, PT, Ed.D., CEAS

Date

Dean, College of Health Care Sciences 
Copyright by Ryan Suder, 2016

All Rights Reserved 


\begin{abstract}
The purpose of this phenomenological study was to understand the lived experience of adolescents who live with chronic pain. All 10 participants were between the ages of 13 and 17 and have lived with chronic pain for at least 6 months. Data sources for the study were two interviews for each participant, participant drawn depictions of their chronic pain, and researcher journaling. The person-environment-occupation model was used to frame the research design. The study found four main themes among the data: pain identity, invisible disease, occupational loss, and uphill climb to regain life. Each theme described the essence of the common experience of adolescents living with chronic pain. Occupational therapists can benefit from incorporating this knowledge base into their practice when providing intervention for individuals living with chronic pain to improve their overall quality of life and occupational performance.
\end{abstract}

Keywords: phenomenological, chronic pain, adolescents, lived experience, occupational therapy, person-environment-occupation model 


\section{Acknowledgements}

I would like to thank each of my committee members for their patience and diligence in helping me accomplish this significant feat in my life. I also could not have completed my doctoral work without the loving support of my husband, Matthew. He stuck with me through the toughest and most challenging times while completing my doctoral work. I love you Hon! To my two children, Madison and Riley, your smiling faces got me up every morning and gave me the drive to see this through to the end. To my Aunt Sharyn and Grandma Ernie, thank you for supporting me throughout the challenging years of being in school and gave me the drive to see it through until the end. My father and stepmother have always been supporters of my educational career. I would like to thank them both for helping me through the tough times. Although living across the country, my sister has been a supporter throughout the long and arduous process. Thank you to my stepfather, Larry, for giving me the inspiration to do whatever was important to me in my life. He also taught me to not sweat the small stuff and keep life in check. I also could not have completed this study without the generous support of each participant, allowing me to learn more about their lives. Lastly, I could never have believed I could accomplish my doctoral degree without my mother being such a great role model. Before she died, she always encouraged me to work to my fullest potential and to expand my horizons through education. She always told me to never give up and continue to try my best. I dedicate this research to her for always being my biggest supporter. I miss you Mom! 


\section{Table of Contents}

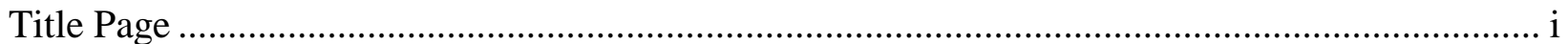

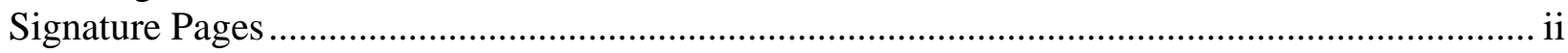

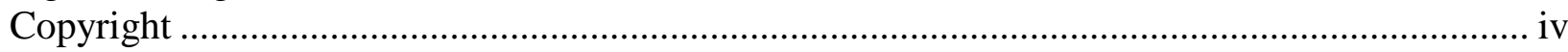

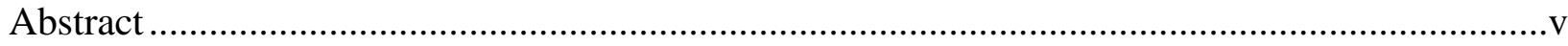

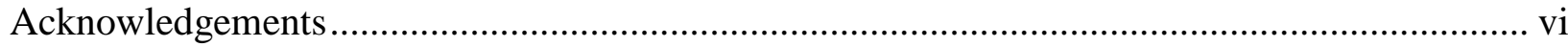

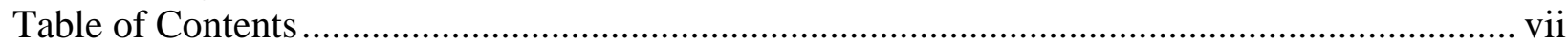

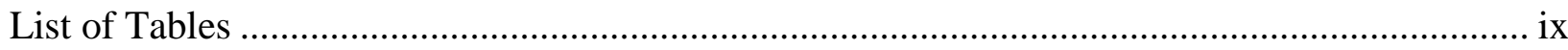

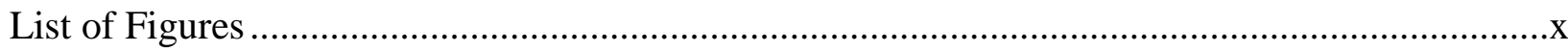

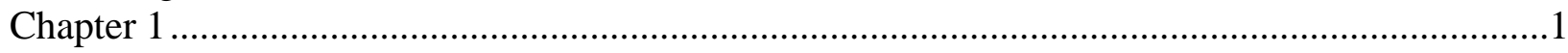

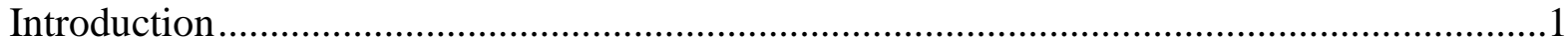

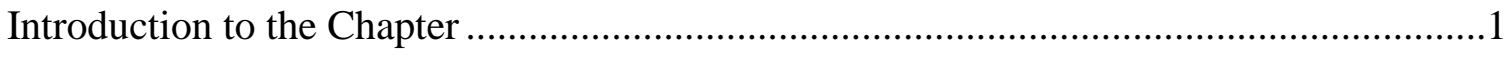

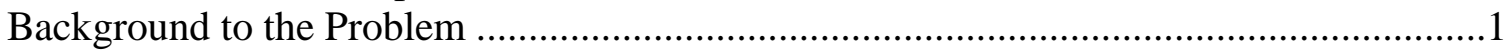

Statement of the Problem .........................................................................................2

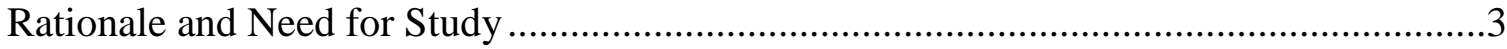

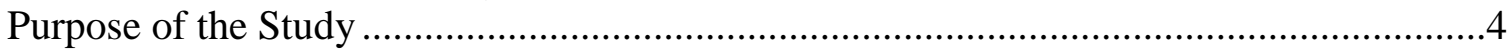

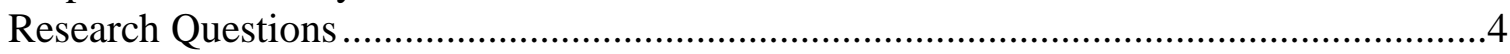

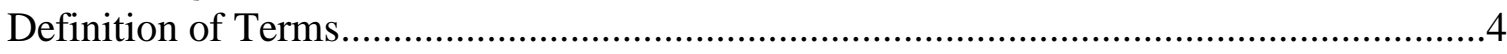

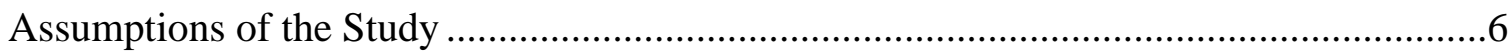

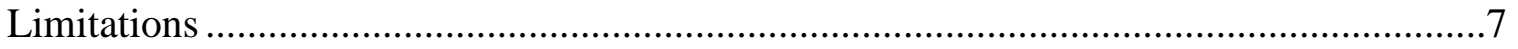

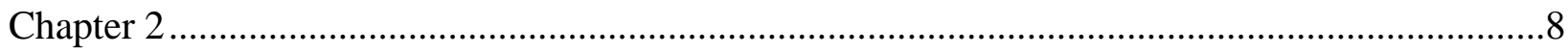

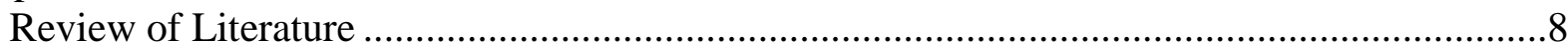

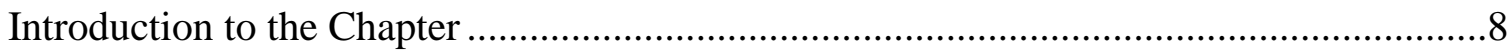

Person-Environment-Occupation Model ...........................................................

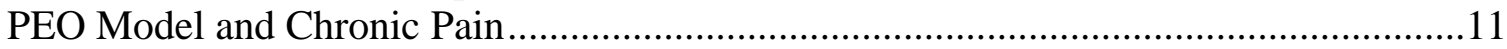

PEO Model Strengths and Weaknesses ..............................................................16

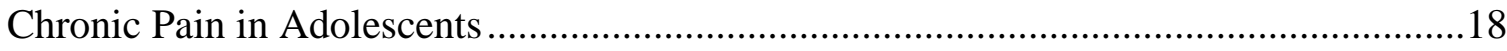

Psychological and Personality Characteristics.....................................................19

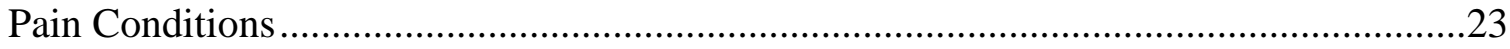

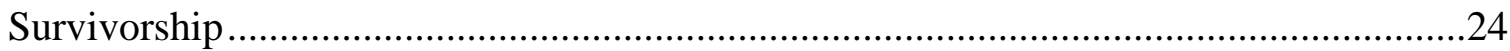

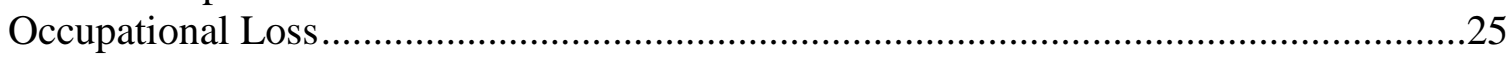

Occupational Therapy Interventions in Chronic Pain ..............................................26

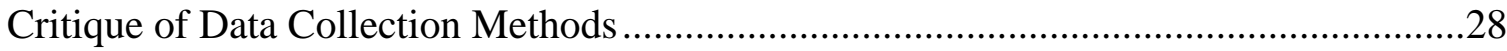

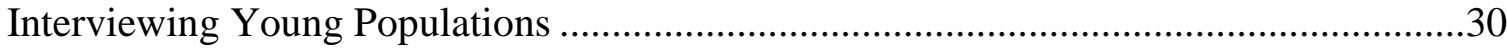

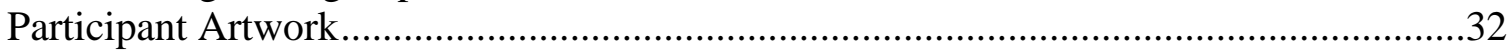

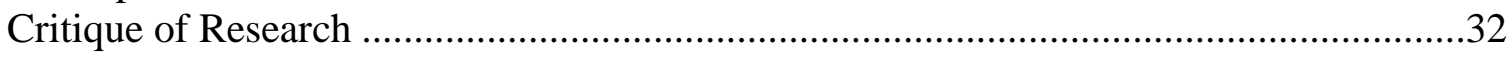

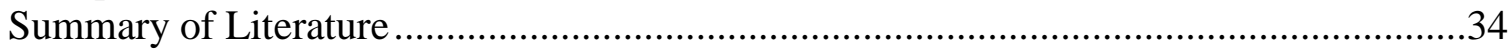

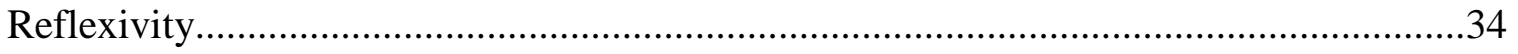

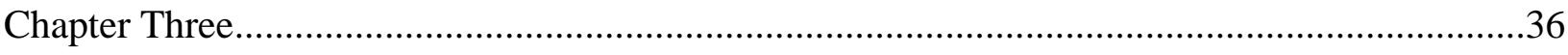

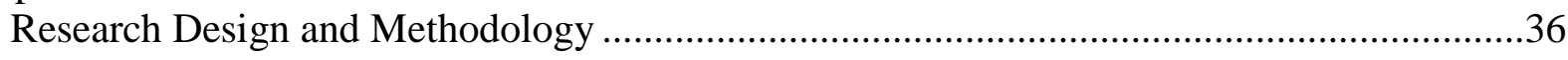

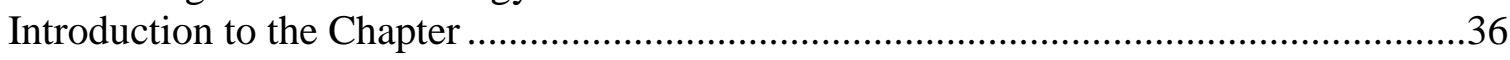

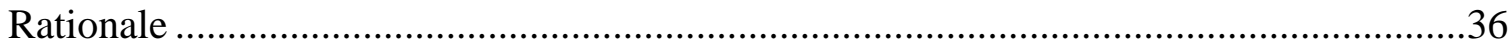

Phenomenology

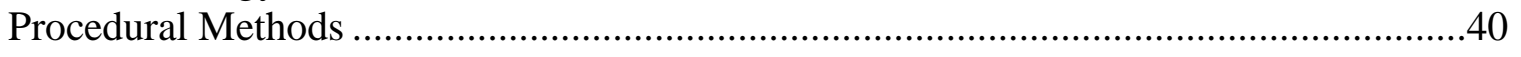


Strengths and Weaknesses of Design .........................................................................41

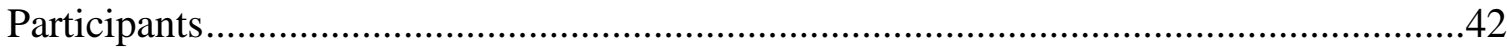

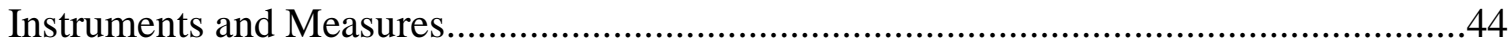

Ethical Considerations and Reviews........................................................................47

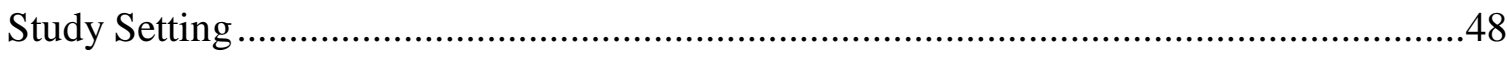

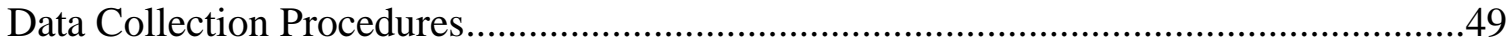

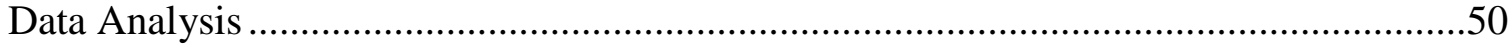

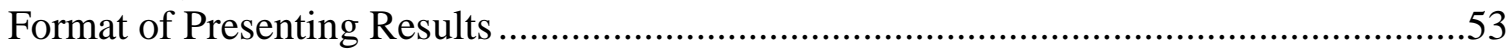

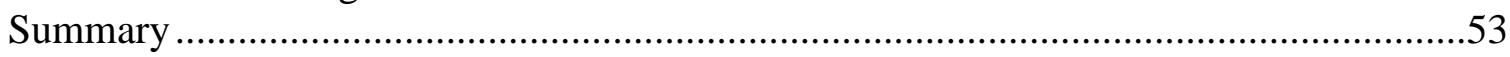

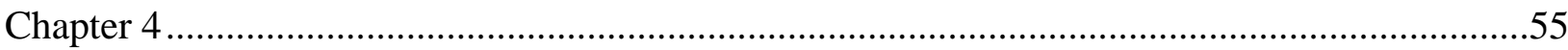

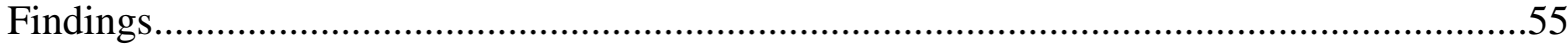

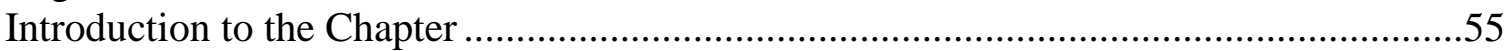

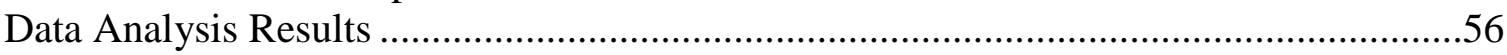

Researcher's Experience of Data Collection and Bracketing .......................................56

Demographics of the Participants ............................................................................58

Individual Textural and Structural Description of the Experience ………....................59

Participant Artwork ..............................................................................................113

Themes of the Findings ...........................................................................................119

Textural and Structural Description of the Meaning and

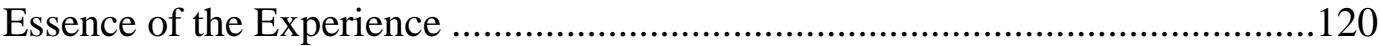

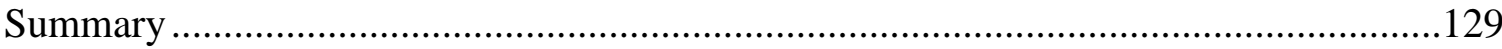

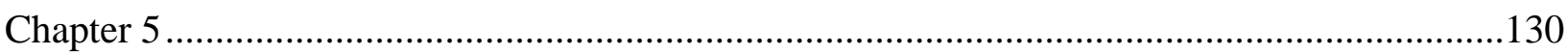

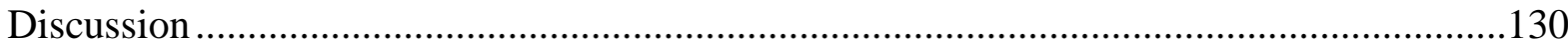

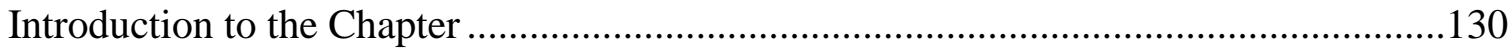

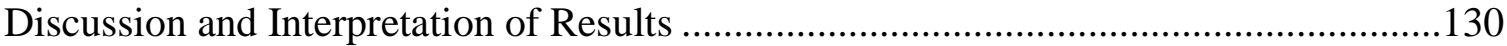

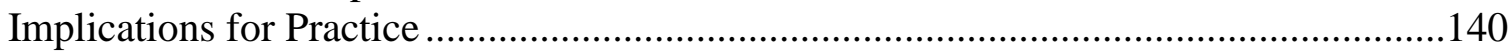

Implications for Further Research ......................................................................142

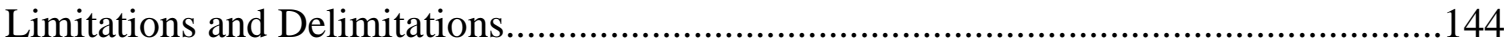

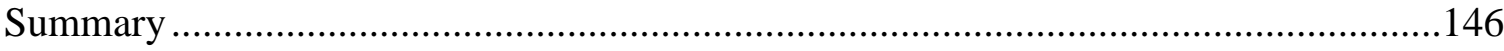

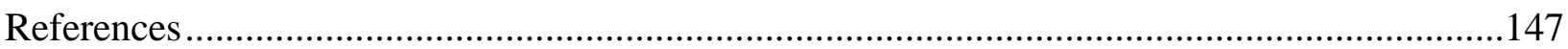

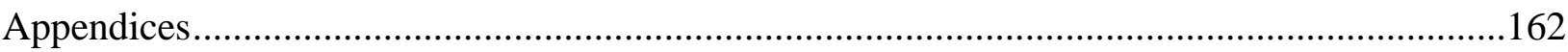

Appendix A. CCF IRB Approval......................................................................162

Appendix B. Nova Southeastern University IRB Approval ...........................................163

Appendix C. CCF IRB Amendment .........................................................................164

Appendix D. Nova Southeastern University IRB Amendment .......................................165

Appendix E. Nova Southeastern University IRB Renewal .............................................166

Appendix F. Recruitment Flyer ............................................................................167

Appendix G. Parent/Guardian Consent Form ............................................................168

Appendix H. Child Assent Form .............................................................................174

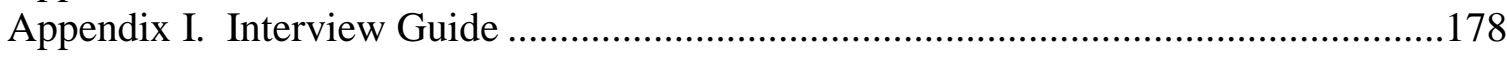




\section{List of Tables}

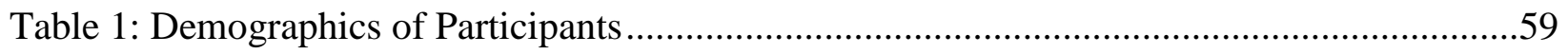

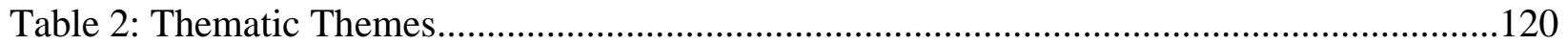




\section{List of Figures}

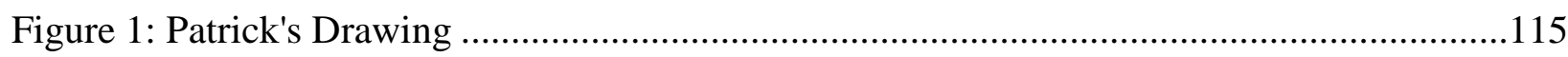

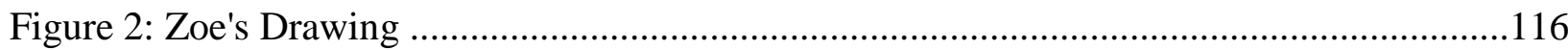

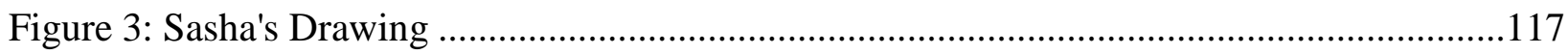

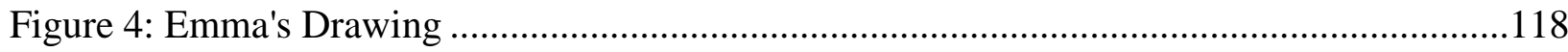

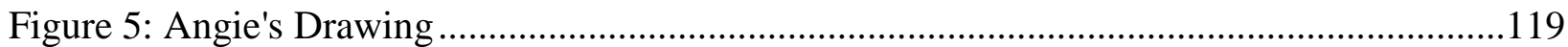




\section{Chapter 1: Introduction \\ Introduction to the Chapter}

Occupational therapy is a profession that works with populations from all age groups and demographics and with both physical and mental illnesses. Occupational therapy practitioners assist individuals to regain the ability to engage in various activities or occupations that help fulfill roles and responsibilities they have in their lives.

Adolescents with chronic pain are one subset of the population that requires occupational therapy services to regain the ability to complete occupations in their home, school, and community. The dissertation study examined the lived experience of being an adolescent with chronic pain in an effort to provide occupational therapy practitioners with a better understanding of how pain may affect occupational performance in adolescents with chronic pain and how the provider may provide superior and more informed intervention. The background of chronic pain, rationale for the study, and the research question are reviewed in this chapter.

\section{Background to the Problem}

In the United States, chronic pain has become an epidemic with an estimated 100 million people suffering from conditions that cause frequent pain (Committee on Advancing Pain Research, Care, and Education \& Institute of Medicine, 2011). The cost of chronic pain ranges from 560 to 635 billion dollars in health care costs and loss in work wages per year, causing a significant toll on the American economy and workforce. Adolescents are not immune from having chronic pain; Perquin et al. (2000) found approximately $25 \%$ of adolescents aged 12 to 18 lived with some form of chronic pain condition. The impact of chronic pain on adolescents can range from poor school 
performance and attendance to decreased participation in leisure activities (Konijnenberg et al., 2005).

Adolescence is an important time-period in the development of social and emotional health as well as academic success. Adolescence also serves as an important time period for building important peer bonds that can have a meaningful impact throughout the remainder of a person's lifetime (Wilhelm, Wedgwood, Parker, Geerligs, \& Hadzi-Pavlovic, 2010). Social bonds can improve occupational engagement in various leisure and social activities. Participation in these activities is very important to build skills and relationships amongst peers. Chronic pain can have detrimental effects about how an adolescent participates in his or her daily occupations. Researchers have documented the long-term effects of having chronic pain, such as poor peer relations and decreased engagement in age-appropriate school-related occupations (Forgeron et al., 2010; Varni et al., 1996). These effects can last throughout the adolescent's lifetime robbing him or her of important opportunities for success in school, relationships, and work.

One important component of chronic pain in adolescence that has not been examined is the personal day-to-day experience of living with the chronic pain. The adolescent's perspective is important to understand because it provides first-hand knowledge of the added obstacles chronic pain brings in addition to the limitations the chronic pain presents in occupational engagement for adolescents.

\section{Statement of the Problem}

Chronic pain has become a worldwide epidemic with an estimated $25 \%$ of adolescents suffering from various pain disorders, including abdominal, limb, and 
headache pain (Perquin et al., 2000; Roth-Isigkeit, Stoven, Schwarzenberger, \& Schmucker, 2005). Chronic pain in adolescence has unknown effects across multiple domains of occupational performance, including school, work, home, and community environments. Despite evidence of functional changes that may occur for an adolescent with chronic pain, such as decreased school attendance and participation in sports (Cohen, Vowles, \& Eccleston, 2009; Konijnenberg et al., 2005; Perquin et al., 2000), there are no studies focused on how chronic pain has influenced their day-to-day occupational performance. Gaining an improved understanding of this lived experience may help occupational therapy practitioners address factors that may have previously not been understood.

\section{Rationale and Need for Study}

The focus of occupational therapy intervention with adolescents living with chronic pain is for improving participation in occupations. Exploring the daily life of this population by understanding how adolescents with chronic pain experience life on a dayto-day basis may help clarify factors that influence their functional abilities, engagement in occupations, and, therefore, overall health and well-being (Hunfeld et al., 2001; Persson, Rivano-Fischer, \& Eklund, 2004). It is imperative that occupational therapists are knowledgeable about how chronic pain can affect a staggering $25 \%$ of adolescents (Perquin et al., 2000). Knowledge of these factors may assist occupational therapy practitioners in the planning of assessment and interventions to meet the needs of adolescents living with chronic pain and minimize the effects chronic pain has on occupational performance in their homes, schools, and communities. The dissertation study provided an eyewitness account to the life of an adolescent living with chronic pain 


\section{Purpose of Study}

The purpose of this phenomenological study was to explore the lived experience of adolescents living with chronic pain. These findings provide a better perspective for occupational therapy practitioners about the experiences adolescents living with chronic pain are going through and enable the therapists to provide more effective intervention options to improve occupational performance and life satisfaction for adolescents with chronic pain. The dissertation study may also lead to future research in the area of adolescent chronic pain and occupational performance.

\section{Research Questions}

\section{Central Question}

1. What is the essence of the day-to-day experience of adolescents living with chronic pain?

\section{Definitions of Terms}

\section{Adolescence}

Adolescence is termed as a period in a child's life that is characterized by a host of physical, cognitive, and emotional changes caused by hormonal fluctuations (Villarruel \& Luster, 2006). This period is also characterized by additional demands being placed to prepare him or her for making the transition from child into adult. The time-period ranges from 13 years old until around 21 years old when the adolescent takes on more responsibilities and becomes an adult. For the purposes of the dissertation study, adolescence was defined as being between 13 to 17 years of age and still has not enrolled into college. 


\section{Chronic Pain}

For the dissertation study, chronic pain was defined as a cluster of symptoms with known or unknown etiology, leading to pain lasting at least 6 months. The pain lasts longer than the expected time for an injury or illness (Persson et al., 2004; Yeung, Arewasikporn, \& Zautra, 2012). The associated pain can have psychological, emotional, and social implications for the adolescent's functioning in daily life (Perquin et al., 2000).

\section{Occupation}

Occupations are self-directed activities or tasks that an adolescent engages in over his or her lifetime, which help them meet the adolescent's intrinsic needs for selfmaintenance, expression, and fulfillment (Law et al., 1996). Areas that occupational therapy practitioners categorize as occupation are activities of daily living (i.e., self-care), instrumental activities of daily living, sleep, education, work, social participation, and play and leisure (i.e., sports and extra-curricular groups; Roley et al., 2008).

\section{Occupational Performance}

Occupational performance is "the dynamic experience of a person engaged in purposeful activities and tasks within an environment" (Law et al., 1996, p. 16). "Successful occupational performance occurs when a person is able to complete a task or activity in a manner that achieves the goal of the task or activity, while satisfying the person” (Law, Dunn, \& Baum, 2005, p. 108). Occupational performance has both a contextual and spatial consideration. The observable qualities of occupational performance can be measured objectively, whereas the subjective qualities are better measured through self-report (Law et al., 1996). 


\section{Participation}

Participation is the act of being involved in an activity that is common with another person or the act of receiving or having part of something, such as engaging in a social activity with other peers (Law, 2002). Through engagement in these activities, humans gain skills and competencies, develop socially meaningful interactions, and derive meaning and purpose in life. Participation is measured through a complex interaction between the person's preferences, type of activity he or she performs, location, who the activity is performed with, and how much satisfaction he or she gains from participating in the self-chosen activity (Law, 2002). There is both a qualitative and quantitative nature to how participation is measured.

\section{Assumptions of Study}

This phenomenological study contained assumptions, which are necessary to carry out this study. One assumption was present in order to investigate the lived experience of adolescents with chronic pain. Adolescents possess insight into their condition in order to discuss and elaborate on the topic of life with chronic pain. Adolescents have been shown to possess an ability to self-reflect on past experiences and describe their experiences in relation to the topic of chronic pain (Kennedy, 1979). Although participants of all ages demonstrate varying degrees of insight and retrospection on their own lives, the dissertation study assumed each participant possessed enough insight into his or her condition and degree of function/dysfunction in order to express valid data for the purposes of data analysis. 


\section{Limitations}

1. The first limitation was the potential source of bias. I worked within a facility that provided services for adolescents suffering from chronic pain. I also had over 10 years of experience working with this population and their families. I worked with the adolescents and their families to promote return to a functional and healthier lifestyle. In order to attempt to control for observer bias, I used reflexive journaling as a tool for decreasing biases toward the research topic, participants' responses, and any pre-conceived notions about the outcome (Lincoln \& Guba, 1985).

2. The second limitation of the study was potential errors in the data when using interviews. This presented potential limitations due to distorted responses of participants, recall error of past events, reactivity of the participant towards the researcher, and self-serving responses of the participants (Patton, 2002). Participants could have potentially changed their stories to appear extreme to gain notoriety or recognition for their suffering. Memory can also become less clear the more distant an event becomes or other distorting variables, such as medication side effects, can lessen the clarity of details. 


\section{Chapter 2: Review of the Literature \\ Introduction to the Chapter}

In this chapter, the overarching models that directed this study are discussed along with their relevance to the study's purpose of finding the essence of the experience of the adolescent experience who is living with chronic pain. Literature related to chronic pain, occupational performance related to chronic pain, and current interventions used by occupational therapy practitioners for this specialized population are discussed along with critiques of the literature in relation to the study and the results.

\section{Person-Environment-Occupation Model}

The person-environment-occupation model (PEO) was developed with the purpose of shifting occupational therapy practice away from the biomedical model in which the human is broken down into parts and diseases are examined on the principles of cause and effect to a transactive approach (Law et al., 1996). A transactive model, such as the PEO, examines the dynamic interaction between humans and their environments, occupations, and roles. These individual components cannot be marginalized into singular relationships; instead they are examined in the larger picture of how each interacts with one another to produce occupational performance. The PEO model helped direct which relationships to examine, how chronic pain affected these relationships, and how each of these relationships worked together to influence occupational performance of adolescents who live with chronic pain.

The person-environment-occupation model helped frame three main constructs that may influence an adolescent's life when living with chronic pain: person, environment, and occupation (Law et al., 1996). The three constructs interact together 
through time, influencing the person's occupational performance. This dynamic process examines how the environment, temporal constraints, physical, and psychological characteristics influence behavior and, ultimately, occupational performance (Law et al., 1996).

The first construct of the PEO, the person, refers to a unique being who assumes a variety of roles simultaneously (Law et al., 1996). The roles are dynamic and vary across time and context. In addition, roles vary, depending on time spent in a role along with its personal significance. In this model, the person is viewed from a holistic perspective, including the mind, body, and spirit. Each of these components has potential to influence the day-to-day life of an adolescent who lives with chronic pain.

The second area of the PEO model is the environment and its influence on day-today life of an adolescent living with chronic pain. Defined broadly in the model, the environment encompasses cultural, socioeconomic, institutional, physical, and social aspects of the adolescent's environment (Law et al., 1996). The environment is forever in flux and encompasses the context in which occupations are performed. This, in turn, influences the level of occupational performance of the individual (Law et al., 1996). In other words, how supportive or demanding the environment is on adolescents living with chronic pain can influence how competent they are in participating in their daily occupations.

The third construct of PEO is the occupations of adolescents. The most elemental concept of occupational therapy is occupation and its influence on human behavior. Occupations are intrinsically motivating activities that humans engage in on a daily basis providing structure, self-expression, and fulfillment of roles (Law et al., 1996). Different 
occupations fulfill different roles and responsibilities within our lives. For adolescents, occupations include those tasks and activities that help them transition from childhood to adulthood, such as engagement in structured leisure activities, employment for the first time, and development of new responsibilities such as acquiring a driver's license. The dissertation study examined common occupations and the effects they have on adolescents with chronic pain. It also examined the effects chronic pain has on participating in occupations, the importance of engagement in occupations in this specific population, and how the other two constructs of person and environment interact with the engagement in occupations. This process of interaction between the person, environment, and occupation comes together to form occupational performance.

Occupational performance (OP) is the resultant factor of personal attributes, environment, and occupations. Baum and Law (1997) best described occupational performance as "the point when the person, the environment, and the person's occupation intersect to support the tasks, activities, and roles that define that person as an individual" (p. 281). Occupational performance is achieved when there is a correct level of challenge, supportive environment for engagement in the task, and a level of motivation and ability by the adolescent in order to accomplish the task. OP is also reliant on the adolescent's level of participation. Law (2002) best describes participation as the act of being involved in an activity that is common with another person or the act of receiving or having part of something, such as engaging in a social activity with other peers. The mere act of participating in occupation can result in a positive self-identity, establishment of roles, and desire for continued engagement in occupation. The PEO model was used to frame the effects chronic pain has on adolescents' occupational performance. 


\section{PEO Model and Chronic Pain}

Occupational therapy practitioners work with adolescents who suffer from chronic pain, and the main focus of occupational therapy is to identify problem areas that interfere with engagement in occupations. The effects of chronic pain can be seen in changes of occupational performance (Hunfeld et al., 2001). Adolescents can present with altered occupational performance due to the physical, emotional, and psychological limitations chronic pain places on them. It is an occupational therapy practitioner's role to assist the client with identifying performance skills, performance patterns, and contexts in occupations that pose barriers to occupational performance and to help restore or adapt those skills necessary for restoration of occupational performance (Roley et al., 2008).

The PEO model provides the foundation that outlines the key areas chronic pain can affect, which ultimately contributes to loss in occupational performance. Each of the three areas, person, environment, and occupation, contributes to the overall level of occupational performance (Law et al., 1996). An imbalance in one or more areas can decrease the ability for the adolescent with chronic pain to complete tasks at prior occupational performance levels.

\section{Person Construct}

The first area in the PEO model is the person and characteristics that make up the individual. Beyond the physical changes disease causes, there can also be mental and emotional effects. Several researchers have studied anxiety in adolescents with chronic pain and have noted its effects on function (Tsao, Meldrum, Kim, \& Zeltzer, 2007; Vervoort, Goubert, Eccleston, Bijttebier, \& Crombez, 2006; Vlaeyen \& Morley, 2004). Anxiety can have an indirect impact on the level of function adolescents demonstrate 
when living with chronic pain. Adolescents with chronic pain who present with increased levels of anxiety sensitivity (AS) or the tendency to view anxiety sensations as dangerous, demonstrate poorer psychological well-being. They generally have poorer perceived general and mental health, greater impairments in family activities, lower selfesteem, and more social and academic limitations due to emotional problems. Conversely, higher levels of AS did not result in lower physical functioning due to physical impairments (Tsao, Meldrum, Kim, \& Zeltzer, 2007). In other words, higher anxiety sensitivity contributed to greater degree of impairment in family activity level and academic performance limitations due to emotional problems, however, did not directly relate to physical functioning or academic performance limitations due to physical health. The levels of anxiety also determined how well adolescents with chronic pain function in their daily lives. In a recent study examining adolescents who demonstrated high anxiety levels, Cohen et al. (2009) indicated there was no correlation between pain levels and how they functioned and demonstrated poor performance across multiple contexts, such as social and school-related activities. In other words, adolescents with chronic pain who have a higher level of anxiety demonstrate disproportionate pain levels and levels of performance. On the other hand, adolescents who have lower levels of anxiety demonstrate poor functional levels that are dependent on their pain levels. The higher degree of pain levels correspond with poorer functional levels. For example, if adolescents with chronic pain have an adaptive ability to deal with anxiety and demonstrate high levels of pain, they would exhibit a poor level of function or occupational performance. Also, improvements in occupational performance were shown when the levels of pain decreased (Cohen et al., 2009). 
The level of positivity in adolescents with chronic pain can influence their levels of occupational performance and pain levels. For example, Gil et al. (2003) found that in children with sickle cell disease, positive mood was associated with decreased levels of pain, more active participation, and less health-care usage. in contrast, Gil et al. (2003) found a correlation between daily increases in stress levels and negative moods with higher levels of same-day pain and reductions in school and social activity. Pain levels were predictive of higher stress levels and lower positive moods that occurred on subsequent days. As stress and pain levels increased, occupational performance declined.

Another area of positive mental health that can greatly influence the level of participation in occupations is acceptance. Acceptance is an active process that requires adolescents to choose to move beyond the chronic pain in their lives and embrace occupations (Viane, Crombez, Eccleston, Devulder, \& De Corte, 2004). The process of acceptance requires the adolescent to turn focus away from the chronic pain and towards participation in life. Part of the process also includes recognizing that there may not be a cure for his or her pain and that the burden lies not with medical providers, but on the individual to return to a "normal" life. A higher level of acceptance has been related to less attention to pain, higher level of participation in daily activities, higher motivation to complete tasks, and better efficacy to perform daily functions (Viane et al., 2004).

\section{Environment Construct}

The second area that contributes to occupational performance is the environment. The environment for adolescents is characterized as the contexts and situations that occur outside individuals and elicit responses from them (Law, 1991). The person's environment includes the following areas: geographical, institutional, social, socio- 
economic, institutional, physical, and social areas (Law et al., 1996). An overwhelming theme in the literature is the influence parents can have on an adolescent who has a condition with chronic pain. Family dynamics is one environmental construct that has an influence on levels of pain and performance of adolescents with chronic pain. (Forgeron et al., 2010; Logan \& Scharff, 2005; Logan, Simons, \& Carpino, 2012; Lynch, KashikarZuck, Goldschneider, \& Jones, 2006; Palermo \& Eccleston, 2009; Palermo, Putnam, Armstrong, \& Daily, 2007; Schanberg et al., 2001). Parents can be both facilitative and inhibitive in promotion of function in adolescents with chronic pain (Logan et al., 2012; Schanberg et al., 2001).

Parental facilitative and inhibitory phenomena have been studied by a number of researchers. The environment an adolescent lives in can influence the level of disability and predict his or her ability to function with the pain (Logan \& Scharff, 2005; Logan et al., 2012; Palermo \& Eccleston, 2009). Specific characteristics about the parents can have an influence over how well the adolescent maintains participation in his or her occupations. One influential characteristic of the parent is his or her level of catastrophizing. Parents who have a higher level of pain catastrophizing or devoted focus on their son or daughter's pain level can negatively influence the extent of pain-related disability (Logan \& Scharff, 2005; Palermo \& Eccleston, 2009). Another parental characteristic that influences the level of an adolescent's occupational engagement is the parent's own pain history. Adolescents who live with chronic pain and have parents with a history of chronic pain themselves show a poorer health status and engagement in occupations; parents who were more likely to seek out medical care for their own pain had children with higher levels of pain ratings and poorer health status (Schanberg et al., 
2001). The last parental characteristic that influences the level of disability for adolescents who have chronic pain is parental protectiveness. Higher degrees of parental protectiveness negatively impact their adolescent's school attendance and contributes overall to school impairments (Logan \& Scharff, 2005).

The school environment is also a factor that may or may not improve occupational performance in adolescents with chronic pain. School is one important context the adolescent interacts within in order to develop the education necessary to live independently in the world. This context can influence the performance levels of the adolescent population. "A positive school ethos, characterized by student and teacher cohesion, positive teacher attitudes towards young people, an emphasis on positive rewards, and consistent and shared values and standards is pivotal in shaping school experience" (Dyson, Atkin, Culley, Demaine, \& Dyson, 2012, p. 34). Overall participation of adolescents with chronic pain improves in schools in which students are expected to work collaboratively and are accepting of all peers.

Overall, the environment can have a significant influence on levels of function and overall occupational performance (Logan \& Scharff, 2005; Logan et al., 2012). These influences range from parental engagement and parental protectiveness to adolescent emancipation. In order to develop balanced occupational performance, a supportive, yet not-overly burdensome environment must be fostered in order for an adolescent with chronic pain to accept the pain level and to maintain an appropriate level of function and occupational performance in all areas of his or her life. 


\section{Occupation Construct}

Chronic pain can have debilitating effects on adolescents' activity level and social functioning at school and in the community along with producing significant absenteeism from school. Konijnenberg et al. (2005) found that of adolescents suffering from some type of chronic pain, $72 \%$ of them suffered from changes in performance in sports activities. Impairments ranged from sitting out for short periods of time to complete non-participation. Over half of them had a high rate of absence from school along with $40 \%$ of them also having some type of limitation in social functioning due to chronic pain. Beyond those occupations completed outside the home, there can be significant negative effects on overall physical status and participation in daily living skills (Hunfeld et al., 2001). Hunfeld et al. (2001) studied adolescents through use of a journal and a quality of life tool and found adolescents who demonstrated higher intensity and frequency of pain also demonstrated lower quality of life in psychological functioning, physical status, and functional status.. This decrease can lead to mental health concerns, such as depression and anxiety (Petrenchik, King, \& Batorowicz, 2011).

\section{PEO Model Strengths and Weaknesses}

Since the PEO model was introduced by Law et al. (1996), it has been used in multiple studies examining the connections between the personal attributes, environment, and occupations resulting in occupational performance (Broome, McKenna, Fleming, \& Worrall, 2009; Cronin et al., 2013; Lyons, 2006; MacCobb, 2013; Peachey-Hill \& Law, 2000; Peloquin \& Ciro, 2013a, 2013b; Ripat \& Becker, 2012; Schwartzman, Atler, Borg, \& Schwartzman, 2006; Strong et al., 1999). 
The relationship between personal attributes and occupational performance has been supported in the literature by other researchers (Vervoort et al., 2006; Viane et al., 2004) Viane et al. (2004) found a strong correlation between acceptance of chronic pain and higher levels of occupational engagement, less attention to pain, and higher motivation to complete daily activity. Findings from Vervoort et al. (2006) also supported the relationship between personal attributes and occupational performance by showing that higher level of catastrophic thinking or focusing on the chronic pain was independently associated with disability and lower level of occupational performance. Lastly, the relationship between occupations and occupational performance has been supported by two researchers. Persson et al. (2004) discovered that in an inpatient pain rehabilitation population, increased engagement in occupation improves their positive perception of occupational performance. The mere engagement in occupation showed improvements in how they believed they were able to accomplish daily occupations. Occupations, as an independent variable, can also have significant impact on how well a participant is able to cope with their pain (Persson, Andersson, \& Eklund, 2011). The more meaningful an occupation was, the more profound impact it had on how well the participant was able to cope with the pain.

Previous researchers have helped strengthen the validity of the PEO model used in occupational therapy research by strengthening the relationships between personal attributes and occupation and occupations and occupational performance. Previous researchers have demonstrated strengthened relationships between personal attributes, environmental influences, and occupations and how each affect occupational performance; however, there are many weaknesses to the validity of the PEO model in a 
study on adolescent chronic pain (Broome et al., 2009; Lyons, 2006; Peachey-Hill \& Law, 2000; Ripat \& Becker, 2012).

\section{Weaknesses}

The PEO model has demonstrated moderate validity in occupational therapy research. Currently, there is no research to support or refute the validity of the PEO model within the scope of adolescents living with chronic pain. Although there is a gap between the postulates of the theory and verification of the current research, the dissertation study explored the potential use of this theory with the population of adolescents who live with chronic pain. Two reasons for further research using the PEO as a framework focused on adolescents who live with chronic pain are to narrow the current gap in literature about chronic pain and the effect of chronic pain on adolescents and to lend support to the framework of the PEO that supports occupational performance through the dynamic interaction between personal attributes, environment, and occupation.

\section{Chronic Pain in Adolescents}

\section{Demographics}

Chronic pain has become an epidemic in the United States with an estimated 50 million Americans suffering from some type of chronic illness that causes debilitating, chronic pain (Turk \& Wilson, 2010). As mentioned previously, some form of chronic pain has been found to be prominent in $25 \%$ of adolescents (Perquin et al., 2000; RothIsigkeit et al., 2005). In 2010, the United States Census Bureau (2010) found that there were over 20 million adolescents aged 15 to 19 . If these two statistics are true approximations of the population, then there are approximately four to six million 
adolescents in the United States with some form of chronic pain, which equates to 10 times the population of Cleveland, Ohio, in present day (United States Census Bureau, 2010). There are no figures about the costs to American society with regard to adolescents living with chronic pain; however, chronic pain for all ages costs taxpayers and insurance companies between 560 and 635 billion dollars in health care costs and loss in work wages per year, causing a significant toll on the American economy and society (Committee on Advancing Pain Research, Care, and Education \& Institute of Medicine, 2011).

Multiple researchers have shown a higher prevalence of chronic pain in girls than in boys (Goodman \& McGrath, 1991; Kaczynski, Claar, \& Logan, 2009; Lynch, Kashikar-Zuck, Goldschneider, \& Jones, 2007; Martin, McGrath, Brown, \& Katz, 2007b). One researcher found the breakdown between sexes is approximately $70 \%$ girls and $30 \%$ boys (Konijnenberg et al., 2005). Some researchers hypothesized that higher levels of internalizing symptoms may influence higher levels of chronic pain in females than in males (Kaczynski et al., 2009). Females are found to internalize their emotions at a higher degree than males, thus increasing the likelihood of females having higher levels of internalizing symptoms. Internalizing symptoms can range from depression, anxiety, social withdrawal, and self-injury. The population of adolescents with chronic pain also has high levels of co-morbidities of depression and anxiety (Lynch et al., 2006; Martin et al., 2007a; Varni et al., 1996).

\section{Psychological and Personality Characteristics in Relation to Chronic Pain}

In addition to the specific type of chronic pain the adolescent is living with, there are also other factors that may influence the effects chronic pain can have on his or her 
life. These factors are based on the psychological and personality profiles of adolescents who live with chronic pain. The profiles are made-up of both stable and modifiable traits that help individuals be more or less able to cope with pain (Yeung et al., 2012). Stable traits are those that are typically developed at a young age that do not change over time, such as physiological self-regulation and optimism. The modifiable traits are those that may change over time due to influences such as environmental or personal factors. Examples of modifiable traits are having social intelligence, benefit finding, and anxiety and depressive symptoms.

\section{Traits}

Stable traits either support resilience or place the adolescent in a more vulnerable state to develop chronic pain (Yeung et al., 2012). Resilience can be defined as the ability to bounce back or overcome a significant challenge quickly (Sturgeon \& Zautra, 2010). The trait that supports resilience is the ability to self-regulate basic physiological response to stimuli, such as heart rate, respiratory rate, and blood pressure. Reducing this physiological response in either duration or frequency can produce less taxing stress response on the body. Another stable trait that supports resilience is optimism toward a future outlook, which could improve coping skills for living with chronic pain by looking beyond the current pain level and instead looking at a positive future despite having chronic pain. On the opposite side, two stable traits that increase vulnerability are affective disorders and neuroticism; both can influence how well or poorly adolescents may deal with chronic pain in their daily lives (Yeung et al., 2012).

Modifiable traits are also broken down into resiliency and vulnerability factors (Yeung et al., 2012). Coping, benefit finding, and family support are all types of 
resiliency factors that benefit an adolescent who lives with chronic pain; however, these factors can change at any time. Benefit finding, the process of changing the painful experience of living with chronic pain into a beneficial experience (Sturgeon \& Zautra, 2010) is a trait that can be situational depending on the environment and the people surrounding the adolescent. If an adolescent lives within a supportive family environment, the teenager maybe more inclined to focus on his or her positive experiences and therefore have a better ability for benefit finding and positive outlook on life.

Anxiety and depression along with pain catastrophizing, the extent to which the adolescent makes exaggerated and fearful appraisals of pain, are modifiable vulnerable factors (Sullivan, Rodgers, \& Kirsh, 2001). Adolescents living with chronic pain who demonstrated higher vulnerability levels were shown to have a poorer outlook on life and a decreased positive affect, which in turn affected the level of disability (Yeung et al., 2012). Both stable and modifiable traits help frame the concept of resilience.

Although there has yet to provide definitive evidence on which traits best determine those adolescents who will overcome chronic pain, a correlations have been found between high levels of interpersonal sensitivity, positive affect, active coping skills, and lower levels of disability in adolescents (Yeung et al., 2012). Adolescents who were able to understand other people's feelings and sensitivities were more introspective with regard to their own feelings and were more emotionally stable as individuals, ultimately assisting with their own pain levels. Adolescents who had a better perspective on life and positive attitude also demonstrated lower levels of disability (Smith \& Zautra, 2008; Yeung et al., 2012). 


\section{Coping and Acceptance}

Along with specific psychological profiles showing better function in adolescents, coping styles also play an important role in living with chronic pain. Coping is an active process of dealing with stress through actions, thoughts, and behaviors (Lazarus \& Folkman, 1984). In order for an adolescent to maintain daily occupational performance, his or her ability to cope with the chronic pain becomes an active process. Two researchers have shown that adolescents in various age groups who demonstrate improved active coping showed improved quality of life and acceptance of their chronic conditions (Jaser \& White, 2011; Smorti, 2012). Furthermore, Karoly and Ruehlman (2006) found that adults with chronic pain who demonstrated higher levels of coping, improved attitude towards their pain, less catastrophizing, and an ability to interact with others in a social environment showed a higher level of resilience. With higher levels of acceptance, adolescents are freed to focus on being able to return to a life full of engagement in occupation.

Acceptance is the active process of acknowledging the chronic pain and moving beyond the symptoms in order to achieve the highest degree of occupation. The actual process of acceptance varies by individuals. The duration of time from onset of chronic pain to acceptance varies as does the degree of acceptance (Viane et al., 2004). McCracken and Eccleston (2003) showed the greater acceptance of chronic pain was associated with less pain, disability, depression, and pain-related anxiety in a study of adults. Coping and acceptance can go hand in hand and complement one another in the process of regaining occupational performance following the onset of chronic pain. 


\section{Pain Conditions}

For the purposes of the dissertation study, the term chronic pain is defined as all adolescents who live with ongoing pain for longer than 6 months. Some types of chronic pain can be attributed to an underlying diagnosable disease, such as Crohn's disease (Rabizadeh \& Dubinsky, 2013). This form of disease, which can cause chronic abdominal pain, can be confirmed through testing. Other diseases, such as functional abdominal pain, are defined by ruling out other forms of diseases that could be causing the same type of pain (Spee, Lisman-Van Leeuwen, Benninga, Bierma-Zeinstra, \& Berger, 2013). For the dissertation study, both types of diseases will be included in order to broaden the variety of perspectives on chronic pain.

In the United States, there are a variety of chronic pain conditions that affect adolescents. The most prevalent cause of chronic pain in adolescents (children 12-17 years of age) is chronic headaches, which affects an estimated $7.5 \%$ of this population (Data Resource Center for Child and Adolescent Health, 2007). The second most prevalent cause of chronic pain in adolescents is abdominal pain, which accounts for $5 \%$ of all general practitioner consultations (Spee et al., 2013). The third most prevalent cause of chronic pain in adolescents is limb pain (Perquin et al., 2000). There are numerous causes for chronic limb pain, such as chronic regional pain syndrome (CRPS;

Brunner, Gymesi, Kissling, \& Bachmann, 2010) or phantom limb pain (Dangel, 1998). Irrespective of the type of chronic pain affecting the adolescent, this dissertation study benefits from the variety of adolescents' unique perspectives. 


\section{Survivorship}

Survivorship with a chronic condition is commonly associated with cancer and in which most of the research is contained. When patients survive cancer, they can celebrate their life and victory over the disease. With chronic pain, patients do not have a life-threatening disease, instead one that continues throughout their lives and can cause significant disability. It is difficult for the chronic pain population to celebrate a triumph when facing the chronicity of the disease. Despite the challenge, survivorship is important for the population living with chronic pain. Leigh (1992) reframed how the health care sector should look at survivorship by looking at the person with chronic illness as living with, through, and beyond the condition.

Adolescents with chronic pain can have challenges and quality-of-life issues throughout their lives. In order to capture the feelings and ownership of their perseverance, the term survivorship can help personify those experiences that helped the adolescent transform and grow. Gallo-Siver and Weiner (2006) also helped define survivorship as a state of not letting the disease define one even as it changes oneself. Cheung and Delfabbro (2016) found adults and children who self-identified as a cancer survivor had higher degree of quality of life and mental wellbeing.

Adolescents with chronic pain do not have the support systems that other groups of individuals have, such as cancer. Large organizations, such as Susan G. Komen, support individuals who have cancer and help to make the public more aware about the condition. There has been a lack of public awareness or support given to chronic pain conditions that might assist adolescents with the transition from sufferer to survivor. 
National organizations, such as these, help provide a support system that can be helpful in overcoming the disease as a survivor and returning to a more normal life.

\section{Occupational Loss}

Adolescents engage in various occupations throughout their day, including daily self-care, driving, socializing with peers, attending school, engaging in after school leisure activities, and potentially working. Each of these occupations is important for their development and maturity into adulthood. Leisure engagement is very important for all adolescents in gaining self-confidence, building self-esteem, and developing social relationships with peers (Ashby, Fitzgerald, \& Raine, 2012; Desha \& Ziviani, 2007; Hunfeld et al., 2001). School participation and engagement is important for adolescent cognitive, emotional, and social growth and helps prepare them for life after graduation. Chronic pain can limit the ability of adolescents to participate in some or all of these occupations. This occupational loss can lead to psychological and physical harm, such as depression and physical deconditioning (Ashby et al., 2012; Hunfeld et al., 2001; Silva, Sampaio, Mancini, Luz, \& Alcântara, 2011). Loss in school participation can lead to social isolation and poor educational achievement (Roth-Isigkeit et al., 2005). Future educational outcomes, such as college entrance, could be affected by poor school participation ultimately affected by chronic pain. Adolescents who miss school or afterschool leisure activities may not obtain a level of physical activity necessary for a healthy lifestyle. Current recommendations are that adolescents should receive at least 225 minutes of physical education/activity per week, which can be difficult to achieve for an adolescent living with chronic pain with poor school attendance (Hills, Dengel, \& Lubans, 2015). 


\section{Occupational Therapy Interventions in Chronic Pain}

Occupational therapy practitioners use many forms of interventions while working with clients of varying ages who have chronic pain. There is a lack of evidence showing which form is the most effective in improving quality of life and occupational engagement. Van Huet et al. (2012) interviewed occupational therapists about their beliefs about important aspects when treating clients with chronic pain. The therapists' answers demonstrated the following themes: maintaining valued roles and having good social support, accepting the long-term nature of pain, using relaxation techniques, setting realistic goals, and pacing activities. These themes are in-sync with one of the core values of occupational therapy: client-focused interventions that address lifestyle and occupational issues in those living with chronic pain.

\section{Complementary and Alternative Medicine}

Complementary and alternative medicine (CAM) is a broad term for interventions that do not fall under the collective term of traditional medicine (National Center for Complementary and Alternative Medicine, 2013). The use of CAM in occupational therapy intervention is justified by the following quote: " [The use of CAM is] within the scope of occupational therapy practice when they are used as preparatory methods or purposeful activities to facilitate the ability of clients to engage in their daily life occupations" (Giese, 2005, p. 653). The term CAM can include interventions, such as yoga, massage, myofascial release, craniosacral therapy, acupuncture, hypnosis, art therapy, and energy healing (Tsao, Meldrum, Kim, Jacob, \& Zeltzer, 2007).

One way occupational therapy practitioners use CAM with the client is relaxation training. Yoga is one intervention that has been shown to improve relaxation, decrease 
the degree of pain levels, and decrease functional disability in adults with chronic pain (Holtzman \& Beggs, 2013; Nambi \& Shah, 2013). The effectiveness in children and adolescents using yoga is promising for children with chronic pain conditions in reduction of disability and pain levels (Evans et al., 2010; Kuttner et al., 2006). Another way occupational therapy practitioners use CAM with the client is a technique called muscle re-education, which is the process of changing the elasticity of the muscle, resulting in reduction of pain. Muscle re-education interventions occupational therapy practitioners utilize are myofascial release and cranio-sacral treatments. Both treatments focus on the fascia layer that lies superficial to the muscle and can become tight over time. Liptan, Mist, Wright, Artz, and Jones (2013) stated there is minimal research that supports the use of either treatment as an effective CAM that reduces pain and minimizes disability levels.

Cognitive-behavioral techniques. Occupational therapy practitioners also use cognitive-behavioral techniques (CBT) to help adolescents living with chronic pain. These techniques help change thinking in order to change the adolescent's feelings and in turn change their distorted thoughts. One type of CBT occupational therapy practitioners use with patients who live with chronic pain is mindfulness training. Mindfulness training focuses on remaining in the present and being open to change and new perspectives (Langer, 2009). The training focuses on the client learning ways to look at the same situation in different perspectives and to become more open to change. An adolescent's life with chronic pain can present many challenges of continued participation in occupations. There are many uncertainties about the frequency and duration of pain on a daily basis. Mindfulness training helps adolescents loosen their grip 
on attempting to control all aspects of their life and to refocus their energy on living within the present (Langer, 2009). In other words,

The perception of uncertainty leads to mindfulness, and mindfulness, in turn, leads to greater uncertainty. As such, mindfulness leads to engagement with the task at-hand. Being situated in the present and involved in what we are doing are two ways mindfulness enables us to be content. (Langer, 2009, p. 283)

Mindfulness leads to more engagement, which can lead to improved occupational performance.

For patients with cancer and accompanying pain, mindfulness training helped reduce their anxiety towards pain, improved their ability to achieve a calm state, enhanced their sleep quality, and improved their energy levels (Kvillemo \& Branstrom, 2011). One participant described mindfulness training as "something takes over that is not directed by your own willpower. It is an unbelievable experience" (Kvillemo \& Branstrom, 2011, p. 27). Hawtin and Sullivan (2011) found that mindfulness training helped arthritis patients become more aware of their pain, learn how their bodies respond inwardly to the pain experience, and accept the chronic pain in order to live a life they want.

\section{Critique of Data Collection Methods}

\section{Interviews of Adolescents}

In the dissertation study, data collection was completed through in-depth interviews, which are descriptive in nature and help to tell a collective story. The purpose of interviews was to enter into other people's perspective or, in other words, live in their shoes for a day to learn about the phenomena being researched (Creswell, 2002). 
The researcher in this study used interviews as a main source of data and relied on the participant to make explicit their experiences and knowledge on the topic. This qualitative methodology included the unique perspective of participants that other methodologies do not because it captures the thoughts, beliefs, and ideas of adolescents who live with daily chronic pain.

\section{Interview Styles}

The dissertation study used a combined approach of a standardized open-ended interview style and interview guide style (Creswell, 2002). The standardized open-ended interview style is a guided process in which the interviewer asks semi-structured questions along with using probing questions that delve deeper into the meaning behind each participant's answers. The questions are formatted to be asked in the same manner across participants. This format makes the data analysis more streamlined and easier to complete. The second form of interviewing is interview guide style, which uses questions or issues to be explored in the interview; however, the interviewer has more freedom to change course or veer away from those questions to pursue a different topic that might arise during the interview (Creswell, 2002). Using both of these approaches provides the structure needed for the dissertation study, but also allows more free-flow to the interview, which allows natural conversation to occur with each participant.

This style has both advantages and disadvantages in comparison with other traditional types of interview styles, such as informal conversational interview. A combined approach provides consistency across each interview with the semi-structured questions and makes data analysis easier and more organized (Patton, 2002). Each question is typically in the same order and uses similar probes to reveal additional 
information from each participant. Research by Steward and Steward (1996) strengthened the argument on the use of a mixed approach to interviews in a phenomenological study by showing free recall is more consistently accurate than answering questions that are specific or directly ask yes/no. Although, generally, institutional review boards (IRB) find semi-structured questions more clear (to protect participants from risks), the informal interview style is important because it allows the researcher freedom to veer away from the structured questions when deemed necessary to gather pertinent data to the study. However, the combined form of interview style also has its weaknesses. Variations in the structured questions can produce difficulties with analysis of the data (Creswell, 2007). Thus, advantages greatly outweigh the potential disadvantages of using a mixed approach to interviewing adolescents.

\section{Interviewing Young Populations}

Interviewing children and adolescents as primary participants (instead of solely using parental reporting) is a valid method for data collection (Alex \& Ritchie, 1992; Bricher, 1999; Docherty \& Sandelowski, 1999; Irwin \& Johnson, 2005; Kortesluoma, Hentinen, \& Nikkonen, 2003; Steward \& Steward, 1996). Children as young as 3 have been shown to have excellent recall of experiences, such as illness or pain (Alex \& Ritchie, 1992; Woodgate \& Kristjanson, 1996). By the age of 6, children showed a recall of $91.7 \%$ of details during a stressful event (Steward \& Steward, 1996). Use of openended questions in the dissertation study will help gather viable data on feelings, emotions, and experiences that cannot be gathered in any other forms of research. When using adolescents as participants in a qualitative research study with interviews as the main source of data collection, there are a few important guidelines to 
follow in order to ensure the comfort of the participant along with reliable data. One guideline to follow during the interview is the researcher's full awareness of the vulnerability of the participant who is living with chronic pain and illness (Kortesluoma et al., 2003). This population sees medical providers regularly and can view them in an authoritarian role, which can influence how they act or participate during the interview. To minimize potential authoritarian perception, the researcher dresses in common clothing rather than the white coat commonly associated with physicians. Disassociating from the clothing worn by health care professionals decreased pressure of the participants believing they need to impress or obey the researcher in order to receive the best care.

The second guideline to follow during interviews with adolescents is focusing on the potential needs they are gaining from the interview. In a one-on-one environment, a relationship may form between the participant and the researcher. The relationship may provide a comfortable and safe environment for the adolescent; however, it may provide an opportunity for him or her to develop too strong of a relationship beyond the researcher-participant dyad. In order to decrease the chance of this type of relationship forming, the researcher remained aware of the developing relationship and provided alternative resources, if needed, to ensure proper treatment was sought. Another way to develop a proper relationship was to be acquainted with the adolescent prior to the interview, which can be achieved through informal discussions with the adolescent during an admission into a chronic pain program or through the initial meeting with the adolescent.

The last guideline to follow during the interview was to gain trust and comfort of the participant (Kortesluoma et al., 2003). Some adolescents may exhibit increased 
anxiety during an interview, thus items, such as fidget toys, can be used to decrease anxiety and to increase open discussion between the participant and the researcher. Also, another way to ease the stress for an interviewee was to start each interview with nonresearch-related discussion at an age-appropriate level.

\section{Participant Artwork}

The dissertation study used participant artwork as one of the methods of data collection. The artwork was analyzed and interpreted within the context of the study and used to help illustrate the meaning of the participant's experience (Munhall, 2007). Using art in qualitative research was not recently founded, however, has had a resurgence in the last few years as a tool to establish increased rigor (Leavy, 2009). Artwork provides a visual medium, allowing participants to express their thoughts and emotions in a nonthreatening method that can enhance the quality of data in a study.

\section{Critique of Research}

\section{Strengths}

The current literature on chronic pain supports the individual components, such as psychological profiles, parental influences, and type of occupations, which together help explain the larger picture of chronic pain. Current researchers show strong correlations between chronic pain levels and parental catastrophizing (Logan et al., 2012), coping styles and acceptance (Jaser \& White, 2011; Smorti, 2012), and personality traits and levels of resilience (Yeung et al., 2012). These quantitative studies provide some evidence of a relationship between chronic pain and particular person, environment, and occupation constructs. Occupational therapy practitioners also use specific forms of interventions that show potential effectiveness in assisting clients who live with chronic 
pain to maintain or return to engagement in occupations (Evans et al., 2010; Hawtin \& Sullivan, 2011; Holtzman \& Beggs, 2013; Liptan et al., 2013)

\section{Weaknesses}

The single most significant weakness with the current literature is the lack of research through a qualitative lens. The best way for researchers to explain the phenomena of chronic pain is through a phenomenologic focus, which relies on the participants to provide a descriptive story of their day-to-day life. Interviews with this population can provide a method to unlock the effects chronic pain has on a person when living with it on a daily basis. This form of research can also discover relationships between the components that quantitative methods have uncovered and create a better understanding from a global perspective.

Another weakness found in the current literature is the lack of research on chronic pain and occupational performance, specifically focused on environmental and personal attributes. Occupational therapy practitioners focus on a client's occupational performance and areas that affect his or her engagement, such as chronic illness. In order for occupational therapy practitioners to improve service to this population, additional research needs to address how chronic pain affects client's lives, which interventions assist in achieving engagement in occupations, and how professionals can better address concerns of their clients. Stronger research on occupational performance both improves quality of care for patients along with reduction of costs associated with occupational therapy services. 


\section{Summary of Literature}

Chronic pain in adolescence is becoming a large public health challenge in the current medical care system with between $20 \%$ to $30 \%$ of adolescents suffering from some form of chronic pain (Roth-Isigkeit et al., 2005). While specifics on psychological and personality characteristics, coping styles, and influences of gender on functioning for an adolescent with chronic pain are known, there is no research bringing all those

\section{Reflexivity}

As a clinician, having worked with adolescents for over 5 years who live with chronic pain, I would consider myself a specialist in this area. I have seen many lives affected by chronic pain. I witnessed adolescents who no longer left their beds because of the excruciating pain in their limbs and adolescents who slept 18 to 19 hours per components together to help explain the essence of life on a day-to-day basis for these individuals. Occupational therapy practitioners do not have sufficient research to guide them in providing intervention that will assist clients in achieving their highest level of occupational performance in a variety of environments. The dissertation study used the PEO model as a framework to examine the day-to-day lives of adolescents living with chronic pain.day due to their associated chronic pain. Working in this field has provided me with more questions than answers about how I could best improve their lives. I started noticing patterns of occupational performance in this population, none of which, were supported by research. I wanted to know if I could do anything as an occupational therapy practitioner to support their occupational performance. I decided that if I gave this population a chance to reflect and express their understanding of chronic pain and 
daily life, they could provide clarity to the essence of life on a day-to-day basis along with shedding light on ways to improve their overall occupational performance. 


\section{Chapter 3: Research Design and Methodology \\ Introduction}

This chapter reviews the research design and methodology used in the dissertation study. This study used a phenomenological design focused primarily on in-depth interviews with adolescents with chronic pain. The purpose of the dissertation study was to use a phenomenological method in order to capture the essence of the essence of life living life as an adolescent who has chronic pain. The study included 10 adolescents who were able to give rich descriptions of their lives living with chronic pain.

\section{Rationale}

The purpose of the dissertation study was to describe the day-to-day lived experience of adolescents with chronic pain using a phenomenological approach. Due to minimal prior research focused on the everyday lives of adolescents who have chronic pain, the best methodology to answer the research question was through a phenomenological approach. This methodology helped to articulate the adolescents' lived experiences into a written expression of its essence through the use of in-depth personal interviews (Van Manen, 1990). This study also informs the reader on the dayto-day experience of living with chronic pain.

Qualitative research is a naturalistic approach that examines how the world works and uncovers untold descriptions of the construct being examined through the storytelling of the participants (Creswell, 2007). This type of research is inductive in nature, examining data from the smaller refined details to the larger, grander themes detailed in the research data. Qualitative research is completed in the natural settings where the participants experience life. The setting is context specific and helps strengthen external 
validity of the study findings (Patton, 2002). Qualitative research can capture the lived experience through interview, observation, and reflexive journaling of the researcher.

\section{Phenomenology}

In qualitative research, there are many methods for discovering the answers to the questions posed. Phenomenology is one methodology that helps answer questions about "phenomena" that are poorly understood. Phenomenology can be considered the study of the life-world or the life we experience around ourselves pre-reflectively (Van Manen, 1990). In other words, researchers use phenomenology when attempting to examine the raw experiences of participants, which include the meaning and nature of their lives. This type of research helps to "construct an animating, evocative description (text) of human actions, behaviors, intentions, and experiences as we meet them in the life world" (Van Manen, 1990, p. 19).

There are various schools of thought on phenomenology, such as hermeneutic (Van Manen, 1990) and empirical or transcendental phenomenology (Moustakas, 1994). Husserl is given credit for development of phenomenology, describing it as the study of how people describe things and experience them through their senses (Husserl, 1931). His techniques have been expanded upon and changed and contributed to different types of phenomenologic methods, such as transcendental phenomenology. The type of phenomenology used in this study was empirical phenomenology. This form of phenomenology is "focused less on the interpretations of the researcher and more on a description of the experiences of participants" (Creswell, 2007, p. 59). In other words, a researcher who uses empirical phenomenology focuses more on the data from rich description by the researcher and completes less analysis on the interviews. The 
foundation of a phenomenological study is essence. Van Manen (1990) described the phenomenological process as the act of discovering the internal meaning structure of the phenomenon. Discovering the meaning for their experience of living with chronic pain provides occupational therapy practitioners a richer understanding for providing services that will improve quality of life for this population. In other words, phenomenology in the case of the present study, examines the nature of adolescents who live with daily chronic pain.

\section{Issues of Credibility}

Qualitative research is concerned with developing rigor, or trustworthiness of the data (Creswell, 2007). The qualitative researcher uses multiple sources of data, varying contexts, and the verification of data by the participants and experienced researchers in the final analysis. The use of these sources of data is a strength of qualitative research. In order to develop rigor, the following procedures were followed: epoche, bracketing, confirming or triangulating data from numerous sources, having studies reviewed and corrected by participants (member checks), and peer data review (Patton, 2002).

Epoche and bracketing. The first steps used in phenomenological studies to improve rigor are epoche and phenomenological reduction, also referred to as bracketing. Epoche is defined as the process by which the researcher separates himself or herself from all potential biases toward past experiences with the phenomena being investigated and self-reflects on prior and current experiences (Creswell, 2007). The process of epoche is one of transparency in which the researcher explores the conscious feelings and experiences towards the topic being researched in order to decrease judgment (Moustakas, 1994). Self-reflection does not occur in one episode, but instead occurs 
through repeated occurrences over time. The researcher reflects on the topic, discovering any biases he may have toward the research topic. Bracketing is the process by which the researcher puts aside all previous experiences and biases towards the phenomena being studied (Creswell, 2007). The researcher takes the phenomena out of the context, dissects it, and examines it in a different light to understand the topic better without preconceived notions. In this dissertation project, the researcher utilized a self-reflective journal to collect all thoughts toward the research topic and participants as well as to record any biases. The journal maintained a running stream of ideas the researcher had towards the research. The process of putting aside biases toward the topic helped the researcher become more open toward experiences expressed by the participants.

Data triangulation and member checks. Data triangulation is a process by which the researcher compares multiple forms of data: interviews from each participant, observations made during the interviews, visual depictions from the participants, and the reflections made in the researcher's journal (Patton, 2002). In the dissertation study, interviews were the primary means of data collection. The researcher collected data until a total of 10 initial interviews were completed as well as any follow-up interviews necessary to clarify topics discussed or questions that arose following a particular participant's initial interview.

Member check is the process of reviewing the transcript data and the themes with the participants. In the dissertation study, the participants reviewed transcripts of the interviews to assess accuracy, reviewed components of the analysis and assisted to clarify or correct mistakes, and reviewed the final document that described the essence of an 
adolescent living with chronic pain. Included in the member checks was peer review of the research by the dissertation committee to ensure research validation.

\section{Credibility of the Researcher}

As the researcher, I am an occupational therapist who has been working for 15 years with children of all ages, living with a variety of disabilities. I have been working with adolescents who live with chronic pain for over 10 years. This experience along with my extensive schooling of 6 years graduate work speaks to my credibility on the subject of adolescents living with chronic pain. In order to ensure credibility of the researcher, I used reflexive journaling to reflect on any biases towards participants or specific topics covered in this research (Lincoln \& Guba, 1985).

\section{Procedural Method}

The following procedures were followed to complete this phenomenological study:

1. IRB approval was given from both Nova Southeastern University and Cleveland Clinic.

2. Participants were recruited through recruitment flyer distributed through Cleveland Clinic referring physicians and through the pediatric pain rehabilitation program.

3. Consent and assent were completed with each participant and his or her parent(s).

4. Date, time, and location of the two interviews were determined by the participant's availability. 
5. The first and second interviews were completed in a quiet and welcoming location. Interviews were audio recorded with two Sony ICD-PX333D. All audio recordings were stored in a secured database in Cleveland Clinic.

6. Each interview was transcribed verbatim into a word spreadsheet document and saved on a secured storage system.

7. Identifiers were removed from all transcripts and codes were given for each participant. The code sheet was locked in the researcher's file cabinet, only accessible by the researcher.

8. Members of the researcher's dissertation committee reviewed a transcript of one interview with feedback provided to the researcher to integrate into future interviews.

9. Three participants were requested to review copies of transcripts along with summary of the results.

10. All transcripts were analyzed through the analysis procedures described in the data analysis section of this chapter.

\section{Strengths and Weaknesses of Design}

Phenomenology is a research methodology that has both strengths and weaknesses. One of the strengths associated with this form of methodology is the ability to comprehend the participants' direct experience with the phenomena (Patton, 2002). The researcher directly connected with the participants' experience of the phenomena through detailed stories of their lived experiences. The researcher strengthened the design through member checks, which helped to confirm the data results. In this process, the participants confirmed the data to ensure their personal experiences matched the 
researcher's analysis. The researcher also used bracketing and epoche to distance himself from his prior experiences. The last strength of phenomenology is the rich description of human experience gleaned from personal interviews. This rich description helped the researcher understand the meaning of living in the participant's shoes and his or her experiences lived day-to-day with chronic pain.

Phenomenology also contains design weaknesses. As mentioned previously, using interviews is a strong method for gaining rich description of the human experience based on participants having strong memory of their experiences (Patton, 2002).

Participants who have a clouded recall or poor recollection of past events may not be able to provide rich descriptions necessary in phenomenology. It is imperative the researcher was aware of this weakness and screen potential participants. The second weakness of phenomenology also pertained to the participant. This form of research methodology required participants who are articulate during the interview process. Rich data comes from rich description of the participants' life events. If the participant was not able to articulate those details, poor data may result. Lastly, phenomenology was focused on rich description of the experience and may have neglected information that led up to the experience, outcomes from the experience, or other factors that may have contributed to the experience (Van Manen, 1990).

\section{Participants}

\section{Description of Sample}

In dissertation study, the purpose was to have a better understanding of day-today life for adolescents living with chronic pain. In order to capture those participants who were knowledgeable about life with chronic pain, 10 participants were recruited 
from both outpatient physician offices and an inpatient pain rehabilitation center.

Participants from both samples had been diagnosed with some form of chronic pain and lived with chronic pain for at least 6 months.

\section{Inclusion Criteria}

The following criteria were used for recruitment of participants:

1. Participant must be between the ages of 13 and 19 .

2. Participants must have been diagnosed with chronic pain by a medical provider, and the duration of pain must be at least 6 months.

3. Participants must be free of any major psychiatric disorder beyond depression or anxiety, determined through chart review or consultation with care providers.

4. Participant must be able to understand and converse fluently in English.

5. Participant must not have entered college-level courses at the start of the interviews.

\section{Sampling}

The main purpose of sampling in a phenomenological study is to ensure variation in data among the population being studied. In this phenomenological study, criterion sampling was used to locate the specific population of adolescents with chronic pain. Specific inclusion criteria that depicted characteristics necessary to participate were reported in the inclusion criteria of this dissertation. Using this type of sampling provided the researcher with the opportunity to choose which participants would provide the most valuable and informative data. This process took place through discussions with current health care providers of the potential participants and/or through pre-screening 
while discussing consenting process with participants and their parents. For purposes of the dissertation study, a sample of 10 participants was included in the data collection process.

\section{Recruiting Procedures}

Subjects were recruited through two means of referrals. One avenue of recruitment was through various physician offices in Cleveland, Ohio. The physicians were chosen due to their experience working with children living with various chronic pain pathologies and were familiar with the pediatric pain rehabilitation program. If a candidate was identified as a potential participant for the study, the medical provider gave the recruitment flyer to the patient and family or legal guardian (see Appendix F) with information about the study enrollment procedures. The second recruitment center was Cleveland Clinic Children's, Hospital for Rehabilitation. Each adolescent admitted into the pediatric pain rehabilitation center who met the inclusion criteria was informed of his or her opportunity to participate in the study along with being provided a recruitment flyer. The proper consent and assent procedures were completed with the participant and family by the primary investigator on this study. Further details on the consenting and assenting processes will be discussed in the ethical consideration section of this chapter.

\section{Instruments and Measures}

\section{Interviews}

Interviews followed a combined approach of a standardized open-ended interview style and interview guide style. The interviewer followed a semi-structured format with pre-selected questions (see Appendix I). The interviewer also had the flexibility to ask questions not found in the interview guide based on responses of the participant. Probing 
questions, described as "follow-up question used to go deeper into the interviewee's responses" (Patton, 2002, p. 372), were used to promote elaboration or expansion of the story told by the interviewee. This combined approach ensured a comprehensive account of the questions for the study while allowing free association of the participants in areas they felt were important to cover. Creswell (2007) recommended that participants remain active throughout the research process by completing follow-up interviews and member checks to ensure credibility and reflection of their viewpoint. The researcher used follow-up interviews to make inquiries into areas that emerged during the initial interview. He also continuously updated follow-up questions throughout the research to reflect additional areas of inquiry that developed during the interviews or observations. The two timeframes for the interviews were within the first week of admission into the chronic pain program and within the last week of the program. Having these two timeframes was a strength of the study by allowing the participant to contemplate and reflect to give additional insight contrasting between the essence of life prior to the program and while in the program.

In order to minimize bias, the researcher used semi-structured questions as a format for the interviews to increase consistency and thoroughness across interviews. The questions provided a guide, but did not dissuade the researcher from adding further questions or additional probes into areas that arose during the interview process.

In qualitative research studies with interviews as the main source of data collection, specific guidelines are followed to ensure quality data gathered during the interview process. The first guideline followed during the interviews was for the researcher to dress in plain clothing without using medical scrubs or a white lab coat 
typically associated with medical professionals. The second guideline that was followed during the interview process with adolescents was to maintain a researcher-participant relationship. The relationship formed during interviews may provide a comfortable and safe environment for the adolescent; however, it may provide an opportunity for him or her to develop too strong of a relationship beyond the researcher-participant dyad. One method to develop a proper relationship was to become acquainted with the adolescent prior to the interview, which was achieved through informal discussions with the adolescent during an admission into a chronic pain program or through the initial meeting with the adolescent. The last guideline the researcher followed during the interview was to gain trust and comfort of the participant, accomplished through use of anxietyreducing techniques (Kortesluoma et al., 2003). An example of a tool the researcher used to reduce anxiety in the adolescents was to provide fidget toys for their use. Also, another technique the researcher used to ease the stress for the adolescent interviewees was to start each interview with non-research-related discussion at an age-appropriate level.

\section{Visual Depictions}

Each participant was asked to visually depict his or her chronic pain through forms of visual mediums, including paper, pencils, markers, and paint. The purpose of this diagram was to allow the participants to describe how the chronic pain affects their body and life. The prompt for each participant was "Use one of these (pointing to the art supplies) materials and make a picture that describes your chronic pain." The participant was asked to describe the drawing on the back of the artwork. 
Analysis of the data occurred using the PEO model as a framework along with the themes that arose in the transcripts. Both a cursory examination along with an in-depth analysis of the visual depiction occurred to help give a description of the essence of life living with chronic pain. The visual depictions were compared and contrasted against the data from the transcripts and the combined thematic descriptions found in the data. The researcher was able to interpret the meaning of the artwork in comparison with the interviews in order to triangulate the data and add to the thick description of the lived experience of adolescents with chronic pain. The researcher scanned each drawing for future analysis and stored them in a secured location.

\section{Journaling}

In addition to completing the interviews, the researcher maintained a journal to depict a descriptive account of each interview. The journal also followed a timeline format to allow for an audit trail. The purpose of the journal was twofold: to make all thoughts of the data, participants, and rich description of the lived experience present and to capture the process of epoche in a written format (Morrow \& Smith, 2007). This form of data documented personal reactions to participants' interviews and observations made during the research study.

\section{Ethical Considerations and Review}

This research followed all IRB, Health Insurance Portability \& Accountability Act of 1996 (HIPAA), and other state and national regulations for research with adolescents. Due to the high-risk population of adolescents under the age of 18 being studied, further safeguards were in place to ensure no greater than minimal risk was to be placed on the participants. In order to properly safeguard all participants, both assenting 
and consenting processes occurred with the potential participants and their legal guardian/parent(s). An open discussion of the research, potential risks, procedures, time requirements, and potential outcomes occurred in order to ensure full understanding of the study. At any time throughout the research process, participants and parents/guardians were able to contact the researcher with questions or concerns about participating in the study. They also were able to revoke consent and withdraw from the study without penalty at any time. No money or external rewards were given to the participant or participant's family for participating in the study. Data in the form of interview audio recordings, transcripts, or other identifying formats were safely stored on the Cleveland Clinic secured computer system. The identification of each participant was kept confidential in the results by using false names and deleting any forms of patient identifiers. The code sheet that identified each participant was only accessed by the researcher and kept in a locked file cabinet. Portions of the transcripts had to be altered in order to maintain confidentiality. All participants and anyone mentioned in the interviews were given false names and dates or locations were deleted from the transcripts.

\section{Study Setting}

The study took place in a safe and secure location for all participants and the researcher. The location was at the Cleveland Clinic Children's Hospital for Rehabilitation. If the participants were not able to travel to the hospital, the researcher was willing to meet them at their home or safe location that would provide a quiet environment for the interviews. The hospital has various conference rooms, which provided a quiet environment to allow the interviews with minimal disruptions. Follow- 
up interviews or member checks were completed at a location convenient to both parties (researcher and participants).

\section{Data Collection Procedures}

A combined approach of open-ended and interview guide styles were used for data collection (Patton, 2002). The length of interviews lasted between 40 and 75 minutes depending on the detail of each participant's answers. Follow-up interviews also varied depending on the length of responses from the interviewees. The participant's family was not permitted to remain inside of the interview room due to the potential influence by the parent. Although no research has been found to show the impact of parents being present during interviews, position papers have been published on the importance of adolescents spending time alone with medical practitioners in order to discuss sensitive information (Ford, English, \& Sigman, 2004). Also, parents of adolescents with chronic pain are often characterized by increased parental distress and negative affectivity, which ultimately may affect the adolescent's interview responses (Palermo \& Eccleston, 2009).

Interviews were audio recorded with a redundant system to ensure patency of data and allow for thorough evaluation and analysis. The redundant recordings were used as a back-up system to ensure no loss of data during the data collection and analysis process. Raw data in audio format were backed-up on a removable encrypted hard drive that were stored in a fire proof, locked cabinet. The researcher was the only one who had access to the cabinet to ensure protection of data and maintain confidentiality of each participant. In order to maintain accuracy, the researcher transcribed the data word-for-word into a 
word processing program. Numerical coding was used in order to de-identify each participant.

\section{Data Analysis}

In the dissertation study, the researcher used a three-step process to complete the data analysis: data transcription, data coding, and thematic data analysis. Initially, the raw data were in the form of transcribed interviews. The raw data from the taped interviews were transcribed verbatim by the researcher. The first two interviews were transcribed prior to future interviews and reviewed by the researcher and committee members. This procedure served as a way to learn from missed opportunities for probes, thus improving the richness of data.

The process of coding was used to convert the raw data into a useable form for analysis. For the dissertation study, coding was completed without a computer analysis program. The transcribed data was placed in a word sheet with the transcription located on the left hand and the coding located in the two right-hand columns. The first righthand column was used to identify initial codes on the first read through. The second right-hand column was used to identify codes identified on the second reading called horizontalization (Moustakas, 1994). During the first or second reading of the raw data, coding abbreviations were developed and located on a different document. This coding sheet evolved as additional interviews were read and analyzed. Abbreviations helped identify the appropriate theme identified in the raw data and were labeled on the righthand side of the transcription. Highlighters were also used to help clearly delineate different themes within the raw data. The highlighted text corresponded to the coding sheet. 
The data was analyzed through thematic analysis as described by Moustakas (Moustakas, 1994) as a modified version of Van Kaam's method of analysis (1966). The data analysis process was framed by using the core constructs in the PEO model (person, environment, occupation, and occupational performance; Law et al., 1996). The process of phenomenological reduction, or bracketing, described as suspending judgment on the natural world to better analyze the experiences of the participants in the study (Patton, 2002) was used during thematic analysis. This process was vital for the researcher to participate in to best describe the raw and real experience in vivid textural description without prejudgment or reflection (Moustakas, 1994).

The overall gradual process of phenomenological reduction was used to look at the data through pre-reflection, reflection, reduction, and then concentrating data to form essentials of phenomena. Further description of how this process occurred by engaging in seven steps of analyzing data collected in a phenomenological study as discussed in the next section (Moustakas, 1994).

1. Review all transcribed data and perform a preliminary grouping by listing every potential expression relevant to the experience, known as horizontalization.

2. Eliminate all data that is not relevant to the experience by asking two questions: "Does it contain a moment of the experience that is a necessary and sufficient constituent for understanding it?" and "Is it possible to abstract and label it? (Moustakas, 1994, p. 121). 
3. Cluster and place statements into themes, based on the constructs contained in the PEO model. These clustered and labeled constituents are the constituents that make-up the core theme of the phenomena.

4. Identify the final labeled constituents through reflection against transcriptions of the data. If determined to be expressed explicitly in the complete transcription nor compatible if not explicitly expressed, then it was eliminated from the analysis.

5. Construct an individualized textural description of the experience for each participant in the study by using the final labeled constituents and themes.

6. Produce an individual structural description of the experience. In this process, verbatim transcription was included in the analysis in order to provide a vivid account of underlying dynamics of the experience. This process helped to describe the "how" feelings of living with chronic pain.

7. Combine all participants' textural and structural descriptions of the meaning and essences of the experience and develop an overall analysis of the meaning of living life as an adolescent with chronic pain.

For verification of themes established in the study, follow-up interviews occurred with three of the participants of the study. During this process, the overall analysis of the meaning of living life as an adolescent with chronic pain was reviewed. The participants were requested to give feedback about the proximity of the data to their personal experiences.

To improve the data analysis process, multiple analysts, including the researcher's committee members, reviewed data in various stages of the analysis. Using the thematic 
verification process with other professionals within the occupational therapy field improved data triangulation and strengthened the validity of the study findings.

\section{Format of Presenting Results}

The results of this phenomenology study are located in Chapter 4 and are presented in the following format: (a) researcher's experience of data collection and bracketing, (b) demographics of the participants, (c) individual textural and structural descriptions of the experience living with chronic pain, (d) participant artwork, (e) themes of the findings, and (f) textural and structural description of the meaning and essence of the experience. In Chapter 5, discussion and interpretation of the results are presented along with conclusions, implications for future research, and limitations of the research.

The results of the dissertation study were presented through an oral dissertation defense at Nova Southeastern University and dissertation publication. The researcher also has plans to publish the results from the study, including data from the interviews and observations in a peer-reviewed journal along with poster presentation at the national occupational therapy conference.

\section{Summary}

This dissertation research, entitled The Lived Experience of Adolescents with Chronic Pain: A Phenomenological Study examined the essence of the meaning of living a life as an adolescent with chronic pain. Ten interviews of adolescents who live with chronic pain were completed in order to transform the lived experience of adolescents into a contextual format that describes the essence of living with chronic pain. The goal of the dissertation study was to better inform occupational therapy practitioners of the 
rich experiences of adolescents who live daily with chronic pain in order to provide more effective and targeted treatment to improve occupational engagement and quality of life in this population. This research may also guide further research about occupational performance in adolescents with chronic pain. 


\section{Chapter 4: Findings \\ Introduction of Chapter}

The focus of this chapter is to present the findings from the analysis of in-depth interviews with 10 adolescents living with chronic pain and schematic interpretations of each child's perception of pain. The in-depth interviews occurred over two, one-hour interviews between the investigator and the adolescent. The interviews followed a structured interview guide, however, still allowed open discussion between the two parties to gain a rich description of an adolescent's life living with chronic pain. The data was analyzed according to thematic analysis described by Moustakas and modified by Van Kaam (Moustakas, 1994). In addition, each adolescent was asked to draw a schematic representation of his or her pain and asked to describe in detail the meaning of the drawing to the researcher. The investigator interpreted each adolescent's drawing, which included reviewing with each adolescent's description of his or her drawing. The first part of the findings section will describe the researcher's experience with the data collection and bracketing. The second part of the findings section will review the demographics of each participant who was involved in the study. The third part of the findings will describe each adolescent's individual textural and structural description of the experience using the meaning of the chronic pain and impact of the pain on his or her life as a guide to each participant's description. The participant artwork will also be located in this section with analysis. The forth part of the findings will provide an overview of the themes identified in the study. The fifth part of the findings will use thick description of the final labeled themes and subthemes within the combined textural 
and structural description of the meaning and essence of the experience and an overall analysis of what it means to live life as an adolescent with chronic pain.

\section{Data Analysis Results}

\section{Researcher's Experience of Data Collection and Bracketing}

I followed guidelines set by epoche to withhold judgment and identify any preconceived notions about the data that was collected and to maintain an open-mind towards the findings. I used a journal before and followed each interview to identify any preconceived notions, reflect on them, and to maintain an open mind towards the stories each adolescent told.

This process was important for me due to the familiarity of working with this population for years prior to the start of this research project. There were three common themes that came from journaling: feelings of sadness or empathy for the participant, difficulties of maintaining researcher role versus the therapist role, and removing preconceived notions from history working with other adolescents who lived with chronic pain.

The first theme of feelings of sadness or empathy for the participants arose due to the challenging and often disturbing lives the adolescents reported living. It was important for me to maintain a clear boundary between myself as the researcher and the participant and avoid becoming distracted during the interviews and data analysis. Maintaining boundaries was not an easy feat for me to accomplish; however, journaling allowed me to reflect on these experiences without undue influence on the interviews and data analysis. One excerpt explains the challenge I had during one interview:

The interview started benignly with no reason for me to feel distraught over her life. This all changed when she started describing her life, void of what she 
cherishes most in her life ... her voice. Having a daughter, this hit home the most. It made me think about how I would feel if my daughter had the inability to do what she loves the most-dance or sing. As a parent, I cannot imagine the emotions or thoughts that would go through my head if she could not do those things and truly enjoy life.

During the interview, I had to take a few deep breaths as these thoughts arose. This allowed me to stay calm and not allow her life to fully sink in. This allowed me to maintain a professional demeanor and to allow me to keep going through the interview.

The second theme that arose during the interviews was the difficulty of separating out both the researcher and treating therapist role. As mentioned previously, in addition to the role of being the researcher, I was also a treating therapist in the chronic pain program. The role of a treating therapist can be prescriptive and supportive in nature, which varies greatly with the role of being a researcher, whereas it is important to remain unbiased and non-influential as possible in order to obtain clean data. The following excerpt describes my experience after the first two interviews:

My largest struggle I feel is the urge or desire to help each participant as he or she is talking about him or her life-altering events due to chronic pain. It is very difficult to listen to their stories and not want to reach out and give him or her a large hug and state that life will be ok. Having both hats (researcher and therapist) it is difficult to segregate the two and only wear one at a time. The nature of OT is to assist others in returning to prior occupations. The nature of a researcher is to uncover the data that will explain a phenomenon. The vast contrast between the two natures is difficult for me to maintain without use of a medium, such as a journal to describe my feelings and thoughts about this process. I have had to use deep breathing and other coping mechanisms that I typically teach the patients in order to maintain professionalism and courtesy towards the participants in the study. I found between journaling and using these coping strategies, I have been able to stay focused and dedicated towards discovering the essence of the lived experience is for adolescents living with chronic pain.

The third and final theme that arose from journaling was removing preconceived notions from history, working with other adolescents who lived with chronic pain. I had a long-standing history of working with adolescents with chronic pain. My personal 
experiences with this specific population can bias beliefs and influence how I interacted

with each participant. It was important for me to journal his experiences and the potential

biases that could influence the interviews. The following excerpt describes the struggle

between influence from prior patient experiences and maintaining an unbiased "clean

slate" when interviewing each participant.

I find myself struggling with past memories of patients I have treated and not allowing those to influence my current interactions with the participants. It is all too easy to allow those past, vivid memories to influence my questions and interactions with the current participants. Those experiences helped shape who I am as a therapist and influenced my clinical decisions for providing best practices. Now that I am in the middle of the interview process, I have to take a step back and freeze those experiences in order to allow me the freedom to be open to the current participants' stories. That step in this research process has been the most challenging for me. After the first two interviews, I had to write a reminder on the top of the interview guide "FOCUS ON THE PRESENT." I used this reminder as a mantra before, during, and after the third interview and found it much easier to stay focused on the current participant's story and allow me to be in the present with as minimal pre-conceived notions as possible. I admit that I am not perfect! That does not mean that I was able to keep all those thoughts from entering my head during the third interview; however, I was able to withhold judgment about the life story.

Epoche was an important component of this qualitative research, improving the validity and quality of the data. The process of self-reflection was partially achieved through journaling. As the researcher, I found journaling to be an effective tool to selfreflect on preconceived notions and biases that may influence the data collection and analysis. When I found new discoveries, the journal provided a means to express those biases and to reflect on the cognitive strategies to minimize the effects of them on the data gathering and analysis processes.

\section{Demographics of the Participants}

In this study, there were 10 participants. Eight of the participants were female and a majority of them lived in a suburb. All 10 participants were Caucasian and 
between the ages 13 and 17. During the period of sampling, all potential participants were exclusively of the Caucasian race. The following table provides information on the participants' demographic information for the study.

Table 1

Demographics of Participants

\begin{tabular}{ccccc}
\hline Name & Age & Gender & Race & Location \\
\hline Angie & 17 & Female & Caucasian & Rural \\
Sasha & 14 & Female & Caucasian & Suburb \\
Sophia & 17 & Female & Caucasian & Suburb \\
Emma & 16 & Female & Caucasian & Urban \\
Mia & 13 & Female & Caucasian & Suburb \\
Lily & 17 & Female & Caucasian & Suburb \\
Emily & 17 & Female & Caucasian & Rural \\
Sam & 16 & Male & Caucasian & Rural \\
Zoe & 15 & Female & Caucasian & Suburb \\
Patrick & 17 & Male & Caucasian & Suburb \\
\hline (Names of participants were changed to protect anonymity)
\end{tabular}

\section{Individual Textural and Structural Description of the Experience}

This section will present the individual participant's background and history with his or her chronic pain. It will also present individual participant's textural and structural description of chronic pain in his or her life along with the impact of the pain. Each adolescent's name was changed and transcripts might have been altered in order to maintain anonymity. Three asterisks in the transcripts depict any changes or omissions. Research Question: What is the essence of the day-to-day experience of adolescents living with chronic pain?

Participant \#1 Angie. Angie described herself as a 17-year-old female living in a rural community in New England. She presented with chronic daily headaches, migraines, depression, and anxiety. Her headaches started over one year ago with a headache that would not stop over a two-week period. She received an exhaustive work- 
up over a few months' time with no organic cause for her headaches and no effective treatment. She stated she lived with both of her parents and a younger sister at home. During the interviews, Angie was very detailed and expressive about her experience of living with daily headaches and the decline in function she saw in herself.

Meaning of chronic pain. Life with chronic pain for Angie meant life of torturous tests and evaluations that led her down a long road of further and further despair and continued regression from engagement in all activities she loved. She described the despair and depression that the chronic pain caused her $(\mathrm{R}=$ researcher, $\mathrm{A}=$ Angie $)$ :

R: Do you feel that defined your life at that point?

A: At that moment, I felt like the headache, yes, defined my life. I felt like this is never going to go away. I feel like it's going to be like this forever and ever. Yeah, I felt like it defined my life.

R: Did you see anything beyond that?

A: No.

Angie had periods of despair, where she could not foresee a future. The pain had become her life and there was no end in sight.

She further expressed how the headaches had changed her mood when there was no end in sight. She described how the lack of end in sight caused her to go into a depressed state. Prior to the headaches, she described herself having a cheery and easygoing personality. The depressed state was significantly different from her typical personality.

A: ... I just had gotten to this really deep depression, like my head wasn't getting any better. I was missing school, I just, my head was getting worse probably, actually. I couldn't do any thing, I was spending every day in my bed. There were times where I wanted to kill myself. I never acted upon it, but I had those thoughts. 
Angie had difficulties overcoming the depressed mood, causing her to withdraw from everyday activities she enjoyed and participate less in family and school activities.

During the description of her depression and total withdrawal from society, she became tearful and distraught over how low her life had become.

Angie faced the unknown of whether the headaches were something life threatening. The challenge of facing this unknown causes great distress and emotional turmoil on her day-to-day life. After initial testing, she still did not have a clear sense of the cause to her headaches. She had no confirmation of disease pathology and no clear treatment plan. The only thing the physicians could tell her was that it was nothing life threatening. She described her bittersweet experience of the challenges of the diagnostic testing while discovering that there is no life-threatening nor clear reason for her headaches.

A: So then afterwards, then they said about 45 minutes later they come back to say ok we're here to take you for your CT scan. We said well we've already had the CT scan. They said well we made a mistake. So it turns out the CT scan we gave you was the wrong CT scan. So ... I wanted to rip out the IV out of my arm even though I couldn't really move because my back was sore. I was tired, because of like from the needle where it went in. I was kind of, yeah, I was incredibly tired, yeah, I was just ready to be done. I was just like I'm done. But like it was like at the point where I couldn't even get up from the bed to the CT scanner. They had to lift me, I didn't have any energy in me. And so I had to go through the whole process again with the dye and all the CT scans came out fine. So like they knew I didn't have anything there. So the good news, it was just a headache. But the question was like ... Why? And you know?

In describing the meaning of chronic pain in her life, she identified a frustration of the disease being hidden from others. The headaches became a part of herself, however, not overtly seen by others. When she missed significant amounts of school and returned back to her classroom, she was questioned by other students about why she missed school. For further clarification about events going on in her life at this time, she had 
received an IV treatment that decreased the intensity of the headaches to allow her to go to school for a short period of time.

A: It made it so it was tolerable, it made it so I could go back to school for the last three days and everyone was like "Oh ***, where were you. You know, you were gone". And I just kind of said you know I had a headache, I had a migraine. And they were like seriously?

Impact of chronic pain. Angie described in detail her loss of occupational

engagement in daily living, including school-related, and leisure-related occupations.

She demonstrated global decline in function across many domains. One example was where she described her experience of losing functional independence in walking to her room for bed.

A: Well, like, I guess before I came here I would get dizzy a lot. Like, really dizzy. And like one, I guess this really doesn't count as special needs, but like sometimes I'd have to have my parents help me up the stairs.

She compared her life to the life of a child with special needs, one in which she needed additional assistance from her parents on an on-going basis. She further clarified that special needs was maybe not the correct word for how she was trying to describe her life with chronic pain needing added assistance from parents.

A: Like, I don't know I like special needs in a way, like serious special needs. I guess like having people constantly having to help you. And, because I guess I didn't really have much of an idea of how broad chronic pain is in a way.

Angie identified herself as an avid singer and musician, playing violin since she was 8-years-old. In the next dialogue, she discussed the frustration and anger she felt because she had to give up leisure occupations that were dear to her heart.

R: How has chronic pain changed your involvement in those occupations (leisure)?

A: I really like to sing, I did a lot of that. I take voice lessons. My parents have always said I have a really pretty voice. And my sister also has a really, really 
beautiful voice. She actually got to tour Quebec and France and Vermont. We have this choir for a couple of years ago to celebrate like the Quadricentennial like discovery of Lake Champlain. So like that was a big thing and so singing was a big, big piece and then when my head got really bad I just couldn't do the noise. Like I couldn't even stand hearing myself sing like that just hurt too much. And playing violin that was another big piece. I'd been playing violin since I was eight years old. And again having that noise right in my ear was just unbearable. I mean it was it was just so bad I couldn't I couldn't do it.

She further described the difficulties headaches have caused on her occupational engagement in her singing in the following description.

R: Any other activities in school, out of school, or within your community that has also been affected by your pain?

A: The Fall musical that was really kind of a crush, like a punch in the face to me. Like a big slap in the face, because I was here (pediatric pain rehabilitation program) and because of the pain, I didn't get to the Fall musical this year. I've been doing the Fall Musicals every year, and this year it was Legally Blond. And you know, normally when you start off doing the musicals, our director, you know, she usually has you do minor roles even if you have a really good voice because she wants you to be in the chorus like helping people out and then when you get to be like a junior or senior that's when you get the big parts. And like everyone was saying A . . ., you're going to get this big role, or whatever, you know and everything like that. Even my choir teacher who helps with the audition process was like, yeah no you're pretty much going to get that part. Don't worry about it A . . . , kind of thing. And so I got really excited and then my head just started to get really bad and a sophomore ended up getting that part. A sophomore girl got that part. Which was kind of like well I didn't get a chance to audition any ways, but like my teachers, like you know what we're still going to give you a speaking part and you're still going to have a part. You're going to have a speaking part, you're still going to have a little solo. We're going to give you a part, you're not you're still going to kind of be in the chorus, but you're still going to have a solo. And you know this is still going to be the biggest role you've got, and you're still going to have the senior play if you're better by then. You know, so we'll work from there A ..., and I'm like ok. You know it's ok. But then it got worse, and I didn't even like make it to the first rehearsal kind of thing. I just stayed home, and then while I was here I just seeing like the updates on the Legally Blond Facebook page kind of thing. And like all the pictures from the rehearsals and everything, and this it ended up looking like this was probably the best Fall Musical they have done in the past two or three years. And I just felt like so bummed I couldn't be a part of it. So that was really heart breaking to me that I couldn't be a part of it and I couldn't have that role that I wanted. 
Angie also describes her occupational loss in relation to the rite of passage of being a senior in high school. She missed opportunities to participate in senior activities, such as completing a senior square in the yearbook. Being from a smaller high school, she emphasized the impetus of completing this project for every student to see.

A: One of the things when you're a senior in your yearbook, you have a senior square, which kind of like has pictures of you, a little inspirational quote, you know, and I didn't get to make a senior square. Like it usually has your senior photo and like because I was here (pediatric pain rehabilitation), I didn't get to get to make my senior square. That was a big thing, I didn't get to make my senior square.

Despite a long downward spiral of decline in occupational performance, she started having moments of improvements in various domains of occupation. One example was her interacting with her mother while in the rehabilitation facility, describing the first time that she sang since the onset of her headaches.

A: But, but like I'm really excited to like a couple of days ago, not a couple of days ago, like last week when I was when it was my last night like staying here. My mom was like, hey you know you realize that tonight's your last night staying here. And I started like singing "Oh freedom" I started going like that and she was like $* * * .$. you're singing. And she's like sing something for me. My mom is like sing something for me, *** sing something for me. And so I just started singing and she's like keep singing keep singing. Sing stuff from your voice lessons, just like sing stuff from like you know your New England Festival auditions and stuff from your All State auditions, sing stuff from whatever. You know just sing and I was just singing and it just felt so good that I could sing. And you know it hurt but I could and it just it was so great.

She also described how important it was to herself to try returning to prior occupations that she avoided. She had to prove to herself that she could achieve the challenges and recognize that she could not avoid life any longer.

A: So there's that and I just you know there's noise everywhere. I mean it's not like you can avoid noise. I mean I've been fortunate when I've been here that there hasn't been it's been fairly toned down for the most part. But you know when I go outside I mean there's noise. 


\section{R: Yes}

A: But like last weekend, I went to the movies cause I wanted to show myself that I could do it. I could do noise, and I did I showed prove to myself that I can do loud noises. I mean it, and when I went to the Rock and Roll Hall of Fame, I sat in one of those big theaters with like the loud rock and roll music playing, showing you all of the Rock and Roll Hall of Fame inductees. From each year from like 1999 to 2014.

\section{R: Yeah.}

A: So you know, it was a half-hour long or something like that so I was sitting there again with that loud rock and roll music playing.

R: Yeah.

S: So again, I showed I proved it to myself then also. So I feel like it's not shaping my life as much as it used to.

Angie came to the realization that the pain no longer needed to control her life and wanted to challenge herself in order to gain her life back. She also wanted to ensure herself that she could accomplish the challenges she self-imposed upon return to home following the pediatric pain rehabilitation program.

In summary, the chronic pain in Angie's life meant long, lonely days without engaging in important occupations with her friends and family, which were important to her self-identity. She had changes in her affect and personality that decreased her ability to interact within her environments. She also described a life without a future, unknowing whether she would be able to move beyond the pain and live a life of an adolescent who is about to go to college. She described headaches as the invisible disease with peers at school doubting the severity and questioning why she had missed school. She also described the difficulties of not having an organic cause to the headaches. There was no prescribed course of action about how to be rid of the headaches. She went on to tell stories about her decline in occupational performance 
across all domains. She described in detail about her disappointment of not being able to participate in her beloved leisure occupations of singing, playing the violin, or performing in the school's play. She ascribed an identity in participating in those activities, which she was no longer able to complete due to the headaches. Lastly, she described her uphill battle to regain her life. She was able to challenge herself by pushing through the pain while completing leisure occupations, such as going to the movies or singing. This challenge took a great deal of courage and trust in herself, best described as a survivor of her chronic pain.

Participant \#2: Sasha. Sasha described herself as a 14-year-old with chronic ear infections, physical deconditioning, dizziness, amplified pain syndrome, lower back pain, and wrist and ankle pain. She also described living within a divorced family. At the time of interview, she lived with her mother and pet dog. Sasha had been in and out of physician's offices throughout most of her life with chronic ear infections without resolution. She had experienced significant decline in occupational engagement with school, social outlets, and leisure.

Meaning of chronic pain. Sasha identified how the chronic pain filled her life with constant medical appointments and testing. She described the meaning of living with chronic pain as living a life going from test to test with no results and living with the unknown about her disease $(\mathrm{S}=$ Sasha, $\mathrm{R}=$ Researcher $)$.

S: So they've tried the tubes. Then they've done a lot of hearing tests, which one yesterday showed that my ear drums are not moving. So today they did a CT scan of the temporal bone and lobe to check for fluid. And tonight I'll have a sleep study to check for sleep apnea. And I've had lumbar puncture, MRI, Cat Scans, $\mathrm{X}$-rays, lots of antibiotics and medications.

R: Through this, what have they told you about your ears? 
S: There's been a lot of doctors that have just said they have no idea. And that they should write a book about me when somebody finds out. That I'll be a textbook case and that they are very, very scarred inside, lots of scar tissue.

She identified herself as Sasha with chronic ear infections. The chronic pain became a part of her and influenced what she talked about with friends or family. She described how difficult it is to start a conversation without it having to evolve around her medical care because that was all she knew.

S: Like a lot of your stories are about everything or about the chronic pain or about your studies and your test. Or your stories are about being in the hospital even the funny stories mostly take place in the medical field.

R: Do you feel that the chronic pain identifies you?

S: Yes.

Sasha struggled with the physicians who either had no answer of how to cure her chronic ear pain or assured her that it was psychosomatic or believed to have no organic cause and instead came from the brain. Mistrust by medical providers also became an important meaning of chronic pain to Sasha. She told a story about the numerous instances in which medical providers have not believed her chronic pain because they could not see it or diagnose the cause.

S: There's been a lot of doctors that have just said they have no idea. And that they should write a book about me when somebody finds out. That I'll be a textbook case and that they are very, very scarred inside, lots of scar tissue and there has always been a lot of doctors that suggested Munchausen or a hypochondriac. Because they thought I was mentally ill and I was making up the pain.

R: Tell me more about, what you were telling me about that?

S: We would go into ER with the pain or to a doctor's office. And they would first ask my parents to step out of room, and they'd try to see if like I was being abused at home or anything to want me to get attention. 


\section{R: Ok}

S: Or anything that would make me want to have the attention from the pain. They would, they have always done lots of psychological test and they have told us that I was just crazy and was making it up since, but other doctors since then who don't think I'm crazy are just say that since they don't know it makes them feel better than to come up with an answer than to just say they don't know and to just blame it on something that's not true, than to admit they have no idea.

Sasha struggled with moving beyond the fact that the physicians did not come up with a definitive diagnosis of why she had chronic ear infections and the chronic ear pain. She described her experience as traumatic and one that did not allow her to regain her functional life. She also had trouble with teachers and students not believing that she was truly incapable of coming to class on a daily basis.

S: There would always be lots of kids and even teachers criticizing since I wouldn't come to school or I would leave early or just that I was absent a lot mostly.

R: Would these teachers say something in class or outside of class?

S: They would say them in front of the class and outside of class. Like some days everyone would be like, I would ask a teacher for work and they were like oh yeah, right you were absent cause you're always absent a lot and they would just sort of point it out or be like that's no surprise that you were absent.

R: How did that impact your day at school?

S: It made me feel bad cause it wasn't like I was trying to miss school or like I didn't want to. That's what I would always say to my parents it wasn't that I wanted to miss school but that I had to.

Impact of chronic pain. Sasha described numerous experiences where she missed everyday occupations that normal adolescents experience. Most of her stories described her lack of school participation and how that affected her pride in the 
schoolwork she accomplished. She prided herself on her grades and academic progress she made prior to the headaches.

S: Like you can't go to school on an everyday basis or even when you can you can't stay a full day because you most likely have a doctor's appointment or a test or you have to take your medication and go to the nurse maybe to get half way through the day and you have different experiences than other people.

She also describes the challenges with maintaining friendships with classmates due to the irregularity of attending school. She described the feelings of isolation because the students may have forgotten about her being at school. This depiction showed the challenges of having and maintaining friends while living with chronic pain.

S: A lot of them aren't contacting me, but I feel like when I go back to school they'll still like me but they've sort of forgotten that I'm not there because they have other friends so if one friend goes missing it doesn't really matter.

Especially me 'cause I was never around to begin with.

Sasha also described the challenges of maintaining independence throughout her day due to limited energy. She believed that her life with chronic pain left her with limited energy each day and that it was too challenging to accomplish everything she needed and wanted to finish.

R: So, how has the pain changed your involvement in activities or occupations you were doing?

S: I can't do them at all. Because if I'm focused on anything, it's being able to go to doctor's appointments or do my exercises and then doing homework and trying to keep up with that. And that's sort of at the very bottom of the list. Because I'm just trying to do the bare minimum now. And because once I get through the school day, if I got through the school day was a miracle, so I really didn't have two or three extra hours to go spend doing that.

Lastly, she used to participate in various school activities that she has not been able to with the chronic pain. She was active in drama club and Model United Nations. The 
chronic pain had made occupational engagement challenging for Sasha in her self-chosen leisure occupations.

Despite significant decline in Sasha's overall occupational engagement, she saw small glimpses of hope and ability to push through the pain in order to regain her life. One quote that depicted her cautious optimism is her description of how to overcome chronic pain and return to a normal life.

S: To keep, to try to keep going and not just say I'll just live with it and I'll just deal with it. Because you just can't deal with it if you don't, if you just ignore it and not, like you have to ignore it but you just can't completely and not tell anybody and just say I'll deal with it by myself.

R: So what will, what would help other kids?

S: To find something that either takes your mind off of it

R: Ok

S: or makes you feel better or find someone that makes you feel better.

R: For you is there any one thing that helps you take your mind off it?

S: My dog mostly.

She also described her long-term goals for schooling. She told the researcher about her hope for attending college and achieving a worthwhile career.

$\mathrm{R}: * * *$ Are there other more long-term goals you have for going to school?

S: To go to college and do what I want with schooling and be good at what I end up doing.

In summary, Sasha described a long life with her chronic pain and a more pessimistic outlook on life. She wanted to make the most impact of her story by giving thick detail about the trips to the emergency room and many physician's offices. Despite the pessimistic outlook, she continued to show some positive outlook on life and that she might overcome her chronic pain at some point in her life. She continued to demonstrate 
significant occupational loss and was at a different point in her uphill climb than Angie was during the interviews.

Participant \#3 Sophia. Sophia described herself as a 17-year-old female from a suburb of a large metropolitan area who was diagnosed with physical deconditioning, chronic headaches, migraines, significant weight loss, abdominal pain, nausea, and history of two concussions. According to Sophia, her chronic abdominal pain started when she received food poisoning from eating Chipotle. She lived with both parents and described having multiple older siblings who live outside of the home.

Meaning of chronic pain. Part of the meaning of chronic pain for Sophia was significant changes in her emotional health. Sophia struggled emotionally with living with chronic pain. She dealt with depression throughout her chronic pain with periods of significant emotional lability and doubt about what she could achieve in her life $(\mathrm{R}=$ Researcher, $\mathrm{S}=$ Sophia).

R: What's the first thing that comes to mind when you think about living with chronic pain?

S: It sucks. It really like messed me up really bad like psychologically. I became, my family has like a history of depression, but I got like severe depression, and I didn't have any help for it because I refused to go on medication. And my life just kind of went downhill, so I last year was just like this big gray area of my life I guess.

She expressed her life as a void, gray area with an unknown future of the quality of her pain or where her future life was heading. Later in her interview, she also identified changes in herself that occurred due to the chronic pain.

S: With chronic pain, you can be very negative, really depressing to be around I guess, unmotivated, not really having like a future, I was really messing up a lot of stuff with school and college applications. So, it kind of looked like I was going nowhere, so I didn't really have anything to look forward to. 
She also described this experience like an ongoing treadmill that she was not able to get off in order to make productive changes to her life. The pain became her life replacing all other productive occupations that previously were in her life.

Throughout the initial months of her abdominal pain, she visited numerous medical providers to rule out any potential disease or pathology that could be serious to her health. In the next excerpt, she explained her frustration with receiving information about the disease being in her head.

S: When a doctor tells you that it like psychological, it's just like in your head. First of all, you like think you're crazy, and you're really not crazy, but when you think you're crazy, it will drive you to go crazy. But when nobody knows what it is and nobody can treat you, then you think that it's never going to go away and it's going to be like this for the rest of your life, and then you don't even want to be alive anymore.

R: Yeah.

R: Anything different that the physicians could have done?

S: I don't know, like the way that the GI specialist put it was just like I don't think he said it in the right way. He basically just said that there is nothing wrong with you, you're fine but it's in your head, that you're making up this pain.

Sophia was also good at being descriptive in her explanations about the missing diagnosis and how the fear towards the unknown existed. In the following, she was commenting on her drawing she made about her chronic pain.

S: Like the battles with scary monsters was kind of like, just like fear not knowing what's going to happen or really what's going on because no one really told me what was wrong with me. It made me really weak, like I felt really weak, I felt like I couldn't do anything. And I had nothing really big cause that's kind of what I felt like, I kind of felt like worthless, that was like nothing. I don't have what it takes to be great; I just didn't really think I was strong enough for that.

Impact of chronic pain. Prior to her chronic pain, Sophia was an avid Irish

dancer. Her facial expressions lightened, and she began to smile when discussing her 
past occupational engagement in this style of dance. She described her experiences

growing up dancing in the following interview excerpt.

S: So when I was 4, I saw Irish dancing on TV, and I was like Papa I want to do that. And he was like if you want to do this I'll pay for your lessons but you have to really want to do this. I said I want to do this, and I'm only 4 years old, but I really wanted to do it. So it's a lot of work, I was a little slower learning than the other kids, so I would have to be pulled aside to go over the steps over and over again just to learn them instead of knowing it and perfecting it. So I spent years trying to be a better dancer, and then I finally started to win competitions. I would get first place and that would make me feel really good, I'd get a trophy or these little plaque things, and I spent a lot of time like working at it because I really wanted to be good at it because it's what I loved to do.

R: Did you see Irish dancing as also a social avenue for you?

S: Yes, I in grade school I didn't have a lot of friends, I was kind of like bullied in grade school, but the girls I met at dance became my best friends. There is these two twins that I became friends with and then our friend S . . I still am in contact with my friend ***. She's in college now, but when she comes home, we'll still go out to lunch. As we've like grown over the years, we're very different people, but we still kind of have that connection from dance and from all that time that we spent like doing the same thing that I don't know, but we will always get along, and we will always be friends. So I'm glad for that.

R: How has the chronic pain changed, obviously your involvement in those occupations that you mentioned?

S: I had to stop dancing completely so that was really annoying and it sucked.

R: When did you realize that you would have to stop?

S: I started like to slow down, and like not because I fractured, broken, sprained my ankle I've done everything to it. I've been on crutches like 6 different times. I was on crutches for a whole summer for like 3 months, so after all the injuries I knew that I had to do something, so I kind of took a break. But then I wanted to go back, but then I got the stomach pain and that made it hard for me to do any exercise let alone something that needs very much endurance and strength, and I just didn't have that.

At home, Sophia also demonstrated significant loss in independence in

completing her daily occupations. She was not able to complete daily chores or

household activities due to the degree of pain she was having. 
R: What about at home? How did the chronic pain affect participation at home involvement with your family?

S: I didn't do anything. I didn't do chores or anything that my parents ask me to. They would really try to push me to go to school, and I couldn't go to school, so that kind of like made them mad because they also didn't know, like they thought that I might be like milking it I guess.

Sophia also explained that her entire family stopped family co-occupations, such as preparing dinner and eating dinner together.

S: *** and the other thing is we used to have family dinners like a couple of nights a week, and I didn't really like my stomach was sensitive to certain types of food, so if they made something I'd want to eat it, or I'd just be too tired and lay in my room while they're eating dinner. So I missed out on a lot of that, and then we just kind of stopped making dinner together like at all. So we don't do that anymore.

Sophia demonstrated significant grieving over the loss of her occupational

performance in leisure and work. She continued to have the drive to return, however, did not demonstrate the skills necessary to overcome the pain and return to those

occupations. She described the uphill climb out of the depression and significant decline since the onset of the chronic pain.

R: How do those challenges shape your life? (Referring to the depression and poor occupational engagement).

S: Then they kind of really brought me down, but now I kind of see it as like a drive to do better. That now if I mess up like with this school situation that now I'm not getting into that college that I wanted to go to and I know I would have gotten into that college if all of this didn't happen. So that kind of gives me more motivation to do everything that I can also, like not losing all my friends and not having anyone to talk too except for my boyfriend. So now that kind of like it made me realize a lot of bad things about our relationship that I didn't notice before, and now I have a chance to reconnect with old friends that I had, which I'm really excited about because now I get to hang out with them this weekend.

She also describes an improved relationship with her father prior to the onset of her chronic pain. With more education about his daughter's chronic pain, the father 
developed a better understanding of the events she was going through and how he could support her better.

R: Tell me about any positive opportunities that you had experienced while living with chronic pain.

S: Since I had the assessment here from chronic pain that really was like the beginning of the new relationship with my dad. Because even like when I had the board of everybody saying that if we suggest a program that will work for you or whatever my dad was like I just thought she was crazy. I just thought she didn't want to go to school, but he learned a lot about what chronic pain is and learned that other people have this.

Sophia prided herself on her academic achievements she accomplished prior to the chronic pain. However, due to missing a great deal of schooling, her grades fell, and she questioned her ability to be admitted into some of the prestigious schools she desired. She described her scenario as a glimpse of hope that she survived her chronic pain and had the potential to be admitted into her top-choice university.

S: *** So now I'm in the situation that I'm in, I wasn't accepted to Marquette, but I wasn't rejected, I not sure if they do rejections. I'm on the waiting list, so I'm doing everything I can to like show them that I really want it and that I know I can do it, but I just kind of have to keep trying harder and hope for the best I guess.

Lastly, Sophia superbly described the path she had been on, and the path that she hoped to continue her life on towards success. She so eloquently stated that the only limits she had in her life were the ones that she placed on herself. She saw the pain she lived with on a daily basis was the only barrier that she could overcome and needed to push past in order to achieve all her lifetime goals.

S: Let's see I've definitely changed my perspective

$\mathrm{R}$ : Which ones stick out the most?

S: Your dream is your story, make it legendary, and I thought to myself, remember this because I know that if I ever start to have bad thoughts again, or if I ever start to go down the wrong path, then I can just look back to what I've 
learned here and hopefully I won't make any more bad decisions like that or let it get to me as much like my pain and everything. And the only limits we have in life are those we set ourselves. So that obviously meant a lot to me, because I did put a lot of limitations on myself when I shouldn't have because that just made me feel like I couldn't do it, when really I don't know if I could have done it because I never tried.

Sophia has had periods in her life in which she was unsure of her future and how the chronic pain would affect her life. She also discussed how the uncertainty of no organic cause to her abdominal pain caused her a great deal of grief and discouragement in continuing her life. She even discussed the emotional trauma that ensued with providers telling her that it was all in her head. Dancing was one of her most rewarding occupations that she lost when facing chronic pain. The occupation gave her identity and formed her social network, which was lost due to the daily chronic pain she suffered from. Lastly, Sophia pushed past the emotional depression and suffering from the chronic pain and gradually turned her life around in order to regain her life and to accomplish all the goals she originally had set for herself.

Participant \#4 Emma. Emma described herself as a 16-year-old with tethered cord syndrome, physical deconditioning, chronic back pain, and chronic leg pain. She also underwent three surgeries in attempt to fix the tethered cord; however, she was unsuccessful, resulting in long-term leg and back pain.

Meaning of chronic pain. Emma had a long history of multiple surgeries to remove tissue around her spine due to slow progression of lower extremity weakness and pain. She took it upon herself to stop surgeries after the fourth one was complete due to complications without results. At first, she struggled to accept the condition of her body and to develop an identity and meaning in life with this chronic pain condition. She also struggled with seeing a future for herself $(\mathrm{R}=$ Researcher, $\mathrm{E}=\mathrm{Emma})$. 
R: What were you thinking as these, well first when you were diagnosed kind of, what was going through your mind and then as you proceeded through these surgeries?

E: I didn't really think light of it at first, I don't think I really came to terms like that it was actually really happening. Just kind of you know didn't, I don't think I could really accept it at first like I was just going through the emotions of what I was supposed to do. It really didn't like click with me until I got like my leg issues stuff like that and then it kind of hit me. It just kind of like put me into a sad kind of life for a couple of years because it took me a long time to accept it.

She also had to face the fact that her tethered cord was not going to get better after the surgeons had tried and failed at four consecutive surgeries. She discussed the reality of the surgeries and the potential ramifications additional surgeries would have afforded.

E: The first surgery was just to take the tethered cord off of basically my muscledura; just to release it so the nerves kind of had more relaxation in the spinal cord could vibrate a little better. And they did that 3 times, it didn't work, it got worse and the $4^{\text {th }}$ time they tried removing part of the lipoma, and if they had taken anymore, they said I would have lost my feeling in my legs and stuff like that.

Later in the interview, she described the state of mind she was in following the last surgery. She described a lonely and dark place in which she felt alone and unsupported.

E: It's just kind of sad, just not a happy place. Like you wake up every day, and you don't want to move, and you go through the motions, and it just gets worse throughout the day. And then you can't fall asleep because you just had so much pain throughout the night that you're just kind of in a different your own little world where it's just kind of sad. You eventually you just kind of have to try and work through that.

Lastly, she described a positive change to her personality that came about when coping with the pain.

R: What characteristics best describe you as a person living with chronic pain?

E: I don't know. I'm a lot more passive I know I'm sort of sometimes. I'm a lot more passive than I use to be pretty aggressive and like not the very nice person. Chronic pain has made me passive and more like trying to think out of the box, I guess. I don't know how to, what characteristics would describe chronic pain. 
It's just kind of like a lifestyle, it's a different kind of lifestyle than the average person.

Another meaning Emma attributed to living life with chronic pain was disbelief

from others about her chronic pain. Despite undergoing numerous surgeries and neurological symptoms in her legs, Emma struggled with individuals not believing her symptoms and absences from school. She attributed that struggle with a lack of education provided to teachers and schools about the issue of chronic pain. She also attributed the lack of concern by the teachers to their busy schedules and lack of time to tutor or give extra consideration for her education.

R: How do you think the school reacted?

E: School wasn't very kind about it. They don't understand that sometimes you have meds that knock you out a little bit, that you can't focus, and when you can't focus because of your pain, they don't really care. Sometimes they wouldn't even let you use a wheelchair if you needed too. You have to get like special permission. They're not very kind, they just don't really care, and teachers don't understand they just. They're like they're like I'm going to give you an exam anyway even though you were out for a week or you were in the hospital. They're not very considerate of it

Emma struggled with peers and teachers not understanding the reason for her inconsistent engagement in school activities, missing days due to pain and medical appointments. At one point in her life, she gave into the pain and let it identify who she was and which activities she would engage in and which ones she would not.

E: People don't really understand it, 'cause they don't understand that I can go to school some days and not others, they thought I was like faking it, or just doing it cause I didn't feel like going or anything. They don't really get it, so it was hard to click with them and sometimes they would like, it would be like I would feel like I was kind of alone because I didn't know anyone that had chronic pain or had, like there was no one that I could talk to or anything. It was kind of like an alone feeling. 
Impact of chronic pain. Emma described her occupational engagement in leisure activities prior to the start of her symptoms of lower body pain and then described how her mood, affect, and occupational engagement changed following the start of symptoms.

R: With it tell me more about those kind of things you were doing, you said track and field. Tell me more about kind of your normal life prior to all of this happening.

E: I would go to school, I would hang out with friends, like I would go to my best friend's house and play on her swing set, and track and field, I was in shot put, I think it was called shot put, I don't remember, it's been awhile, discus, I was doing the 200, I think, and high jump and I was trying out long jump, I could do all of it, I could do anything I wanted to do. I was really active, like I was doing like, I was kind of like that go out and getter and like nothing would stand in my way I'd just do it.

\section{R: What's changed?}

E: I think I've become more passive and stand in the background because I can't do stuff. And I kind of lost my go out and getter personality, and I can't 'cause I can't go out and do stuff really anymore, 'cause it was just too painful to do stuff, so I just kind of stayed in the background.

Emma later described the affects chronic pain had on completion of everyday

tasks that she enjoyed.

E: It makes everything harder. You can't like, somebody could like get onto the floor and not even think about it, and you have to be like, how am I going to get on the floor and not make everything worse. And it's also like going to school and trying to learn and you can't focus and people just think that you're flunking just because you're dumb, but really you're trying. And at a young age, it also sets you away from your friends 'cause everyone, they don't understand, so I guess it's different, you're kind of away from everything, and you have to try and figure out how to make it work.

Emma also discussed how her sleep has been affected, which directly affected her ability to engage in her daily occupations. She described having a limited amount of energy per day and needing to spend it wisely in order to make it through her day. That limitation might have interfered with her ability to complete leisure or school-related occupations. 
E: Like you only have a certain amount of energy throughout your day. Most people they got like 8 hours sleep, they can do whatever they want, they could change plans if they wanted too. But you kind of have to think about how far I'm going to make it through the day? How far, am I going to be able to stand there that long, or am I going to be able to do this. It's like more of you have to figure out what you do with your limits, whereas the average person can go just run a mile, you kind of have to set your own limits you have to think things out a little more. It's a little different.

Lastly, she described the occupations that gave her the most reward, however she was unable to complete at that point in her life.

R: What activities or occupations help give you identity or meaning in your life?

E: Soccer, you knew I was going to say that one.

R: Soccer, yeah.

E: Running, I want to do it but can't yet, painting, drawing. I have dogs, playing with them, and my family, trying to go out, like going to movies most of that stuff I can't really do.

Part of the process of living life with chronic pain was a slow, gradual

improvement in her occupational performance. Emma described a long road to recovery from her multiple surgeries, with mixed emotions about her treatment she received. She saw her only hope was to take matters into her own hands and to look towards recovery and living life the best she can.

E: I think there is one experience, after my $3^{\text {rd }}$ surgery, I had a follow-up, and I wasn't telling anyone I was in pain or anything or had issues, and my doctor had not been telling me the full truth. And he finally told me that if I hadn't gotten my surgeries, I would have had paralysis, and it would have most likely lead to paralysis, and that just kind of hit me because previously, he had told me I only had an $80 \%$ chance of keeping my legs and in surgery, so I feel like that was a moment where I had felt like I had to like control my pain, only me. It needed to be all on me try to figure out how to get around without surgery or without any doctors. That's when I lost faith in doctors.

Further, she described the transition from seeking medical treatment to an introspective outlook on her treatment. She described this transition as becoming a survivor of her 
chronic pain in which she needed to look beyond what happened in the past and live a life that she wanted to live.

E: I think so. It's not as hard. When I first got the diagnosis I was not understanding it and a couple of years I just didn't, couldn't accept it. I was just not a happy person and then like the last year I've had I came to acceptance and here has really helped. Trying fully like understand how to deal with chronic pain.

Emma described a different presentation about how her chronic pain started from the first four participants, however, had similar parallels in her ability to identify herself with the chronic pain. She also had difficulties with school and friends not understanding her chronic pain and how it has affected her life. She was very active in sports and activities prior to the chronic pain, however, saw a significant decline in occupational engagement across all domains. She also described her journey gradually back to a more productive and engaging lifestyle as a teenager.

Participant \#5 Mia. Mia described herself as a 13-year-old with chronic abdominal pain and deconditioning secondary to flu and prolonged headache. She received a special treatment for her headache that caused prolonged nausea and vomiting. Following the treatment, her headaches subsided, but she had recurring abdominal pain.

Meaning of chronic pain. Mia discussed her life with chronic pain and how it came with challenges of her unknown future. She discussed her concerns about whether the chronic pain will continue throughout her whole life and decrease or increase in severity. She came to identify herself as a person with chronic pain $(\mathrm{R}=$ researcher, $M=$ Mia).

R: What characteristics best describe you as a person living with chronic pain?

M: Living with chronic pain before I came here, I was sad, alone, and honestly, scared of what was going to happen to my life, you know. It's just like scared am 
I always going to live with this? And I understood that, even if I do get better this is still going to be an issue you know. This point of my life will still always be an issue even when I'm 21, I might feel better but I'll always have the chronic pain that has the chance of still coming back.

Mia made a few comments throughout her interview regarding her chronic pain as an invisible disease and that people do not understand the sort of pain she is going through and do not believe her symptoms. The following comment described her frustration with people not understanding her chronic pain and how that affected her interaction with peers at school. Mia stated, "Agonizing, you don't get much communication; you're in a lot of pain. You want to talk to people but you just can't." Mia also expressed her frustration about peoples' perception of her; if they cannot see anything wrong, they do not believe her.

M: Yeah. People don't understand. They don't, they never will because they don't have it, and they don't really, a lot of people don't have sympathy, like they'll have sympathy if you have a broken leg, I'm sorry you know. But if they can't see it, it's not real. And so people don't understand that this is still an issue no matter what. You know, even if they don't believe it it's an issue to the person that actually has chronic pain. And like if someone had headaches and couldn't focus on reading, a lot of teachers don't understand that. Like you have this and that this is an issue like you have to get back to doing this. You have to go back to school, you have to do this, but if you lived with like a year with chronic pain, you'd realize that you just can't go back to your normal life without slowly working your way back to it. And that's pretty much what the program was just slowly working your way back to normal life.

Lastly, Mia described an experience with her teachers when they did not believe she was sick and could not do the work. She discussed the situation in which the teachers treated her in the same manner as students who fake being sick to avoid being present.

M: I tried to do makeup work, and I'd get nauseous and throw up you know. It wasn't just going to school and walking around, it was school in general. Like it gave me a headache, and it made me nauseous, and I just couldn't do it. But then when you say I can't do this to the teacher, they're like, they don't understand, because they wouldn't like, because there's like a lot of people that fake being sick, you know. 
Impact of chronic pain. Mia described occupations that she used to engage in and that brought her identity and pride through participation. She stopped completing these occupations due to the chronic pain, causing her distress and inability to fulfill her desires to please herself and others while engaging in each of them.

R: Which activities or occupations help to give you an identity or meaning in your life?

M.: Pretty much my music because my mom really, really loves music, and I feel special that I can play music like on the piano and the harp, and I think it just makes me different than every person that's either an athlete or artist. Music is something that I really, really like, and you know I'd like, I was never ever able to do it because the focus would make me nauseous, and I really miss it, too. Because I wrote music before this, I was, you know, happy with what I was doing, I played piano like at recitals, and I loved it. I loved the harp you know, I'd, it made me special and then everything just came to a halt, and I couldn't do what made me feel special. And so I didn't feel special anymore. I just felt like a normal ordinary medial test rat pretty much after that because I didn't have any difference in my life than the only importance in my life I had was just going to doctor appointments and laying in bed, and it was worse. It wasn't what I really wanted to do. No one wants to spend their life going to doctor appointments and laying in bed. And you always, you want to do stuff that you want to do, you know, you want to do what makes you happy, and you want to do what makes other people happy too. You want to see your friends; you know, I was always good at piano and harp. I always did those and my Girl Scouts that made me social, that made me happy that I could see all these people doing the same stuff as me. And being happy to do it, and you know, and then everything just stopped, and you just wish you had importance, you wish you could see other people, you wish you could like do, I was a happy person and then everything just stopped and you just become like is this my life now?

Mia later discussed her family's co-occupation with pain and its effects on all their

emotions. Chronic pain became a central component of each member of her family and determined how they were going to live day-by-day.

M: They've all been worried about me, and I've said they have their own lives, and they need to be worried about their life, they don't need to be worried about me. And you know, I was scared for them for a while because they were so worried about me, they weren't focusing on their life. And their lives matter you know. 
Mia reflected on the year that she demonstrated significant poor occupational engagement and her feelings on people's misperceptions about chronic pain.

M: It's hard to think about your life before chronic pain and after when you, once I get back into my normal life, I will look back on these, you know this entire year and be like that was my life then and that was an entire year wasted that I could have been doing stuff if I didn't have chronic pain. And you just want to talk to people but you; it's hard because you, a lot of people don't understand that chronic pain is an issue. A lot of people want to go like to the mall or something, and you just can't walk that far and you just can't do it. You always feel bad when you have to tell people no, that you just can't do that. It's hard because people don't understand how hard chronic pain is and a lot of people go on the, I don't know what, well if they can't see it, it's not real.

Lastly, she described the loss of playing music and the inability to use it as a form of coping. As discussed earlier, music was an important occupation in her life and was a great loss to her during the tough periods of her chronic pain.

M: When I could play music, it was a distraction, and when I couldn't, I couldn't use music as a distraction into my pain anymore. It was something that I leaned on, and then I just couldn't anymore. Now I'm going to try to go back and be in classes again. I'm going to start writing music again 'cause I think I will have enough focus to do that.

Part of the impact chronic pain had on Mia was her ability to look introspectively on the activities she needed to do to regain her life over time. She also alluded to the fact that part of the recovery process was to stop listening to her body pain and to push through it. She had two weeks in the inpatient rehabilitation program prior to this interview.

M: Even though the chronic pain will still be a thing, I now know that I have these coping techniques to use these, and I know that if I just keep on a normal functioning schedule and don't listen to what my stomach needs, then I will be fine it will go away, you know.

Earlier in the conversation, Mia discussed the kind of life she wanted to return to and demonstrated a glimmer of hope for returning to her prior occupations. 
R: So, describe more about what kind of life you want to go back into.

A: The kind of life I want to go back into was pretty much my schedule before everything went downhill. I mean I would wake up, I would go to school, I would spend times with my friends. I'd go to class, I've always really loved learning, so you know, just get in a consistent schedule. Like I want to go back to piano classes, I want to go back into harp classes. I want to go back into Girl Scouts, because I was never able to focus enough and do you know, I've never had the motivation my stomach just wanted to rest. My life pretty much ran on my stomach pain and what it needed and it wanted.

Lastly, she described a prior occupation that she was able to accomplish. She was able to celebrate the accomplishment with her mother, recognizing her progress on her uphill climb to regaining her life back.

A: And I just continued to keep an open mind to this because I thought that if I tried and keep trying, I could just you know, maybe this could work. And then I was able to walk like two miles, and like I would have passed out before that and I thought that was really special and my mom was very happy.

Mia lived with abdominal pain and significant decline in her occupational performance across all domains in her life. At times, she expressed that her life had an unknown future due to not being able to look past the chronic pain. She also became depressed and did not want to leave her house. Her abdominal pain was seen by peers and teachers as a way for her to avoid school and an excuse to skip class. This situation brought increased anxiety about re-entering school when she felt well enough to do so. She expressed throughout her interview that most people do not understand her and her pain condition so that only those with similar chronic pain conditions may understand. She demonstrated significant occupational decline from all domains of her life, including school, leisure, and self-management. Pain became Mia and her family's main occupation, spending a great deal of time at doctor's appointments and scheduling the 
family's life around Mia's illness. Mia expressed hope and desire to return to her normal life prior to the chronic pain and had developed skills necessary to complete that task.

Participant Six: Lily. Lily described herself as a 17-year-old female who had a long history of chronic pain, starting at age 8 when she lived through and overcame chronic regional pain syndrome (CRPS) in her leg. She was able to return to prior occupations without pain after months of rehabilitation and psychological assistance. At age 15 , she started having chronic daily headaches and migraines with no evident cause. Subsequently, she then suffered from three concussions while playing soccer with one episode of loss of consciousness.

Meaning of chronic pain. Lily described the meaning of chronic pain in her life as depressing and very difficult. She did not find joy or happiness in life, rather isolation and inability to engage in activities she enjoyed $(\mathrm{R}=$ researcher, $\mathrm{L}=\mathrm{Lily})$.

L: I was upbeat. I wasn't depressed. I don't know, I liked to have fun. I wasn't really down that much. I didn't get sick very often. Not like that probably even matters but I like to joke around a lot even sometimes when I'm supposed to be serious. Active.

R: Can you further describe, what was it like, living life with chronic pain?

L: You're not happy; you don't enjoy things as much. You, I don't know, like things that you used to love, you really don't care about any more. Not necessarily family, but like either sports or certain activities, you don't like to do them anymore. You don't really have a positive outlook on life, you like think really negative thoughts, it's like I'm never going to be able to do what I want to do in the future, or I'm always going to have pain, or like why me or crud like that, and you think that no one can help you 'cause you've been to so many doctors. You don't really like yourself either 'cause it's almost like you're giving yourself the pain.

Lily tirelessly went from physician to physician, hoping for a cure for her chronic headaches, however, never found the cure. She described the hopelessness around this experience along with her life with an unknown future with continued chronic headaches. 
L: Yeah. Because after going to each doctor after a while they just can't do anything for you so you just feel like no one can help you.

R: Ok. Did you feel like you can't help yourself?

L: Yeah, kind of. I feel like I know things that make it worse and something that make it better, but besides that I couldn't really do anything.

Lastly, Lily described her experience with chronic pain and self-identified that chronic

pain had taken over all aspects of her life.

L: I mean not to be a Debbie Downer, there's not any positive things about having chronic pain. Not that I can think of right now. 'Cause it pretty much takes over your whole life.

Impact of chronic pain. Lily described her frustration with current medical providers and described her lack of desire to pursue further assistance from them. She felt a lack of hope that medical intervention would help or cure her headaches. The chronic pain changed her way of thinking about Western medicine and how it may or may not assist her.

L: Well I don't like most doctors. Just 'cause for the first part of it, most of them said, oh I can fix your headaches. We'll do this, and either it didn't do anything, which you know was kind of what I was thinking at first. But my mom always tells me to be hopeful, so I still was. Then we'd go to a different doctor, and he would make it worse, with either saying to get Botox, and I did and that made it really worse. Or they'd say like this will work and you know if doesn't at first, just wait a few weeks, and it will kick in for medicine or something. After a while you keep going to doctor after doctor even if they don't say you know, we can fix you, like this will work, it might not work for you but it works for other people. And then you just get sick of going to doctors and you don't want to go to them anymore.

For Lily, participation in sports was an important occupation that she lost due to the chronic pain. Many of her co-athletes knew her dedication to the sport, however, doubted her intentions when she started missing soccer practices. Some classmates also doubted her intentions on missing school or leaving early. 
L: When I first had them, some people thought I wasn't actually having headaches. They just thought I didn't want to do soccer or didn't want to do school. Which is kind of dumb cause who doesn't want to do their favorite sport? I mean I can be lazy but not that lazy. That's just bad. I mean a few of them were supportive, I mean a lot of them were supportive then after a while they started, not to drift away, but they didn't ask as much, and they didn't say anything really. And then like this past year I was gone for two months straight? And only one person had texted me from school asking how I was doing? She actually is a girl who had a concussion and was out for like three months with it so she understood what the headaches were like. But even my best friend didn't ask me really anything. Which was kind of odd but I mean, I'd rather have like three close friends than like 10 who aren't so I didn't expect people to text me, even if they did I really didn't care that much. As bad as that is.

Lily described her degree of occupational engagement in active leisure both before and during life with chronic pain along with the degree of absenteeism from school in the following excerpt.

L: I used to be involved in lots of sports, like 3 sports a year. Including golf plus travel skiing and travel soccer, but I haven't skied in two years and I haven't played golf in like three for school.

$\mathrm{R}: \mathrm{Ok}$,

L: I missed a lot of school. Had to make up homework over last summer and I only had like two legit weeks of summer. 'Cause the rest of it I was doing homework. So that was fun.

Lily later described the degree of disability she experienced from the chronic pain and its effects on her occupational performance across all domains, including school, work, social, and leisure.

L: I stopped being active, and I was in my bed a lot and I didn't, I stopped hanging out with friends. I more just stuck with family and then I started to not hang out with family. I just stuck in my room. And I couldn't go to school. And I couldn't hang out with friends because of my head pain and because I couldn't manage it and I didn't really do anything I wanted to. Kind of sucked. It didn't kind of, it sucked.

She discussed how her chronic pain affected her family's occupational engagement and how the family's participation evolved around her current condition. 
L: It was a lot harder for my family because we had to, if we were going to go somewhere, we had to make sure it was ok for me. We had to make sure this won't hurt your head, or if it does we have to make sure we have a place where you can go if it makes it better. Or I'd miss a lot of my college sister's band concerts and like going to those really shows support for her and she got like sad about those. I had to leave my sister's birthday dinner cause I felt so crappy. I didn't go to one of my sister's birthday dinners cause I felt so crappy. My family is constantly worried about me. You're a lot more crabby. I mean I know I can be kind of crabby in general but you get a lot more crabby. You're not really focused on the positive anymore. There really is no positive, it's just all negative. If someone tries to cheer you up, like why do you do that cause you're not helping. Or those (pause) ... no point.

Lastly, Lily described the loss in independence of completing tasks, such as her instrumental activities of daily living (IADLs), such as walking the dog. She had that responsibility prior to the onset of the chronic pain, and it soon became the mother's responsibility once Lily was not able to complete the task due to pain.

$\mathrm{R}$ : Do you have any responsibilities for that dog?

L: Yeah, I usually have to walk her every day.

R: Ok. Were you continuing that?

L: Nope.

$\mathrm{R}$ : Who did that then?

L: Mom.

$\mathrm{R}$ : Is she happy to give that back to you?

L: Yeah. More than welcome.

$\mathrm{R}$ : Are you ready for that?

L: Yeah.

Lily had to overcome pain twice in her life with the earliest episode when she was 8 years old and the newest episode when she was 17. She had experienced an uphill battle from the first episode, however, continued to struggle with the accompanying 
depression and feelings of helplessness to overcome the chronic headaches and return to a functional lifestyle. In the next excerpt from the interview, she described an earlier form of coping that helped her be a survivor of her chronic pain and make that gradual climb out of disability.

L: I mean I like going out for dinner or food. Sometimes, if I would miss a day of school, I'd had a rough week, and I hadn't gone to school much, my mom would tell my boyfriend or tell my friends to get me out of the house. Which makes sense, cause you shouldn't be at home for that long anyway. I mean that helped not necessarily being active but maybe just talking with people. Like if people were to come over and make cookies or something like that. Like that would be ok. I mean that helps cause I'm more distracted rather than focusing on it. Restaurants are just good in general. I like, it's a good distraction.

At some point in her uphill climb, she returned to soccer, despite poor school attendance. She was able to engage in a form of meaningful leisure occupation that improved her self-esteem and outlook on life. She described her forward thinking once completed with the program, showing hope for a return to prior occupations.

L: I mean I played soccer this past fall, but I wasn't able to do skiing because I was so far behind in homework from my pain. I mean once I go back I will be going back to stuff. While pacing myself. I don't know.

Lily not only had to overcome one, but two different forms of chronic pain at different stages in her life. The first period was when she was a younger child, needing to utilize different skills to return to prior occupations. Despite having this prior knowledge, the second episode caused a downward spiral of events, including mood and personality changes in her, an uncertainty of where her life was heading, a significant loss in occupational engagement across all domains, and a long and gradual uphill climb back to a functional daily life. At the time of interview, she was still on the path towards a healthier and more productive lifestyle, being able to push through the pain and knowing that she truly had survived two different forms of chronic pain. 
Participant \#7 Emily. Emily described herself as a 17-year-old female who lived with chronic regional pain syndrome (CRPS) in her left leg following surgery to her knee. She received numerous medication treatments including Ketamine drip leading to a comatose-like state and nerve blocks. Her recent nerve block prior to the interview produced great results with limited pain to her leg.

Meaning of chronic pain. Emily struggled for a while on what the pain meant to her and her life. She described in very simple terms how she identified living with chronic pain along with the degree of pain intensity $(\mathrm{R}=$ researcher, $\mathrm{E}=$ Emily).

R: Ok. So what's the first thing that comes to mind when you think about living with chronic pain?

E: It sucks!

R: You want to elaborate some more?

E: Well for me, it never went away, it was a solid 7, like 24/7, so sometimes it would get up to a 10 , like maybe like every other two days but that would still happen, and that's when I took the oxycodone, but then once I was on gabapentin, I can't take anything else with it. So I had to just tough it out, and I like using putty things, I like to squeeze things I don't know that's just me but I have these putties that I squeeze when I'm in a lot of pain. That seems to help me 'cause I don't feel like the whole breathing think works on me.

Emily also described her feelings of despair and not wanting to engage in any of

her occupations due to her emotional state. She went into detail comparing her emotional state with an adolescent who has Asperger's syndrome due to the monotone voice.

R: Any other experiences that kind of help describe what it is, like living day by day with pain?

E: You get into, like at the very beginning and in the middle I had this really dark period where I just didn't want to talk to anybody, just like get out of my room, I don't want you in here. And like I ate I just lived in my room.

R: Ok. 
E: That was my house, my bed and my room; I didn't want to go anywhere. And there would be sometimes that I read on line that sometimes when you get into a really bad emotional state, you can present with CPRS, so you can present with symptoms of Asperger's, so like that really robotic monotone, talk like not very emotional, and I had that a few times. And even my counselor said it was right, so I guess the Internet was right. But it's hard keeping up that's what I would say the main thing, it's really hard to keep up with friends, with school, and with stress, you just have to make sure that you just try to keep up as much as you can. Because if you don't, you are going to get way behind and that creates more stress which makes the pain go up. So that's the main goal to make the pain go down.

Lastly, Emma described the dark state that she was in during the most challenging stages of her chronic pain. She described it as a transition all people with chronic pain must venture through at varying speeds dependent upon acceptance of the chronic pain.

R: Ok. What feelings or thoughts stand out about, let me start that again. What feelings or thoughts stand out to you in describing living with chronic pain?

E: That dark state.

R: Ok.

E: 'Cause I mean you can't avoid it, it's just gonna happen at some point. It's gonna happen unless you're the world's strongest person on the inside. I mean it happens at some point and you just have to find your way out of that. I guess just emotions would be a good word to describe it. Because you're happy at sometimes and then like somebody can say something and you'd be mad, you'd just be mad at them the next second. And my mom would be like, whoa, that's a quick change, like I'd be happy and laughing and then she'd say something and I'd be like death stare and I just, you have to try and be happy or else the pain goes up. 'Cause when you're mad, obviously, you're stressed because somebody's making you mad, which makes the pain go up. And I was mad a lot. Probably more than I should have been. But, I was probably in that dark state longer than most kids cause it took me a while to accept it. But that's my advice to anyone else get through the dark state and then I think you'll go on from there and move on from there. You'll go on from there.

As mentioned previously, Emma struggled for a while with her diagnosis of

CRPS because she believed there was something structurally wrong with her knee that was causing the pain and discoloration. To Emma, chronic pain meant "uncertainty" in the diagnosis of her CRPS due to the way it is determined; CRPS is determined through 
ruling out all other diagnosis and determine through clinical signs of the disorder. Not having a specific test or scan to diagnose CRPS was scary and unfulfilling to Emma.

E: Cause I still wanted to see if anything was in there. Cause I really did accept it late, later than most kids.

R: Ok.

E: It wasn't something like a real injury that it was like all not in my head in my nervous system.

R: What would you say then that helped you get to the point where you accepted it?

E: Probably knowing that there wasn't anything wrong in the MRI.

R: Ok.

E: Like why does this hurt? There's nothing wrong with my knee, like why does it hurt so bad? Cause I felt that kind of pain before when my knee dislocates, but hopefully that won't ever happen again thanks to my surgery but just that, the MRI told me there was nothing in there. So I mean what else could it have been? There was literally nothing in there that could have done this to me. So this was my last resort, like it had to be this cause there's nothing in there.

R: Ok. So once you obviously got the results.

E: I was literally praying that there would be something in there.

$\mathrm{R}$ : And there wasn't.

E: No there wasn't.

Impact of chronic pain. Emma enjoyed school and was a good student. Her

focus became more and more difficult due to the pain, which caused additional stress and anxiety. She described the cycle as Stress $\rightarrow$ increased pain $\rightarrow$ increased anxiety $\rightarrow$ increased school stress and how it made it more difficult to maintain occupational performance in school.

E: But school is kind of hard to concentrate because if I fell behind or if I didn't understand something I would get really nervous and stress that I have to stay after school or something, and then that would make my knee hurt, and then I'd 
have to go to the nurse, and then I'd miss more stuff, and I still cycle of stress, pain anxiety school stress and yeah.

R: Ok. You mentioned kind of the stress pain cycle, did you realize before you kind of had the chronic pain that there was significant stress at school? Or did this happen more after you had ... (participant answered prior to completion of question).

E: It was more after because I'm pretty good with school. I keep up with my homework and everything, and I still have A's and B's now. I just was a little bit behind buy I don't have the grades that I wanted. Like I have A's and B's, but I wanted all A's. So I'm good at school I keep up following behind just makes me nervous and anxious that I'm not going to get my A's. That's just who I am, I just like to get A's 'cause I want to go to a good school.

Emma also described an opportunity to socialize and interact with her friends.

She verbalized her frustration with not being able to perform all the same tasks that her friends were completing and instead had to stay downstairs with the baby (best friend's baby step-brother). She lost her independence to go up and down the stairs and participate in a video dance game, which was identified as one of her favorite leisure occupations.

R: What's it like living day to day with it?

E: Well, friends was my main issue, I wasn't going to school a lot and my friends, I mean, I have awesome friends, my best friend $\mathrm{K}$. . . is great, she is so supportive and but I'm not the kind of person who likes to tell people about my pain and like wear my heart on my sleeve. I don't want to burden people with that and, so I keep it to myself, I mean she knows what I have, but I just don't tell her like how bad it was. But I went to her home a few times during it, but she has a really hard house to get around, like there's nails and stuff, they're doing construction and she lives on a hill, they got chickens, and they have a lot of stairs. So, she invited more people over this was just one time, I remember it was so hard for me to deal with everything, I just had to like go sit down for awhile. Well all the kids they wanted to go see their alpacas, so I stayed inside with K . . step brother, and he's a baby, but I stayed inside with him, it was really hard 'cause they were like out there having fun, and I was just sitting there in pain with a baby, and like they went upstairs, and I like only wanted to do stairs only when I needed to. 'Cause there's only one bathroom in the whole house, and it's upstairs.

R: Ok. 
E: So, I only wanted to go upstairs when I needed to, so I didn't go upstairs with them, and she was like showing them the house, and I couldn't keep up, and then I just had to sit down.

R: Ok.

E: That was a hard one 'cause I just can't keep up with them. I love to dance, I can't play Just Dance, that's my favorite game in the whole world. I normally play it four times a week for like 3 hours, and I'm not good at dancing, but I love it. That says my name.

At one point in the interview, Emma described her dilemma with having friends sleep over. She described herself as a person who kept things from others, not wanting to burden her friends about her pain. She felt that they would not understand her and her pain, and she did not want to bother with explaining to them the details about her daily life. She commented in the following excerpt about a sleepover and the need to escape the party to visit with Mom due to the significant pain.

E: While they are there. I mean, I like to hang out with them and see them, but sometimes it's not a good time. Like if I feel pain coming on I'll just go downstairs, and I'll sit with my mom for awhile, and I'll just tell my friends I'll be right back. If it happens, it's only happened like twice.

R: What happens then?

E: I just stay down there for like an hour while they watch the movie, and then I go back up. Sometimes they're asleep when I go back up.

R: Have they ever said anything?

E: About me staying down there really long?

R: Yeah, asking you what's going on?

E: No not really. I mean they knew what was going on with me. Not like CRPS, but they knew I was in pain, so I guess they just didn't apply that. They really didn't say anything. Not to me, maybe they talked about it while I was downstairs, but they didn't say anything to me. 
Emma described her frustration with the CRPS and the resulting loss of occupational engagement with her swimming. In the next statement, she discussed the frustration with not being about to go to state championship. It could have been one of the paramount moments for her as a high school swimmer to make the cut to proceed to state championship.

E: I missed half of the season, and my coach told me that if I hadn't had this injury, well CRPS that I would have gone to regional's, which means I could have gone to states. I wish he hadn't told me that 'cause that made me so mad just at life and CRPS, that made me so mad.

Lastly, Emma described the co-occupation of the chronic pain by mother. Mom was only able to work when Emma was back in school, which was a limited amount of hours per week. She described the work mom had to complete on a daily basis in order to help her daughter Emma.

E: My mom, she made doctor's appointments, and she did everything. She made my food, took me to school whenever I need to go, she dropped everything if I, I mean she's awesome.

R: Was she working before this happened?

E: Um hum. But she only worked, she worked when I was in school every day like before this happened, she was working every day of the week, like 4 or 5 hours a week.

R: Ok.

E: But after it happened, on half days, she would go in for like an hour.

R: Ok.

E: Maybe. When I wouldn't go at all, I told her she could go if she wanted to, but I didn't really feel comfortable staying in the house by myself with this happening 'cause if I was hungry, I couldn't go downstairs. 'Cause like in the beginning, I was really like wobbly and there was a few times where I almost fell down the stairs and that would have been really bad. And I have fallen a few times, but I know a special way to get up like if no one is there. But yeah my mom was great, 
she did everything, she'd call my doctor, she's the one who organized the whole program she corresponded with $* * *$ and made it all happen.

Emma had a long road to recovery with significant difficulties accepting the diagnosis of CRPS and the treatment necessary to regain occupational engagement. During the interview, she described an interaction she had with her mother and her impression of Emma's strength and ability to overcome the chronic pain and regain life.

R: Ok. Which characteristics best describe you as a person who lives with chronic pain?

E: My mom tells me I'm strong but I'm really not.

R: Why do you say that?

E: I'm weak. You've seen me do pushups.

R: Ok.

E: Maybe strong on the inside but not on the outside.

R: Clarify that a little.

E: I don't know, like I've dealt with it.

R: Ok.

E: As a person, I mean I have those periods were like I'm oh my God, I hate my life, and then there are periods like I'm ok, I'm better than I could be. It just depends, so I guess I'm strong on the inside but not on the outside. I'm pretty focused now that I have my nerve block. And I was like I was determined to get good grades. Even though the pain was there, I had to get good grades. That was my main goal and I still haven't finished, so but I'm going to get a good grade on it.

Emma also described the survivor mentality she needed to accomplish in order to return to a normal life and engage in prior occupations.

E: I mean it's not going to get better unless you do something, so

R: Ok. 
E: I just kind of accepted that 'cause if you don't want to be a mushroom or potato for the rest of my life.

R: Ok.

E: I mean I like my bed, but I don't like my bed that much. Like to the point that I would stay there all day. I mean I like to get out.

Lastly, Emma described her gradual return to her social group at school. Her

friends recognize that she was acting more like her typical self, even enjoying goofing around with others.

E: Like even my friends said that, but the day I got back or the $22^{\text {nd }}$, the day I got my nerve block, I actually went to school, and I sat with my friends at lunch, and there is these rednecks that sit next to us, and they always throw stuff at our table, and I'm always the person who throws back cause no one has the balls to do it. So I'm the one who throws it back, and I threw it back and everyone is like yeah she's back. That was a good feeling. I probably wouldn't have done that if I was on crutches.

Emma made significant changes since she originally received the diagnosis of

CRPS in her leg. She took an extended time period to accept the diagnosis and move on with her life and return to prior occupations. She described a dark pathway that consumed her life and made leaving the house difficult. Emma lost a significant amount of independence both at home and school, not being able to climb stairs, enter the bathtub, or drive without assistance from her mother. Pain consumed both Emma's life and her family's life; her mother became her dependent caregiver when not in school. Emma finally started the uphill climb, following the MRI confirming there was no structural damage to her knee and that CRPS was the correct diagnosis. She described her motivation to improve occupational performance in the areas of swimming and dancing. 
Participant \#8 Sam. Sam described himself as a 16-year-old male with daily chronic headaches post viral infection in addition to migraines, nausea, and dizziness. Prior to the headaches and migraines, he was very active outdoors in the wilderness and in his school. He was a good student and very close with his church. He lived with his mother and father at home. He also described having two brothers, both out of the home.

Meaning of chronic pain. Sam attributed his family's history of chronic pain to the meaning of his own chronic pain. Sam had a family history of headaches and migraines along with neck problems. Pain had become a family identity; however, he felt that he gained support from his family due to their ability to associate their experience with his $(\mathrm{R}=$ researcher, $\mathrm{S}=\mathrm{Sam})$.

S: It just lets me know that I'm not alone that some people know how I feel. R: Some people? Are there specific people?

S: My parents definitely do, my mom has some bad neck problems, and my dad has migraines and so does my brother. And my other brother has been in a lot of pain from wrecks and physical injuries. So my entire family, I was lucky to have them because I can get support from them. And a lot of my friends, too. So far I haven't really had any friends who have just said it's just headaches or I've had migraines, too, they're not that bad.

Sam also described the effects migraines had on his personality and overall emotional state. He initially described himself as an easy-going, loving person that was very social and loved to interact with his friends. The next excerpt described the changes the migraines had on his persona.

S: Sad because who wouldn't be sad with chronic pain. Frustrated, not really angry not really. I was never really angry I don't know why but just not. I am frustrated just not angry. I can be a little bit grumpy when I have bad migraines.

Sam also described how living with chronic pain had also improved his overall maturity and patience. 
R: You said that's changed?

S: No, no, I meant the without what I've been through, I would not be the person that I am now.

R: How has it developed you?

S: More mature I guess. Understanding, not quick to jump at something.

Initially, Sam was very nervous and scared about the uncertainty of why he was

having migraine headaches. The uncertainty of which disease could be causing these headaches was unsettling and made living life very difficult. He described that period of uncertainty in the following excerpt:

S: When it started I was just scared.

R: Ok.

S: 'Cause I didn't know what it was. The only thing I knew was that I was in pain; very bad pain just scares some people or at least normal people. Then when we were starting to figure out I was frustrated and then after because I couldn't really do anything about it. And then after that I was determined for those like January through summer I was determined to get on with my life. And it worked for awhile, but it still came back. Then I just got sad cause I couldn't do things.

Impact of chronic pain. Despite Sam being a good student and getting along with majority of students at school, he had a significant decline in school function. He missed a vast amount of schooling, making it more difficult as time went on to return.

S: And I tried to make it to school any day I could.

R: How often was that?

S: At first, 3 times a week, then 2, then 1, then it was rare for me to be at school. And then January hit, and we decided to switch schools, but I skipped a year. Let's go back to that year. When I got better for the first 6 months, I, well I got better, but not as better as I did in the second summer.

R: Ok. 
S: So I was starting to do better, and I was starting to look fine, and then like really late August or sometimes around fall, I started to get worse again. And actually it started when I was at a different house, living with my cousins because my mom and dad were out of town. And I just started getting worse and worse and worse and worse, and then after December or January, I just decided to go on and try to act like it's not there. So I went to school every day, and in the morning from like 8 to 3 , and just kept doing that until it was very, very hard to do. And I just started to get better and better, and then there was summer, I had to participate in service school, got most of it done, but then I got sick again, and I was already in $10^{\text {th }}$.

In the next excerpt, Sam described the ongoing challenge of engaging in daily occupations when having chronic pain. He described the difficulty to gain the motivation to engage in occupations on a daily basis along with the issue of no regular schedule.

S: It's just the interference.

R: Interference?

S: Of daily life.

R: Ok. Can you tell me more about that?

S: With chronic pain, it's hard to do things. It's hard to get motivation to do things. Everything's like 5 times harder, and you have to take into account your chronic pain, and you have to have a loose schedule because you don't know whether or not you're going to be feeling really sick or really good.

R: Tell me more about the loose schedule.

S: The loose schedule because some days I could not do it. I could not get out of bed, then on other days, I could get out of bed, but I just felt really, really bad, and other days I could like do regular life for that day.

Sam also gave pain a human-like characteristic, bullying him to not move or participate in desired occupations.

R: Tell me more about the frustration with chronic pain? I want to try and understand that a little better.

S: It's frustrating because you can't always do anything about it.

R: Ok. 
S: Sometimes it's just there, and you have to accept that's it's there and move on, and it's hard to move on because you're in pain. The pain makes you want to not move on and just stay still.

He further described the difficulty of engaging in occupations due to the migraines and the accompanying difficulties of tolerating sound and light.

R: What's it like living day to day? I know you talked about your schedule and how it's interfering with daily life, but can you tell me more about living it day to day? When you wake up, when you go to bed throughout your day?

S: Throughout my entire day, I have a continuous headache. But it's not the headaches that bother me, it's the migraines. And I don't know when they'll come. And when migraines come, they get really, really painful, and if there is loud noise or bright lights. It interferes with things like going to church because it's loud in church or at least a loud church, if it's a quite church I have no problem.

R: Ok.

S: But I can't go anywhere with that big base booming noise 'cause it affects my head in a negative way, I cannot be in a dark room and then turn on the lights because it would increase my headache.

R: Ok.

S: I couldn't do too much physical activity 'cause it's too much strain on my body and will affect my headaches. I did physical therapy, I tried pushing through it, and I got through two physical therapies, like continuous physical therapies.

Lastly, Sam described how chronic migraine headaches interfered with his engagement in his active leisure occupations. Part of his identity was tied to completing these occupations, such as Rangers in Training program. He was not able to participate in that program this year due to his chronic pain and inability to maintain the physical requirements of the program.

R: Ok. What about kind of a little bit, this question is similar to what I've asked you before but has the chronic pain changed your involvement in those activities?

S: Yes. 


\section{R: How so?}

S: I can't do them as often as I want to. Some of them I can't even do well, like mountain biking. Because of it, I can only go like a mile or two. I can't do mountain biking, I can't do rock climbing, I can't do a lot of the things I want to do, but some days I can, but those are only like the ones like fishing, swimming, not too much of hiking, I cannot hike, it's too long anyway. There is also, I can do bowling, but not for long, last time I tried bowling was on my birthday, and I scored 165 , but then the rest of the games I only scored 70 and below.

Prior to the onset of migraine headaches, Sam was an active adolescent both within his school and through participation in his leisure occupations. Despite losing significant occupational engagement in schooling, leisure occupations, and work-related activities, he was determined to push through the discomfort of the migraines and return to a normal life. He reported on the characteristics that best described him living with chronic pain.

R: Which characteristics best describe you as a person living with chronic pain?

S: Characteristics with chronic pain?

R: What characteristics best describe you as a person living with chronic pain?

S: Well I wouldn't call myself a recluse because I try to get out as much as I could.

R: Ok.

S: Characteristics? Determined I guess because I really I was determined to at least do some things normal kids my age would do.

Lastly, Sam described his conflicting thoughts on the challenges of pushing through pain while still maintaining a healthy attitude. His last sentence summarized his thoughts on how he survived the chronic pain experience and the process that built his character and his ability to push past the pain to regain his life.

S: Pushing through something that's hard is always is going to, well, not always, I can't say always, but it's usually going to be rewarding, I mean it just is. So like 
when I say character I like to say it would raise up my, it would lower my nervousness and fear of the pain, and it would make my excitement and, I want to say charisma but I'm not sure that's the right one. It would make some of the frustration go away because frustration is one of the worst emotions with chronic pain. You get frustrated a lot. And so is anger. Of course frustration and anger run hand in hand, but I try not to be angry or frustrated because it's just not going to help anyone. It's not going to help me, it's not going to help my family; it's just going to push them away. Sure I might be grumpy when I'm in pain but other than that I won't get like when someone's in pain, they would yell, or someone's in pain, they would throw something at you to try and get you away. 'Cause they're just mad at everything, so I'd like to think it gave me character to get past things like that.

Initially, Sam was unsure about the cause of his headaches, which caused a great deal of conflict in his life. He had both a long road of decline in function along with a long climb back to his normal life, which he continued at the time of the interview. He lost occupational engagement in all areas of his life, including school, work, leisure, and social participation. He described how chronic pain affected his ability to overcome the obstacles in order to engage in daily occupations. Lastly, he discussed his plan for regaining his life and how his experiences enriched his life and developed his maturity.

Participant \#9 Zoe. Zoe described herself as a 15-year-old female living with chronic daily headaches, migraines, and physical deconditioning. She further described her family with divorced parents and multiple siblings. Prior to her chronic headaches, she was active in school, swimming, and reading. She had a significant occupational loss in her daily routine gradually with the onset of her headaches.

Meaning of chronic pain. Zoe's initial meaning of her chronic pain was uncertainty and the idea that the pain might be deadly. Initially, when Zoe attended multiple medical appointments, she did not know the reason for the headaches. Her family was not sure of which practitioners to see in order to rule out any dangerous cause of the headaches $(\mathrm{R}=$ researcher, $\mathrm{Z}=\mathrm{Zoe})$. 
Z: I started out going like into my pediatrician cause usually you don't really know a lot about like who to go to, if you haven't gone through a lot of this especially since none of my family members have not had a lot of medical problems.

Zoe also discussed the point when she had enough of what medicine had to offer and decided that she had to live with the chronic pain.

Z: Like he tried me on a couple of different stuff, but like a lot of medications, make me really, really dizzy. So, like, we tried a lot of that stuff, and then we went back to a different doctor at Nationwide. And then like when I went into the hospital that's I think that's when we switched doctors. And then 'cause I went to the hospital twice, and I got like a lumbar puncture on the second time I went back 'cause it got to a point where I couldn't take it anymore.

Zoe discussed her concerns for fellow peers not understanding the difficulty she

was going through or how the chronic pain had complicated her life. She also discussed

how difficult it was to experience this level of chronic pain at such a young age.

R: What's the first thing you think about when living with chronic pain?

Z: It sucks, like to be honest with you, but like there is also good things. 'Cause we're getting a lot of life skills like people don't go through this until they're older. I've said this before like in some of my groups and stuff like people don't go through this like a lot until they're older. Like kids don't usually understand this 'cause they don't have like the mental capacity to understand that kids can suffer and that type of stuff but adults can do it, and also kids can do it at the same time. Like kids can get cancer 'cause we've like had that at our school and like kids understand that. But like chronic pain, people can't see, but like cancer, people usually can see because people start to lose their hair and all that stuff, but like chronic pain is harder to see.

Later, she elaborated on her description of the life with chronic pain. She became tearful when describing the friends she had lost through the process along with how difficult the re-integration process was for school due to her invisible disease.

Z: To describe it. Well like no one can see it, which is like the hard part 'cause nobody can understand unless like you've lived it. So like having kids who have lived it here really helps. 'Cause like for me ... I'm sorry! (crying). 
R: Don't worry about it.

Z: And the friends I had were just like push through it no matter what, and like you can still come to school. And like that's the goal, but I'm not going to be stumbling around and tripping over things, and not like sitting in class even if like I can't think. 'Cause, that's what people were like the friends were saying just like come to school no matter what 'cause they couldn't understand it or see it, and that's really hard.

Impact of chronic pain. Zoe struggled with school attendance due to her chronic

headaches. She described her school attendance at the initial onset of the headaches. She

also described how the side effects of the medications sometimes outweighed their

benefits over the headaches.

Z: And like it got really bad. Like we got the lumbar puncture, and they did a variety of stuff. They checked my eyes because I have Brown Syndrome like when I woke up one of my eyes aren't equal. Then we went to her, and I still go to her and then I've seen Dr. ***, and like they work together and like a few medications make me dizzy, so it's like really hard to find medications that don't make me dizzy. And then like in December, it was really hard 'cause I was in bed 'cause I left school 'cause I couldn't think 'cause I was on way to much dithromax 'cause I'd gone up to the max dose. And then I couldn't think, I couldn't concentrate, and then I like I didn't resume school until late January or early February, and I still like was having trouble concentrating, and I resumed with a tutor, and like I'm still doing school. And like I probably haven't, like been able to get back to everything, till like a month or so like my full concentration. So like it took me a while.

Next, she described her experience with school and her rapidly declining attendance.

Z: Like when I was going to school, I definitely like sometimes was a lot better, like my teachers are really good like they're very helpful, my schools been great like I'm on a 504 plan, and a lot of schools don't do that, especially for like headaches and stuff, which is really good. And then like, I want like, I would miss school, and like I have a twin sister, and she would like sit and take home the work for me and like I would do it even if I didn't feel like I could have gone to school, and then the next day I would go, and I would bring the work and stuff.

\section{R: Um hum.}

Z: And like I got to a point where I couldn't do that anymore. And like I didn't want to go to school if I didn't have the work done, and then like I stopped going to school, and like I just kept going farther and farther behind. 
Zoe also reported extensive occupational loss with her sleep. She had a poor sleep pattern along with limited restful nights. She described the difficulties that occurred when trying to wake up every day.

S: My sleep is everywhere, like I have trouble falling asleep and staying asleep and waking up. Like now the waking up is a little better. But like now I don't have to set it as loud like I can set it on half volume now on my phone. I'm really excited about that because I had to blast it, and I always woke up my parents or my sister, my mom. I usually don't remember waking up during the night, but like sometimes I have the feeling that I just woke up because I'm super tired and like sometimes I do remember it, like, 'cause I had a sleep study, and like it said I woke up three times during the night and I only remember waking up once. So, like I usually don't remember it at all. And then falling asleep, I just have trouble with it, like I kind of just usually stare at a point till I just like fall asleep and that seems to work for me.

Lastly, she describes the inability to participate in an active leisure sport, such as swimming, due to the chronic headaches.

S: I haven't really like done a lot like I really want to get back to swimming. And like that's a big thing for me cause like, I couldn't do it last summer or during this winter cause I left school, and then when I, I had a really bad summer, so I couldn't do it. Like I signed up, but I had to like cancel and all of that because I was like in bed. So, I couldn't do it.

Part of the impact of her chronic pain was the slow process of improving her occupational engagement in activities she enjoyed. Zoe described the obstacles she would need to overcome on her uphill climb towards improved occupational performance in the future as well. She discussed how each of the experiences living with chronic pain made her stronger and improved her ability to push through the pain.

R: Ok. What characteristics best describe you as a person living with chronic pain?

Z: Resilient.

R: Ok. 
Z: Do I have to explain them or ...

R: It'd be nice.

Z: Ok. Resilient, because like after December, like in that bad time, I like accepted it, and like realized I'm going to have to live through it. There's going to be ups and downs, but I'm going to have to push through it, and like live my life because I don't know how long it's going to be that I have this. Or am I going to have it the rest of my life? I just don't know. And then, another one. Strong, because like I've pushed through it, and like I had a hard time with it in December, like I got to a point like I said where I fell down the stairs, and that was really hard on me. And I like pushed through everything.

Lastly, she contrasted chronic pain with someone who has cancer. She describes the physical changes someone who has cancer encounters versus someone with chronic pain does not have any outward physical changes, making it difficult for classmates to understand the difficulties they are going through.

Z: Like kids can get cancer 'cause we've like had that at our school and like kids understand that. But like chronic pain, people can't see, but like cancer, people usually can see because people start to lose their hair and all that stuff, but like chronic pain is harder to see.

Zoe struggled with her chronic daily headaches. She demonstrated occupational loss across many domains, including sleep. Poor sleep affected participation in many of her occupations, including attending school, playing sports, and engaging socially with friends. This lack of participation ultimately caused her to lose all friends, which was a major stressor for her. She discussed her uphill climb towards being able to regain control of her life by pushing through the pain. She identified herself as resilient and being able to succeed.

Participant \#10 Patrick. Patrick described himself as a 17-year-old male who has chronic daily headaches due to a concussion along with physical deconditioning. He was on track to graduate this past May, however, was not able to return to school in time to complete all work necessary. During the interview he demonstrated anger and 
frustration at the child who forced him down to the ground by grabbing his football helmet and throwing his head down to the ground. Despite this anger he expressed, he stated he would not wish his headaches upon that child.

Meaning of chronic pain. Patrick's life changed instantly the moment he received a concussion on the football field. His headaches would come and go initially, then become more persistent and had a higher degree of severity. Patrick's meaning of chronic pain was represented by his whole life living in his house with minimal connection to the outside world. Pain became his life, investing every moment into ways to avoid increasing the severity, which eventually led to changes in his overall emotional state and how he came across to others $(\mathrm{R}=$ researcher, $\mathrm{P}=$ Patrick $)$.

R: Any other characteristics that best describe you as a person living with chronic pain?

P: Way more quiet. Like I talked about earlier, I kind of have a fuller voice for a 17 year old or just for a person all together. And I would not talk like this at all. I can even, here I'll give you an example. I would talk more like this (in a low raspy voice), very raspy because it wouldn't hurt my head as much. Instead of talking like this, you know the richer fuller voice that people know me for. The raspier voice was just way easier for me to talk and less painful. I was definitely not as happy, I definitely was not as happy cheerful, they're both the same thing. So yeah, I mean overall I was just down in the dumps. When it comes to chronic pain really depression, chronic pain for me almost go hand and hand. It makes sense, I mean thinking about it just, it is a mental and physical thing. You know physical, you're in pain, for me it was 24 hours a day, seven days a week, that's going to take a toll on you physically. And I was just so tired I could have slept any time. You know snap my fingers, and I was out. I mean it's hard being positive when you're in that pain. Oh, maybe I'm going to be good tomorrow, no you're not. Even the next day, no, or maybe in an hour, no and just having it where, oh maybe next week. When that next week comes around you're not better, maybe next month, no. It got to the point where I was going to say maybe next year. I'm here and you know what I'm thinking about? Hey in a year I might not have headaches.

He further described his unknown future and whether he would be able to continue his life despite the chronic pain. 
P: This sucks for me to say, and I really hate saying this, there's a reason I'm on Topamax, there's a reason I'm on Prozac, and it's because there was no hope. The reason I came here was because this is our last hope. The nerve blockers, everything, nerve blockers, the Botox injections into my skull, and this clinic was the last thing possible for me. And that's it, there was honestly no hope. And to this day my mom will probably cry on this ground, cry anywhere if she thinks about it again. I would, too. Think about it. I mean it's taken a bit for me to keep a straight face here. But, there really was no hope.

Lastly, he described some of his darkest moments with depression and his chronic pain.

He demonstrated great insight into the tumultuous times battling suicide.

P: And I mean starting where I began, there is a reason why I'm on Prozac because there was nothing for me to do. And I'm going to end on a sad note here. There were points where I almost, sorry there were points were I almost thought about killing myself. Because I really did not see any reason to stay alive. And it sucked; it's no way a life should be.

Patrick described the scenario that occurred when his accident occurred and when

his headaches developed. Due to the mechanisms of the injury, there was no visible scar or injury to others on his team and classmates. In the following description, Patrick explained the initial injury that led up to his disease.

P: The reason I was admitted was because I was, well, we believe this is the cause of it. I have headaches and the reason we believe I have headaches is because I was face-masked in football. I was face-masked in football by a fellow teammate during a practice where he attempted to snap my head back and bring my head towards the ground where my chin hit the pavement, well the turf. The next day I went to the hospital because I was throwing up and had a headache in school. Was told I had a concussion, and ever since that day, I've had extreme headaches. And I really haven't been able to live life ever since.

Later, Patrick explained how he identified his personal identity and how his chronic pain affected his role as a "den mom." He also explained how he kept it hidden from others in order to "glue" himself back together in order to continue to help his friends.

P: I wrote it on my pain sheet while doing RT one day. That, it was a symbolism sheet of what it feels like whenever I'm in pain. And it was something like this, I'm a leader, I'm a Den Mom, I will always help people, and it's just about half way through the little segment I wrote is a picture of broken glass. So I will 
always help people then under it, no matter how many times I have to glue myself back together. It was hard that no one understood what I was going through. It felt as if no one could see my disease.

He also described how he had to grow up too quickly and how most people do not understand his chronic pain.

P: I'm not a normal teenager; you know I've been in predicaments where grownups haven't had to face.

Impact of chronic pain. Patrick suffered great occupational loss from his

concussion and chronic headaches. He described his downward spiral of how chronic pain took over his life.

R: So you told me some of your history as far as the chronic pain, went to the hospital. Tell me more after you were discharged from the hospital. What all happened?

P: Well, I was able to finish that year. I was getting the headaches once, twice a week, but I was able to finish it. During the summer, we thought it was all over, you know I wasn't getting the headaches, maybe once, twice a month, but nothing really to severe, and nothing we were even worried about. I mean we honestly didn't bat an eye at it.

R: Ok.

P: The following school year, my head, which was the first of many, exploded. Where it just got way worse, I was getting the headaches three, four times a week. I continued as far as I could in school until I was just missing so much school, I couldn't continue. About half way through that year, so just the beginning of second semester, we switched me over to home learning, where I had a teacher come to my house and tutor me. I really didn't complete my classes of junior year. I'm still technically a junior, a very late junior. And that's where I'm at, ever since then my headaches have just been to the point where 24/7, it's level 7 or 8 headache. Blindness, I'm either asleep or awake, I couldn't see from either of my eyes some days or just one of my eyes, left or right, partially in both eyes. I would either be asleep, or I'd be walking around, but I couldn't watch TV, I couldn't listen to music, I couldn't talk because all of that would hurt my head too much. I had to take the collar off my dog and my cat for that matter because those two things hurt. 
He further described how his life was reduced down to living solely in his room and

house. He rarely left the house to complete any form of leisure occupation.

R: Go back to before you came in the program, as far as bed and suffering. Can you tell me more about that?

P: What is there to say? That's what my life was: bed and suffering. I didn't leave my house unless I was dragged out by my parents. That was to either go shopping at most 3 hours on the weekend or to go fill up a gas tank in one of their cars. I didn't see my friends unless they came to visit me or by some luck of God, I was able to function during a weekend or Friday. That, I mean, the sad truth is I was in bed or roaming around my house brainlessly, 24 hours a day, 7 day a week for months. I was unable to do some homework or most homework, pretty much, or all homework, let's go with all homework. I was unable to do anything normal. I mean heck, my high school graduation was yesterday. My 2015 class was yesterday. My original intended class, even if I wasn't to graduate early 2015 was my intended class. So 0 and 0 , I struck out graduating early, oh I have my original class, no I'm now a year behind. That was my life. That and suffering.

Lastly, he described how the noises around his house limited his ability to complete daily occupations, such as his pets' collars or the dishes.

P: The house was noisy, the stairs creaked, they will always creak, I mean it's an old house. I had to take the bells off my dog; I had to take the bell off my cat's collar. I couldn't put away dishes from the dishwasher I mean that's loud, we have ceramic plates. I mean the thought of my dog barking makes me cringe. I couldn't, I mean we live right by a street; you know a single car honking would set off my head or make me 10 times worse. So, I mean I was stuck in the house.

A part of Patrick's return to functioning was to forgive the child who caused the

concussion and move on with his life. He had made great strides towards that effort and

described that in the following section:

P: *** I don't wish this on my worst of enemies is honestly true. I wouldn't wish this on the kid who gave it to me. That's karma ok, sure whatever, but it's too cruel of a punishment. After feeling that and suffering through, it I don't want to give it to anyone else. I don't want to have anyone else feel this. Why not help possibly fix this or try and be able to help fix this ailment.

Later, he discussed how he had grown from this experience being able to empathize with others who are in pain. 
P: You know it sounds cheesy, and you know I bet you that a good chunk of people you've interviewed have said this, but this has made me I guess more understanding more well-rounded person. You know, when I was a kid, I didn't understand when kids when other people were in pain. Oh get up it's just a bruise you know I never understood that pain. And now that I've felt it I understand what it's like to go through it. It's oh so just changed me as a person. There's no way of explaining it, you know my mom, my dad will tell you it but it's a good thing

Lastly, he described his ability to push through any challenge in his life and become a survivor. He prided himself in being able to come out of that darkness and being able to return to productive occupations.

P: Going through this pain and going through the program has almost made me a little more mature mentally because I have to be able to cope and get through my life. I have to get ready for adulthood. You know I'm turning 18 next month in almost 30 days. Getting through this, this could possibly be the lowest of a low in my life. I mean this is an excellent thing to say if I'm able to survive this I can survive anything. I can do it if I'm able to bounce back I can do it. I can and will. I will survive, I meant there is so many different ways I could say it, but it's all going to come down to its changed me for the better. It's perseverance, I can tolerate more pain I guess, that's a bad and a good thing. But it's just changed me a lot.

Patrick had a significant decline in occupational engagement across all domains,

including those in his house. His own environment became a limiting factor in his ability to cope with his pain and remain functional. He demonstrated significant depression from the inability for him to see where his future was heading and realize the decline in his occupational engagement. Despite reaching a severe level of depression, including suicidal thoughts, he made great strides in his ability to make the uphill climb to regain his life.

\section{Participant Artwork}

As part of those participants who received inpatient chronic pain treatment during the study, he or she engaged in creative expression drawings. Each drawing depicted his 
or her pain and life living with chronic pain. The expressive drawings of five participants who received inpatient chronic pain treatment over the course of this study are presented below. The participants were given verbal prompts of "Use one of these (pointing to the art supplies) materials and make a picture that describes your chronic pain." Each participant was asked to describe the drawing and its relationship to his or her pain. The researcher also analyzed each drawing and described each drawing in relation to the themes that arose from the data.

Drawing one by Patrick. The first portion of the drawing depicted a foreverexpanding pebble in a small box. The box could not contain the pressure from the pebble and, therefore, broke. The mushroom cloud represented a large explosion in his head. The last portion of the drawing depicted shattered glass; he described this part of the picture as his invincibility. No matter how many times he broke, he was able to put himself back together and to persevere. He also wrote out the words "It is part of me. Constant" describing the ongoing struggle with chronic pain that was part of his life. He described himself as a person who can overcome any obstacle by his description on the artwork. "No matter how many times I may shatter, I will always come back together." Despite having the chronic pain, he felt that he could "glue" himself back together in order to remain a leader amongst his family and friends. 


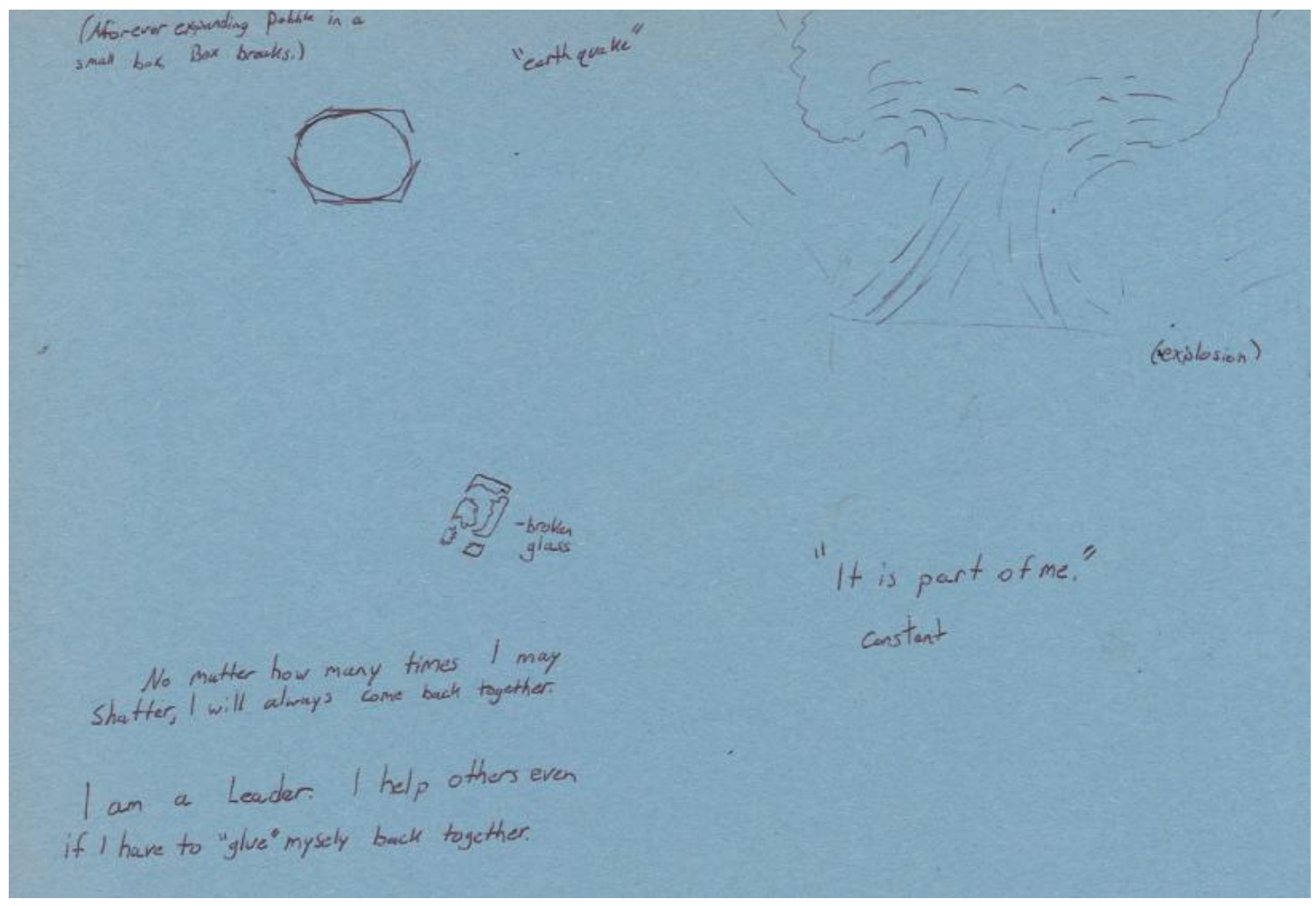

Figure 1. Patrick's drawing.

Drawing two by Zoe. The second drawing depicted the types of pain her

headaches caused. The arrows depicted sharp pains that were located in certain areas of her head, the can representing the squeezing feelings of her headaches, and the red vein on the side of her head as the throbbing portion of her headaches. The lifeline in the middle of the paper represented both the correspondence of spikes in pain along with the vicissitudes of her daily occupational engagement. 


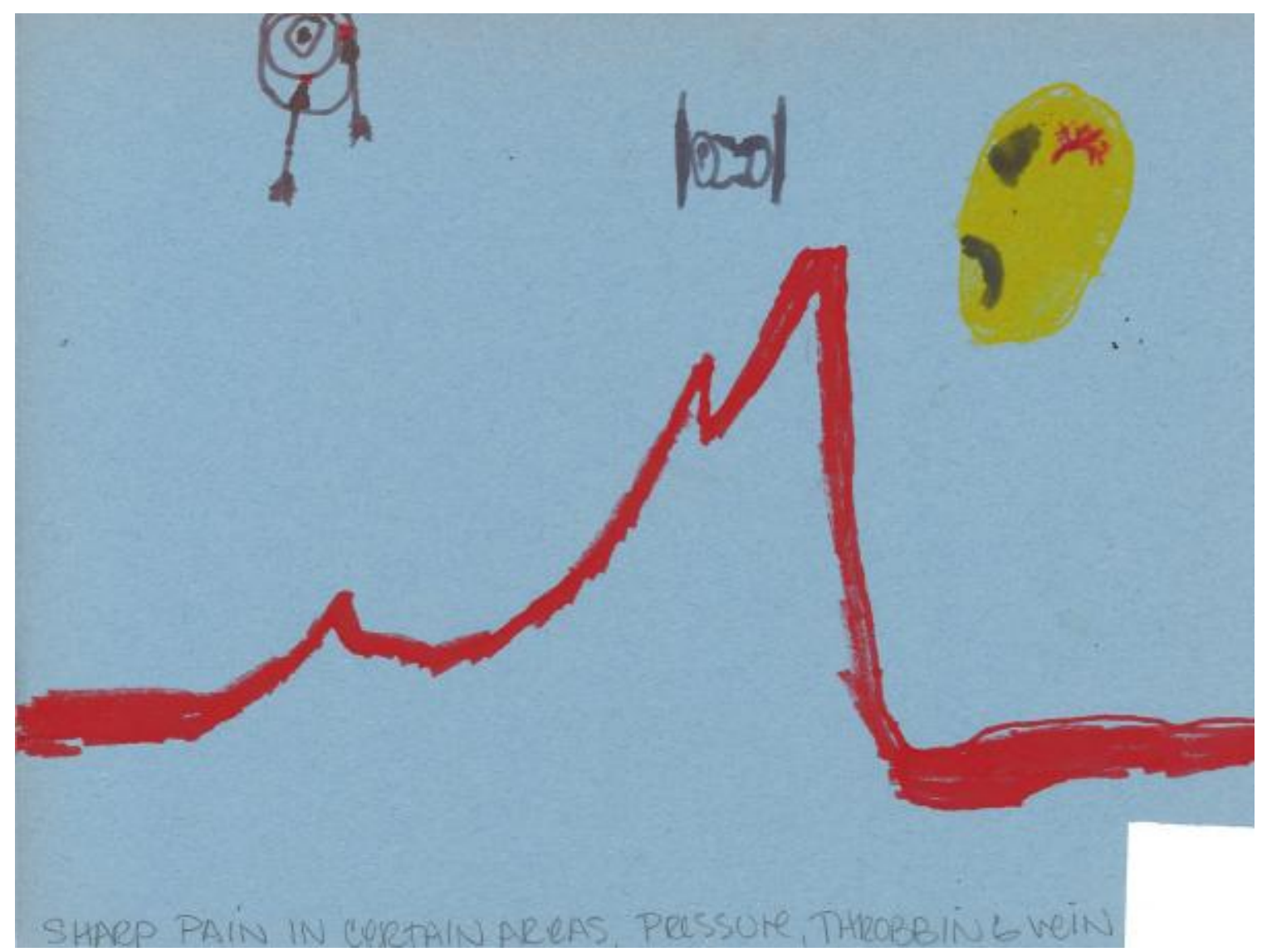

Figure 2. Zoe's drawing.

Drawing three by Sasha. The third drawing depicted the participant's sad emotions, including crying, fear, and the process of emotional release caused by the chronic pain. The lightning represented the striking pain of the headaches along with darker colors represented the darkness that lie inside of her (depression). The lettering was supposed to say "Head," however, was an error. The pain had caused strong emotional changes that changed her overall self. She used strong analogies of lightening and rain as striking pain and depression in her picture. 


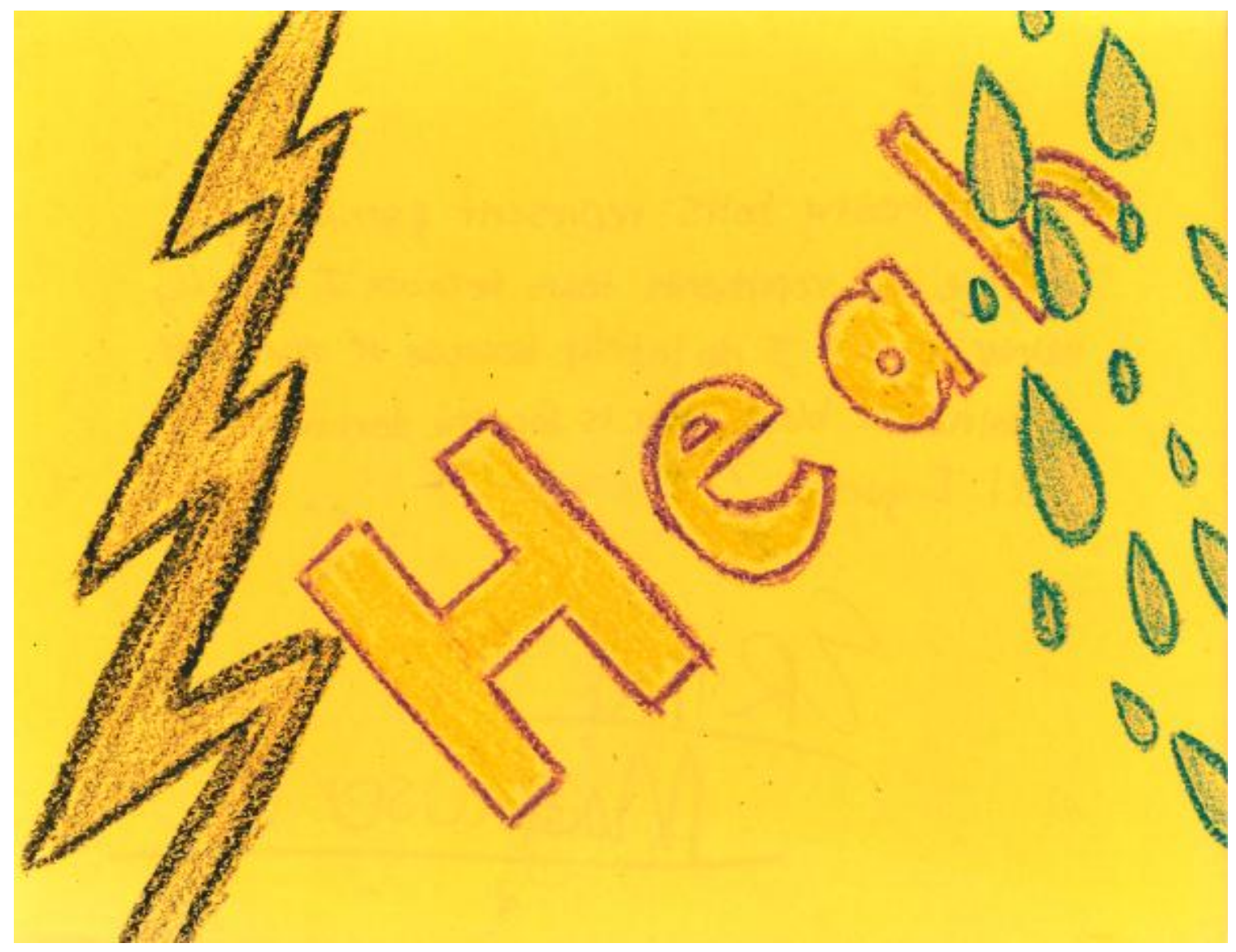

Figure 3. Sasha's drawing.

Drawing four by Emma. The fourth drawing depicted her persistent and penetrating daily headaches. The clock represented how headaches occurred at all hours of the day with the boom that represented the loud noises she heard on a daily basis. Notice the varying sizes and print font she wrote the words "Boom" in her picture. The changes in the size of the print depicted the varying degree of pain she felt every day. The drill represented the penetrating headaches that she felt. The large ear represented the noises that are always present and non-avoidable and the explosion represented the explosive headache that she was feeling. She used the clock as a way to depict how the pain had become all encompassing at all hours of her day. 


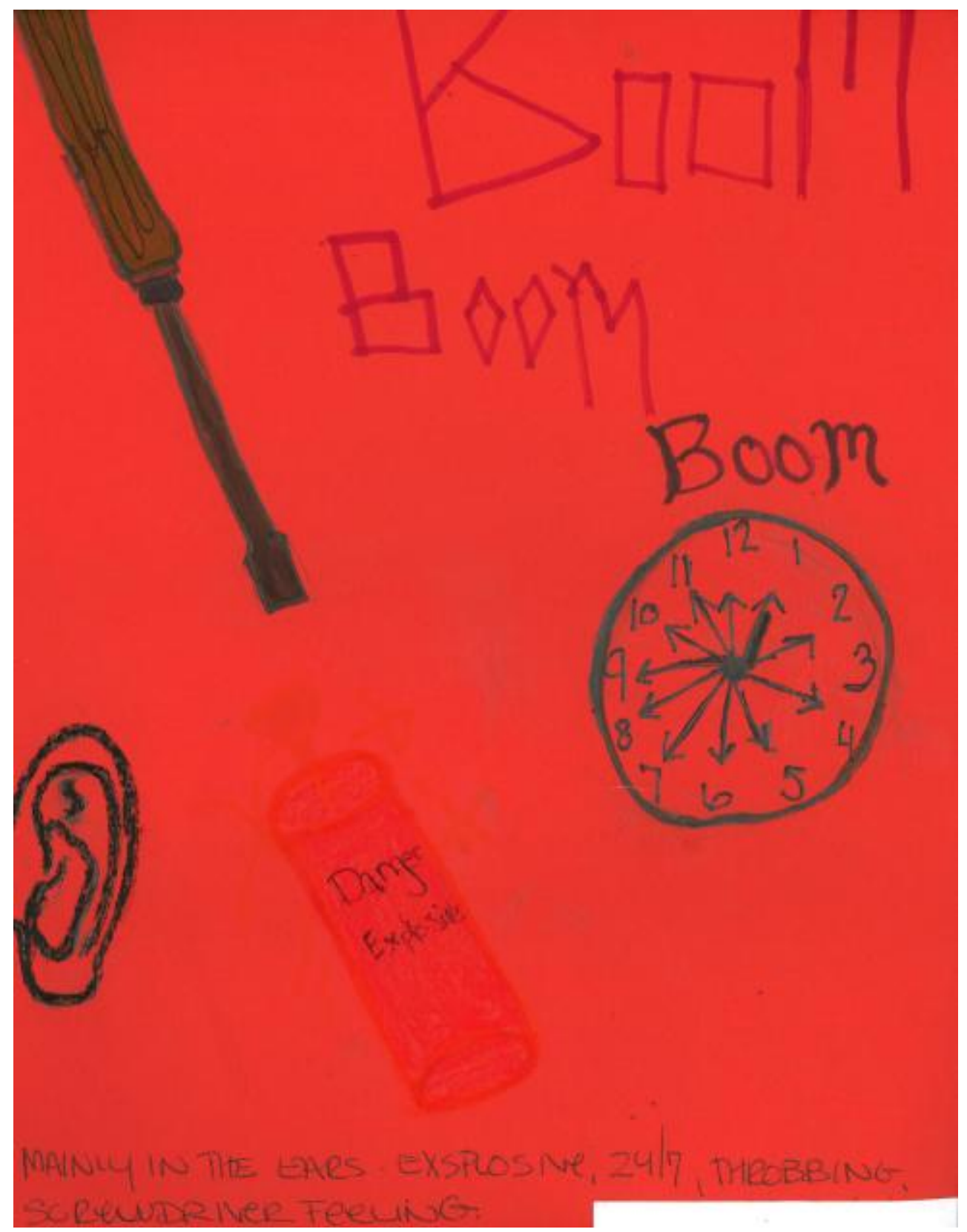

Figure 4. Emma's drawing.

Drawing five by Angie. This participant's drawing represented the disorganization and massive chaos she felt inside due to the chronic headaches. She depicted the disorganization through the jagged lines. She labeled her chronic pain as living in hell with the red and yellow representing heat and fire. She also labeled her drawing with the following words "Smash my head against wall—Chaos." If viewing the 
drawings as two depictions, there was a transformation between the top and bottom one with a more organized picture on the bottom. The bottom picture also had more dark tones representing more mood disturbance.

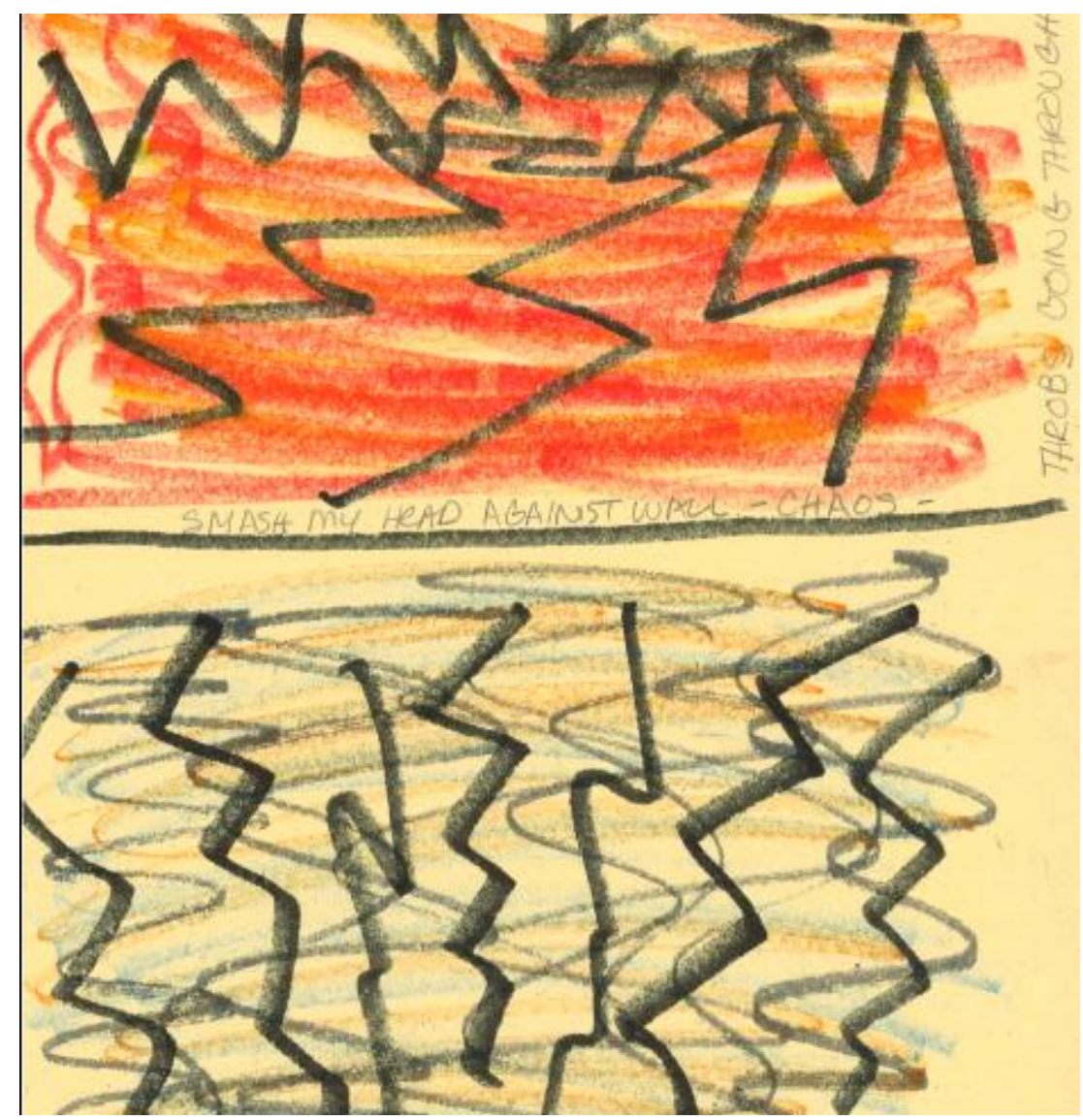

Figure 5. Angie's drawing.

\section{Themes of the Findings}

During the process of data analysis, four overarching themes were evident for all participants in the study. Results of the analysis illuminated the tumultuous lives adolescents living with chronic pain live on a daily basis. The themes that arose from data analysis are pain identity, invisible disease, occupational loss, and uphill climb to regain life. Themes and subthemes were organized in Table 2.

Table 2

\section{Thematic Themes}




\begin{tabular}{|c|c|}
\hline Thematic themes & Subthemes \\
\hline Pain identity & $\begin{array}{l}\text { Changes in self } \\
\text { Unknown future }\end{array}$ \\
\hline Invisible disease & $\begin{array}{l}\text { Uncertainty of diagnosis } \\
\text { Fabrication of symptoms }\end{array}$ \\
\hline Occupational Loss & $\begin{array}{l}\text { Loss of independence } \\
\text { Pain becoming main occupation }\end{array}$ \\
\hline Uphill climb to regain life & $\begin{array}{l}\text { Survivor } \\
\text { Push through pain }\end{array}$ \\
\hline
\end{tabular}

\section{Textural and Structural Description of the Meaning and Essence of the Experience}

Results of the thematic analysis were isolated by combining themes from each participant, reducing them down to the essentials common to the participants' experience, and eliminating those that were not common among them. The themes that emerged from the thematic analysis were pain identity, invisible disease, occupational loss, and uphill climb to regain life. Each main theme also had subthemes that are described in each corresponding section below and presented in Table 2 .

Pain identity. The pain identity theme described the label and attributes that corresponded with living a life with chronic pain. Each participant in the study identified him or herself with this label and described in detail how chronic pain affected his or her life. Society has used labels, such as ethnicity, race, or gender to identify specific characteristics about a person. Adolescents in the study use the label chronic pain to describe themselves. This description aligns with the person construct in the PEO model (Law et al., 1996) because it becomes part of their personal identity: things that make them unique. Different from other labels, such as gender or race, chronic pain was seen as a hidden identity that most people, including friends and relatives, were not able to see or identify with. 
The reason for adopting the identity of living with chronic pain differed slightly for each participant, however, was directly related to the challenges each faced on a daily basis in order to maintain some assimilation to a normal adolescent's life, such as attending school, playing sports, or visiting with friends. The label helped to describe the challenges and obstacles they faced in order to return to typical life.

One subtheme that emerged under pain identity was changes in self. The adolescents in the study reported changes in themselves while living with chronic pain. They felt changes in their moods, their sense of helplessness, and sense of hopelessness about their future. They described challenges with feeling very depressed and anxious. Most adolescents reported having no pre-morbid history of depression or anxiety, prior to the onset of the chronic pain. Most reported not feeling themselves while living on a daily basis with chronic pain.

Emma captured the essence of the subtheme changes in self in the following quote:

It's just kind of sad, just not a happy place. Like you wake up every day and you don't want to move, and you go through the motions, and it just gets worse throughout the day. And then you can't fall asleep because you just had so much pain throughout your body that you're just kind of in a different . . . your own little world where it's just kind of sad. You eventually just kind of have to try and work through that.

They felt chronic pain had taken over all parts of their life and made it difficult to live the life that they previously lived. Angie expressed her mood disturbances and her chaotic life in drawing five. She eloquently depicted how her life felt chaotic due to the chronic pain and that it caused her to feel depressed and anxious. She described this part of her life as living in hell. Sasha also depicted her depression through her drawing of raindrops and lightning bolts, showing the wide range of emotions felt while living with chronic pain. 
The second subtheme that emerged was unknown future. At some point in the interview, each participant expressed concern about their futures. For some participants, this concern occurred sooner than it did for others. Some expressed the concern for their futures as soon as they started the downward spiral of poor occupational performance while others did not express concerns until months after they started demonstrating poor occupational performance globally. It became clear in the data that a majority of the participants had a well thought-out plan for their futures, including college and a career. This plan soon became distant or non-existent when they started to have chronic pain. It became difficult for each participant to see a future for him or herself or a way to execute the original plan for the future. Mia described this subtheme best in the following quote:

Living with chronic pain before I came here, I was sad, alone, and honestly scared of what was going to happen to my life, you know. It's just like scared . . . am I always going to live with this? And I understood that, even if I do get better this is still going to be an issue you know. This point of my life will still always be an issue even when I'm 21, I might feel better but I'll always have the chronic pain that has the chance of still coming back.

Invisible disease. A commonality among all participants was the challenges associated with living with an invisible disease. Peers and adults could not physically see the disabling chronic pain and the adolescent living with the chronic pain perceived others as believing he or she was faking the pain or the pain was psychologically driven. The perception of faking illness was described as widespread and across many domains including school, sports teams or extra-curricular groups, and home. According to the PEO model, the environments adolescents interact within are extrinsic factors that influence their occupational performance (Law et al., 1996). Many adolescents had difficulties with teachers not fully understanding their pain and thus not supporting them while needing to be out of the classroom. Others verbalized troubles with peers 
understanding why they are not able to participate in fun peer-related activities, thus ending friendships. Because of the misperceptions about chronic pain by peers and teachers, most of the adolescents in the study expressed a need to keep information about chronic pain hidden or give limited details about the condition. This, in turn, increased anxiety and isolation in the school environment and was a recipe for failure. Patrick expressed this theme best in the following quote:

The following school year, my head, which was the first of many, exploded. Where it just got way worse, I was getting the headaches three, four times a week. I continued as far as I could in school until I was just missing so much school I couldn't continue. About half way through that year, so just the beginning of second semester, we switched me over to home learning, where I had a teacher come to my house and tutor me. I really didn't complete my classes of junior year. I'm still technically a junior, a very late junior. And that's where I'm at ever since then my headaches have just been to the point where 24/7 it's level 7 or 8 headache.

The first subtheme identified under "invisible disease" was uncertainty of disease.

Each participant expressed concern about the unknown about his or her diagnosis and prognosis. Chronic pain was described as a type of condition that is typically not discovered through definitive diagnostic work. In other words, there was not a test that discovered whether the adolescent had the chronic pain condition. For instance, chronic headaches typically were not revealed through a magnetic resonance imaging (MRI) or other types of blood work. Instead, the MRI and other tests came back negative for anything significant, such as tumor. The physician ruled out all other causes for the headache and in the end and came up with the diagnosis of chronic daily headaches. Throughout the process, the adolescent had to live with the uncertainty of whether or not he or she would die from this condition or would be diagnosed with some type of 
condition and lived with the question of how life would be lived with daily headaches.

Sophia explained this subtheme in the following quote:

It was pretty scary. I didn't, I mean like the test made me nervous like having to do all that stuff, 'specially like the barium swallow that was really gross, but since I was a kid they gave me Kool-Aid in it. But once like all these test were coming back negative, they said I didn't have Crohn's, I didn't have Celiac, I didn't have all these things. So they're saying like no, no, no, but my mom's like well, that's a good thing you don't have Crohn's because that's a very severe disease. But also like not knowing what's wrong with you is kind of worse. So it was all kind of like stressful, I guess. It's scary.

The second subtheme identified was fabrication of symptoms. Participants perceived peers and professional staff, such as physicians, believing all symptoms they expressed were made-up or in their head. There was a consensus among all participants that they perceived, at least initially, that their medical providers believed all their symptoms were in their head. Participants' ability to trust their medical providers along with accepting the chronic pain was complicated by the perception of all their pain being caused by mental illness. In order to have full trust in their physician, the participants felt that the provider needed to listen fully to their story and to believe that their symptoms were real and not made-up.

Occupational loss. Each participant expressed significant occupational loss in his or her life while suffering from chronic pain. This topic has the strongest relationship to the main question about life with chronic pain and has a direct relation to the PEO model, describing the decline in occupational performance due to the interaction between the person, environment, and occupation (Law et al., 1996). Each participant expressed that chronic pain had significant global effects on his or her occupational engagement in various contexts, including at home, school, work, and during extra-curricular and social activities. Lily explained occupational loss in the following quote: 
I stopped being active, and I was in my bed a lot and I didn't, I stopped hanging out with friends. I more just stuck with family, and then I started to not hang out with family. I just stuck in my room. And I couldn't go to school. And I couldn't hang out with friends because of my head pain, and because I couldn't manage it and I didn't really do anything I wanted to. Kind of sucked. It didn't kind of, it sucked.

Chronic pain had significant effects on their ability to participate in school on a regular basis. The process had a snowball effect in which the adolescent would miss school on a semi-regular basis, adding to the amount of schoolwork to make-up. The adolescent would not be able to make-up the work on time, adding to the stress and anxiety of missed school along with adding to the chronic pain symptoms. They would also miss practice of their favorite sport or activity, reducing the amount of social interaction with friends. Zoe depicted her significant fluctuations in her occupational performance levels in her drawing using the red lifeline. Her ability to cope and the degree of engagement in occupations was depicted in her artwork.

The pain would limit the ability to leave the home, further isolating them from age-appropriate social interaction. Those adolescents who had a job at the onset of their chronic pain were not able to continue working on a regular basis, which limited their financial resources necessary to purchase items, such as a car or car insurance. Adolescents that wanted to obtain a job, an age-appropriate occupation, were neither able to apply nor work on a regular basis. The occupations that gave meaning to each of their lives were unachievable or achieved on such an irregular basis they became less desirable. This process led to increased depression and anxiety. Some participants described this process as a downward spiral, unable to stop themselves from reaching the bottom. In turn, this process caused them to have less desire to live or succeed in life. 
One subtheme identified in the study was loss of independence. Each adolescent in the study identified some degree in loss of independence. Some adolescents described a greater and more significant degree in loss, requiring ongoing assistance from one of their parents to accomplish their daily occupations, such as bathing and walking. Other participants described a loss of independence as the inability to drive themselves places due to their severity of headaches. The data also showed the importance of obtaining independence as a teenager was important, but very difficult with the ongoing battle of living life with chronic pain. Patrick explained the subtheme loss of independence best by describing his life stuck in his room attempting to avoid all noises while losing all ability to take care of himself:

The house was noisy, the stairs creaked, they will always creak, I mean it's an old house. I had to take the bells off my dog; I had to take the bell off my cat's collar. I couldn't put away dishes from the dishwasher I mean that's loud, we have ceramic plates. I mean the thought of my dog barking makes me cringe. I couldn't, I mean we live right by a street; you know a single car honking would set off my head or make me 10 times worse. So, I mean I was stuck in the house.

The second subtheme identified under the main theme of occupational loss was

pain becoming the main occupation. Along with the decreased occupational engagement came the void of occupational identity each participant identified with while living with chronic pain. Pain soon became the main occupation, filling the void that had occurred. A majority of their life became focused around chronic pain and the requirements to live that type of life. Doctor appointments soon replaced school attendance, medical tests soon replaced school examinations, and life within the four walls of their bedroom soon replaced the soccer or baseball field. Participants described this pain of their life as "sucking." That word helped capture the great despair that filled their lives while suffering from chronic pain. Emma depicted her life as a constant drain, pain being 
unavoidable and all encompassing due to the chronic pain in her drawing. Her drawing depicted a life in which pain had become her main occupation.

Uphill climb to regain life. The last theme that emerged from the data was the uphill climb to regain life. The participants described a long and treacherous path they each had to climb in order to regain prior occupational engagement. One important aspect of the recovery process was acceptance of the chronic pain. They each described different parts of their recovery process when they accepted the chronic pain and decided they needed to fight back in order to regain their life. Despite each describing an uphill climb, each participant had a slightly different experience when it came to how he or she initiated the climb. None of the participants described their journey as complete at the time of interview, rather an ongoing battle he or she needed to face each day. Each participant identified returning to school as the most important occupation he or she needed to accomplish. The participants described the success of school as leading to advancement in college and success in a career. The other important occupation each participant discussed was some form of leisure occupation, whether it was an active sport or some form of sit-down activity, such as painting. The participants identified the leisure occupation as one that they enjoyed and felt pride in prior to the onset of the chronic pain. Angie described the challenges that each participant described on the uphill climb to recovery in the following quote:

Like I don't know I like special needs in away, like serious special needs. I guess like having people like constantly having to help you. And because I guess I didn't really have much of an idea of how broad chronic pain is in away. Like, in just, yeah and I guess now when I think of living my life with chronic pain I know it's definitely doable because I've proved to myself I can. 'Cause I did it last weekend and I doing it now. And, you know, it just means a little extra work. And it might mean, you know, having to take maybe a few more medications than other people. Like, like I still I'm going to stay taking the Amitrix as a rescue 
medication in case it spikes up to a migraine. Like to the nausea to the point where it's like this but with the nausea. But, but like in general I think the living with chronic pain I think it just means living your life, but just having to work a little bit harder. And just, yeah just having to work a little bit harder and just having to push yourself a little bit harder than other people might have to.

The first subtheme identified was being a survivor. Identified by the participants as a traumatic event in their lives, they felt that their experience with chronic pain could be assimilated to other traumatic events, such as living through a house fire or living through cancer treatment. The participants described the event as very challenging; however, they were able to persevere through the event and become a better person and more equipped to live life than their peers. A majority of the participants identified living with chronic pain as not fair and that no one should have to live a life with it; however, they were able to see how chronic pain gave them insight into themselves and how they matured through the process. Patrick's drawing further strengthens this subtheme by depicting how he could overcome being "shattered," being able to come back from each challenge he faced from the chronic pain.

The second subtheme was the ability to push through the pain. Participants identified one of their strengths as being able to push through the pain in order to regain their lives. They acknowledged it was not an easy process, but one that each adolescent living with chronic pain would need to achieve in order to overcome the pain and live a more normal life. Each participant described some form of skill either he or she learned or had learned prior to the chronic pain that helped him or her overcome the severity of pain in order to focus on the occupations he or she enjoy. The coping skills differed among the different participants; however, the common thread was that the skill needed 
to be used on a regular basis in order to overcome the pain and focus on the function of daily life.

\section{Summary}

The purpose of Chapter 4 was to present the findings, which resulted from the analysis of the interview data and participant artwork. In this phenomenolgic study, the researcher used in-depth interviews and visual depictions of the pain from adolescents who lived on a daily basis with chronic pain in order to develop themes to help describe the essence of life as an adolescent living with chronic pain. The data analysis led to four main themes for the study: pain identity, invisible disease, occupational loss, and uphill climb to regain life. In this section, detailed descriptions of each participant's life were given, a combined analysis of the adolescents' life living with chronic pain along with analysis of the visual depictions completed by participants in the study. The next section gives a detailed interpretation of the data, recommendations for future research, and limitations of this study. 


\section{Chapter 5: Discussion}

\section{Introduction to the Chapter}

This phenomenologic study asked the question "What is the essence of the day-today experience of adolescents living with chronic pain?" Adolescents living with chronic pain helped to answer the question through in-depth interviews and visual depictions of chronic pain. Ten participants were individually interviewed over two separate sessions with five of them completing a visual depiction of their chronic pain as well. Thematic analysis (Moustakas, 1994) revealed four main themes and two subthemes for each of the main themes. The themes were framed using the PEO framework, focusing on the interaction between the constructs of person, environment, occupation, and occupational performance (Law et al., 1996) to help give a representation of the essence of life living with chronic pain. In this final chapter, the researcher discusses the results, implications for practice and future research, limitations of the study, and recommendations for future research.

\section{Discussion and Interpretation of Results}

Four major themes emerged from the study data: pain identity, invisible disease, occupational loss, and uphill climb to regain life. Subthemes under each theme were identified and will be discussed. The first theme was pain identity; each subject identified him or herself as someone who lived with chronic pain, and it identified a part of who they are. The second theme was invisible disease; chronic pain is a disease that cannot typically be seen, and therefore, a disease that is difficult to explain and to gain empathy from peers, health care providers, and teachers. The third theme identified in the study was occupational loss; each participant identified a significant loss in his or her 
ability to maintain a productive and meaningful life engaged in self-chosen occupations. The fourth theme identified in the study was uphill climb to regain life; each participant identified a steep decline in occupational engagement followed by a slow and steep uphill climb in order to regain his or her life and become productive once again.

\section{Pain Identity}

The first major theme identified in the study was pain identity. As identified in the PEO model, the personal attributes (part of the person context of the model) are those identified by the individual that help give him or her an identity and that directly interact with the environment and occupations the adolescent engages in for the purpose of occupational performance (Law et al., 1996). An important aspect of living with chronic pain was identifying oneself as living with chronic pain. This process occurred in a similar manner to patients diagnosed with cancer (Gallo-Silver \& Weiner, 2006). It also helped define an identity in the challenging lives the participants led. This process for the participants did not occur overnight, instead it occurred over a longer process of learning about the condition and embracing it as part of themselves. An important process of pain identity was acceptance of the pain condition. The process of acceptance occurred in various manners and over varying lengths of time for each participant; however, each participant described this process as important for recovery. Participants were torn between life prior to the pain and life now living with the pain. Viane's study about acceptance and functional improvements (2004) supported the finding found in this study of a relationship between acceptance of chronic pain and higher levels of occupational performance. Acceptance was also a common construct supported from the data in this study found in the uphill climb to regain life theme. An important part of returning to a 
more normal life was to accept the chronic pain that the adolescents were living with and to move beyond the pain in order to regain their prior life and engagement in occupations. Subthemes to pain identity were changes in self and unknown future. Long-term mental health problems that were reported in this study, such as depression and anxiety, can result from added stress and anxiety in all contexts for the adolescent living with chronic pain. This finding is supported by current literature on anxiety and chronic pain (Gil et al., 2003; Lynch et al., 2006; Varni et al., 1996). Depression, levels of anxiety, changes in mood, energy level, and overall enthusiasm for life can change as a result of chronic pain, which can lead to decreased occupational engagement and enjoyment. Participants were not able to engage in occupations if always tired and depressed on top of the pain. These changes are reflected in the PEO model that states personal attributes, environment, and occupations directly influence the level of occupational performance (Law et al., 1996). Mood changes are personal attributes that can have an influence on how well the adolescent with chronic pain can engage in self-chosen occupations. Ultimately, chronic pain can cause significant life changes in all personal attributes affecting mind, body, and soul. The downward spiral led them to being uncertain about the life they wanted to lead, which may have changed their career choices, their college experience, or their momentum for graduating high school.

\section{Invisible Disease}

Meyer described some identities as hidden, such as sexual orientation causing stigma, prejudice, and discrimination (Meyer, 2003). The label of chronic pain was identified as being similar to other subgroups, such as sexual orientation, because a chronic pain disease can be hidden from others. All participants stated their condition is 
unlike a broken bone or cancer because adolescents with these conditions typically have some physical sign there is something wrong. With chronic pain, it is very typical for the adolescent to have no outward sign he or she is living with chronic pain. Chronic pain's hidden disease drove adolescents with chronic pain to find a commonality and bond with other adolescents with chronic pain. Adolescents with chronic pain have a hidden identity due to the inability for laypersons to discern who has it or who does not. The inability for peers or authority figures to fully identify with those living with chronic pain can lead to added stress and anxiety (McCracken, 2005). The findings of this dissertation study found peers, especially of adolescent age, demonstrate difficulties empathizing due to inability to identify with the friend's chronic pain to their own lives. Teachers who did not understand or appreciate the dynamics of living with chronic pain may not give the appropriate and needed accommodations to the student in order to maintain daily school attendance and participation. Poor support by teachers and school administrators led to poor education opportunities and eventual withdrawal from school attendance or participation.

The subtheme fabrication of symptoms stemmed from the cause of the chronic pain typically not easily seen by peers, such as a broken bone or viral infection. A majority of the adolescents in the study identified being teased or not believed by their peers or teachers regarding their symptoms. This disbelief from peers caused a further separation from friends and increased social isolation. According to the PEO model, decreased social contexts (part of the environmental context in the model) can contribute to decreased occupational opportunities and thus decreased occupational performance, which can lead to decreased mood and other psychological effects (Law et al., 1996). A 
slow progression of losing friends led to decreased participation in school events, such as football games or going out with friends. This led to further depression and removal from socially appropriate activities.

The second subtheme associated with invisible disease was uncertainty of diagnosis. Due to difficulties diagnosing their conditions, the adolescents in this dissertation study felt an inability to accept their chronic pain. When a diagnosis was discovered from ruling out all other potential diseases, it was disconcerting and was commonly expressed as "what if they missed something"? "What if it is cancer, and they have not found it yet"? Or "What if it is a deadly disease they just do not know about"? were common comments about the initial stages of living with the chronic pain. There was a lack of direction for treatment associated with a lack of definitive diagnosis. If the adolescent did not receive a diagnosis he or she could be certain about and that there was no other disease, it was very difficult for him or her to accept the diagnosis and to move forward in life. This uncertainty also led to an unclear treatment pathway for the family to follow. There was not a prescribed way to cure the disease, instead a confusing pathway that did not explicitly describe how the adolescent and family should proceed with living life. These challenges lead to either a gradual or a steep decline in occupational performance.

\section{Occupational Loss}

One of the most discussed topics was the loss of occupational performance across all domains (school, home, leisure, and social). This process was common with the participants in the dissertation study and found in other studies on adolescents with chronic pain (Persson et al., 2004; Roth-Isigkeit et al., 2005). The loss of engagement in 
meaningful occupations (part of the occupation in the PEO model) led to increased depression and anxiety and ultimately a decreased desire to live or succeed in life. It became a slippery slope of decreased occupational engagement, withdrawal from social engagement in school and active leisure, and further emotional decline. The results from the dissertation study underscored the importance of engagement in meaning occupations as means to further development in social, physical, cognitive, and overall quality of life. Without the adolescent's ability to engage in occupations, his or her meaning of life became unclear.

An overwhelming consensus from the participants was that leisure occupations were the first to be lost due to the complexities and physical demands placed on them. Despite the adolescents having the strongest urge to continue participating in leisure occupations, they could not maintain the necessary engagement in the sport or activity in order to continue. They needed to drop out or greatly reduce the degree of participation. Participants believed leisure was very important due to the nature of it as a co-occupation with other peers that provided a balance between leisure and social participation. When the adolescents were unable to participate in these meaningful occupations, it caused a significant domino effect to other areas of occupation. Decreased participation in school, interaction with friends, and working a job led to decreased desire to return to full occupational performance. Participation in meaningful leisure occupations is an ageappropriate activity that improves positive youth development and represents trajectories of development (Petrenchik \& King, 2011). Therefore, adolescents with chronic pain had a hole or a missing part of their daily routine, causing a rift in their developmental trajectory. 
The adolescent's environment was an important factor in the degree of occupational loss he or she encountered. The adolescents' parents (part of the environment in the PEO model) played an important role in the participants' occupational loss. Many of the participants expressed some form of pain disability in one or both of their parents. The co-occupation of pain between the adolescent and their parent became a non-productive and unhealthy relationship that resulted in decreased occupational engagement and further disability. This finding corresponded with current literature on co-morbidity of pain symptoms within one home and the impact it has on the family's occupational engagement (Schanberg et al., 2001). Chronic pain and disability became commonplace in the home and a return to normal function was not priority, which affected the ability of the adolescent to overcome his or her chronic pain and improve engagement in their life.

Another parental factor described in the literature but was not found in the results of this dissertation study was parental catastrophizing. There is a correlation between the degree of parental catastrophizing of their child's pain and the degree of disability demonstrated by the adolescent with chronic pain (Logan \& Scharff, 2005; Palermo \& Eccleston, 2009). The results of this dissertation study did not reflect the influence of each participant's parents level of catastrophizing and his or her own degree of disability. Collectively, the results showed the opposite. The parents were very supportive in helping their son or daughter to return to a healthy and active lifestyle. A possible cause of the variation is decreased insight by the participants about their parents degree of catastrophizing or potential parent-child enmeshment. 
Loss in independence occurred with the loss in community mobility (driving, ambulation, or riding bicycle), including the inability to escape the realm of the house or loss in ability to self-manage basic daily living skills. Once again, one or both parents became a caregiver for the adolescent (Palermo \& Eccleston, 2009). For the adolescent, this process possibly led to a loss in role and caused further emotional distress. In place of the role of active and independent adolescent was the role of the chronic pain patient. Pain became the main occupation for these adolescents. School attendance was replaced by medical appointment attendance and leisure performance was replaced by sleep or passive leisure. Electronic devices became a main leisure occupation as well as an avenue for social interaction.

\section{Uphill Climb to Recovery}

In order for the adolescent to return to a balanced life engaging in meaningful age-appropriate occupations, they had to make an uphill climb to recovery. The results of the dissertation study showed that coping and acceptance were identified as important processes in reversing the downward slope, which corresponded closely with the literature that showed acceptance is an important step in overcoming chronic pain and demonstrating a healthy level of occupational engagement (Harris, Morley, \& Barton, 2003; McCracken, 1998). In order to make progress in daily functioning, the participants needed to accept the chronic pain diagnosis and accept the absence of a "cure" for their chronic disease. In addition to acceptance of the chronic pain, they needed to utilize various coping skills to overcome the pain and to make the gradual climb to recovery. The forms of coping used varied by each participant, however, had similar outcomes of improved functioning and occupational engagement. Although the process of the uphill 
climb to recovery was different for each individual, the commonality of the process was similar. Obtaining a close set of friends or family to support them through the process was important. Each participant started gradually by engaging in occupations for short periods with gradual increase in frequency and duration. As postulated in the PEO model (Law et al., 1996), the data in this dissertation study demonstrated that in order for the participants to find an appropriate level of occupational performance, they relied on a balance of personal attributes, the environment, and appropriate occupation.

A common subtheme was pushing through the pain in order to achieve the occupations desired by each participant. The participants described this process as one of the most challenging events in their lives and something they faced on a daily basis. Each had his or her own process for pushing through the pain; however, it was important to rely on family and friends as a source of strength during the tougher times. It was also important to have some form of occupation to look forward to on a regular basis, such as dancing, cleaning the house, and playing basketball. By pushing through the pain on a regular basis, each participant felt he or she was a survivor of this painful disease. Each participant identified him or herself as a survivor of chronic pain, which helped him or her identify a commonality with other adolescents with the same disease. This unique bond helped unite those with chronic pain and reduce the loneliness felt by having this condition. This finding closely aligned with the literature (Cheung \& Delfabbro, 2016) that showed patients with cancer self-identified as a survivor in order to develop a sense of self and a commonality with others experiencing similar experiences. In the literature, this was defined as survivorship (Cheung \& Delfabbro, 2016; Gibson et al., 2015). Similar to patients with cancer, participants in this dissertation study described a lonely 
period not knowing anyone with some form of chronic pain. Finding other survivors of chronic pain helped them to continue striving for improved occupational performance and return to a more normal life. Another important component of survivorship was reengaging in self-motivating occupations. Engagement provided the means for the adolescent to identity who he or she was as an individual along with being part of a group.

Engagement in meaningful occupations, such as leisure, was an important component of recovery. Leisure was the first self-chosen, motivating occupation that helped with returning to a normal life and improving quality of life. Modifications in the context, type, and frequency were important in the initial stages of engagement, which permitted a degree of engagement in some form of leisure without worsening the degree of pain. The leisure activity might not have been the identical form of prior occupation, however, permitted some degree of social interaction and feelings of success during engagement. Engagement also improved the participants' sense of well-being and quality of life. Adolescents expressed a sense of accomplishment in being a part of something important again. Both physical and emotional improvements were expressed through leisure engagement. Although still very challenging to accomplish, participants expressed that they felt like they could more easily tackle their chronic pain after they engaged in some form of leisure occupation. Engaging in leisure occupations allowed the adolescents to test and re-develop personal abilities through appropriate levels of challenge and stimulation (Petrenchik \& King, 2011). 


\section{Implications for Practice}

Occupational therapy practitioners have worked with adolescents who live with chronic pain in various settings, including schools, clinics, and hospitals. This dissertation research has some implications for occupational therapy practice with adolescents in a variety of settings, including providing a better understanding of the barriers to occupational performance for adolescents with chronic pain. In addition, the dissertation study underscores the importance of the therapeutic use of occupations as means to wellness and recovery.

There are personal attributes, such as mental health or personality traits; environmental factors, such as school regulations of no book bags in the halls or no water bottles in the classroom; or forms of occupations, such as attending gym class, which affect how adolescents perform in their self-chosen occupations. This dissertation study supported the role of occupational therapy practitioners being stronger advocates for students who have this "hidden" disability of chronic pain. Occupational therapists can help the student by improving accommodations needed for adolescents with chronic pain to succeed in the school environments, such as allowing them to have water at their desks, use of book bags in the hallways, and use of electronic books instead of print version to limit the amount they carry. Occupational therapy practitioners could provide improved interventions to this population by knowing these barriers and targeting either modified ways to engage in occupations, strengthening personal attributes in order to allow engagement, teaching coping strategies to improve occupational engagement, or a combination of any of these strategies to improve overall occupational performance across all domains. 
The practitioners can also help improve advocacy for this population. This area of practice is twofold: help to improve self-advocacy for the student and help improve advocacy by the parents for their adolescents. Improving self-advocacy for the student comes from education about chronic pain and 504 plans or other modification plans, teaching about the process of transitioning from high school to post-secondary education options, improving the adolescent's coping and assertiveness abilities, and education about the importance for disclosure of the pain condition to the school. Parent education about ways they can help advocate for their child is important. Educational curricula should include areas such as 504 plans, transition to college, role of leisure participation in recovery, appropriate levels of parent-child interaction, and ways to be supportive for the adolescent but continue to encourage the highest degree of occupational engagement.

Occupational therapy practitioners in schools and the community can help play a vital role in education of other staff and professionals. The occupational therapy practitioners' background and education in mental health and occupation-based intervention enhances the ability to educate other professionals about chronic pain and its effects on occupational performance across multiple environments. It is important to educate other professionals about the ramifications of these effects along with ways modifications can be made in the environment in order to improve overall engagement and performance of an adolescent with chronic pain.

The last implication for practice is the importance for occupational therapy practitioners to include siblings, parents, friends, and teachers when developing the plan of care at evaluation and periodically throughout treatment. Inclusion is an important step in the evaluation process due to the complexity of chronic pain and how it can affect 
the family and how the family can affect the adolescent with the pain and their occupational performance. Siblings can provide an important and unique perspective to how the chronic pain is affecting their brother or sister and with professional guidance can provide motivation for the adolescent to return to prior occupations or to try new ones. Often times, the parent is directly affected by the adolescent's chronic pain, taking time away from work and delaying or stopping prior occupations. Including parents in the care plan can be vital to improving the overall health and wellbeing of the family.

\section{Implications for Future Research}

The focus of this phenomenological study was to explore the lived experience of adolescents who live with chronic pain. Although the initial question was answered through this study, other questions emerged that need to be further scrutinized and researched. Three areas were identified for further research in the area of occupational therapy practitioners' role in treating adolescents with chronic pain. First, due to the scope of the study, only the adolescent's perspective was taken into account for the data collection. The parents and siblings of an adolescent with chronic pain could provide additional perspective about how the adolescent's chronic pain affects participation. The adolescent's chronic pain does not only affect him or herself, it affects the entire family. A study interviewing the parents and the siblings would provide additional content to the overall understanding of the essence of life living with or around someone with chronic pain.

A second area of research is implementation and measurement of the effectiveness of an occupational-therapy-practitioner-led leisure occupational performance group using a PEO model. As described in the results, leisure is one of the 
first motivating occupations that adolescents return to during their uphill climb to recovery. The group's focus would be for providing leisure occupation-based activities with peers who also have chronic pain in order to assess effectiveness of occupational therapy intervention on leisure participation, social-emotional skills, and quality of life. This group would focus solely on adolescents and be located in the community. Limiting the age group to adolescents would improve the cohesiveness of the group. Providing the services in the community provides real-world experience with either leisure occupations they used to participate in and/or provide an environment to allow exploration of new leisure occupations.

The third area for future research is an occupational-therapy-practitioner-led parent education group about the effects of chronic pain on occupational performance for adolescents with chronic pain. The group would address the common themes identified in this dissertation study: pain identity, invisible disease, occupational loss, and the uphill climb to regain life. The group would help parents become more aware of the global affects chronic pain can have on adolescents and educate them about ways to improve participation and enjoyment in daily occupations for themselves and adolescents with chronic pain.

The fourth area for future research is examining further the uphill climb to recovery longitudinally past 6 months of being in a pain rehabilitation program. There is no literature about this important aspect of recovery following the initial diagnosis of a chronic pain condition. There is a poor understanding of this process and ways that occupational therapy practitioners can help to speed up this process and to maximize the potential occupational performance of the adolescents living with chronic pain. There is 
also a poor understanding of methods or interventions practitioners could deliver to improve outcomes of this population.

The last area for future research is expanding the research for direct services provided by occupational therapy practitioners and outcomes related to occupational engagement and performance of adolescents with chronic pain. Identifying key interventions used with this population by practitioners will help determine effectiveness and improve success and speed of recovery. This process will also help to delineate a clearer guideline to practice.

\section{Limitations and Delimitations}

A better understanding of how humans work and live within the world has developed over time. Humans use phenomenological methods to understand phenomena that are poorly understood. The method has its strengths, but also has its limitations and delimitations. One limitation with this phenomenological study was its inability to generalize to the general population. Although generalizability is a limitation with phenomenology, it was not the aim of this study. The population and sample numbers were chosen specifically to find the point of saturation of data, which was achieved with 10 adolescents.

The second limitation worth noting was the time constraints of when each interview occurred. A majority of the sample was simultaneously enrolled in a threeweek intensive pain rehabilitation program while completing the interviews. The interviews had to be stacked within a one- to two-week period due to unavailability of the participants in the first week of their admission. This posed a limitation for the study due to the limited two-week time period in which the participant had to think between the two 
interviews and reflect on their life living with chronic pain. According to Munhall (2007), permitting time between interviews allows for self-reflection and potential for increased details about their experiences.

The third limitation of the study is the nature of self-reporting in the interviews and its potential for over or understating the entire scope of the adolescent's life.

Although children over the age of 4 are accurate up to $96 \%$ of the time during interviews (Steward \& Steward, 1996), there is still a potential for over or underrepresentation of information during a 1:1 interview with a researcher. The use of two interviews was used to allow the participant to clarify any overrepresentations or underrepresentation of data from the prior interview and to improve the accuracy of data reporting.

The fourth limitation of the study was the blurring of roles for the researcher. The researcher was both a treating therapist for the pediatric pain rehabilitation program along with sole researcher for this study. This limited his ability to fully separate from being the treating therapist while interviewing the participants. It was very important for him to continuously use both epoche and bracketing in order to complete each interview with a clear and open mind about the participants' responses without prejudgment (Creswell, 2007; Moustakas, 1994). The limitation of the researcher's blurred role might have also limited the participants' willingness to open up about their experiences with chronic pain.

The one delimitation self-imposed by the researcher was not expanding the population for the study to include family members or peers of adolescents who live with chronic pain, which would expand the scope of this study outside the timeline and ability of the researcher to complete this dissertation study in a timely manner. He chose the central storyteller, the adolescent in order to capture the essence of life living with 
chronic pain. Future studies might include other members of a household or peers of the adolescent in order to gain a better appreciation of the impact chronic pain has outside the adolescent himself or herself.

\section{Summary}

Chronic pain is like a broken alarm clock. Imagine that your morning alarm clock goes off at $7 \mathrm{am}$, and you roll over to hit the snooze button, but it doesn't turn off like it's supposed to do. You try banging the snooze bar, switching the alarm off, unplugging the clock, taking out the batteries, and even throwing it out the window, but it still keeps ringing. You're clearly awake at this point, so the ringing alarm clock is not doing any good anymore, but it just won't turn off. The pain alarm in our body can be just like this broken alarm clock. It can just keep ringing and ringing even though it's not helping us in any way (Coakley \& Schechter, 2013, p. 3).

This phenomenological study explored the lived experience of adolescents with chronic pain. Interviews and schematic representation of their lives gave an in-depth look into the essence of life living with chronic pain on a day-to-day basis. In this dissertation study, 10 participants agreed to give their insights into living with chronic pain. The results showed that the participants experienced commonalities, which the researcher organized into four themes: pain identity, invisible disease, occupational loss, and uphill climb to regain life. The dissertation study illustrated to occupational therapy practitioners the underlying issues adolescents face when dealing with chronic pain in order to provide insight into the decline in occupational performance. The dissertation study also provided insight into ways to help the adolescent make the uphill climb to return to prior occupational performance levels across all domains. Occupational therapy practitioners can help maximize occupational performance in adolescents with chronic pain to improve quality of life and the adolescent's future physical, emotional, and social trajectory. 


\section{References}

Alex, M., \& Ritchie, J. (1992). School-aged children's interpretation of their experience with acute surgical pain. Journal of Pediatric Nursing, 7, 171-180.

Ashby, S., Fitzgerald, M., \& Raine, S. (2012). The impact of chronic low back pain on leisure participation: Implications for occupational therapy. British Journal of Occupational Therapy, 75(11), 503-508. doi:

$10.4276 / 030802212 X 13522194759897$

Baum, C., \& Law, M. (1997). Occupational therapy practice: Focusing on occupational performance. American Journal of Occupational Therapy, 51(4), 277-288.

Bricher, G. (1999). Children and qualitative research methods: A review of the literature related to interview and interpretive processes. Nurse Researcher, 6(4), 65.

Broome, K., McKenna, K., Fleming, J., \& Worrall, L. (2009). Bus use and older people: A literature review applying the person-environment-occupation model in macro practice. Scandinavian Journal of Occupational Therapy, 16(1), 3-12. doi: doi:10.1080/11038120802326222

Brunner, F., Gymesi, A., Kissling, R., \& Bachmann, L. M. (2010). Disease-related knowledge of patients with chronic regional pain syndrome. Journal of Rehabilitation Medicine, 42(5), 458-462. doi: 10.2340/16501977-0539

Cheung, S. Y., \& Delfabbro, P. (2016). Are you a cancer survivor? A review on cancer identity. Journal of Cancer Survivorship: Research and Practice. Advance online publication. doi: 10.1007/s11764-016-0521-z 
Coakley, R., \& Schechter, N. (2013). Chronic pain is like ... The clinical use of analogy and metaphor in the treatment of chronic pain in children. Pediatric Pain Letter, 15(1), 1-8.

Cohen, L. L., Vowles, K. E., \& Eccleston, C. (2009). The impact of adolescent chronic pain on functioning: Disentangling the complex role of anxiety. Journal of Pain, 11(11), 1039-1046.

Committee on Advancing Pain Research, Care, and Education, \& Institute of Medicine. (2011). Relieving pain in America: A blueprint for transforming prevention, care, education, and research. Washington, DC: National Academies Press. Retrieved from http://www.nap.edu/catalog/13172/relieving-pain-in-america-a-blueprintfor-transforming-prevention-care

Creswell, J. (2002). Qualitative interviewing. In C. Laughton (Ed.), Qualitative research \& evaluation methods (pp. 339-427). Thousand Oaks, CA: Sage Publications, Inc. Creswell, J. (2007). Qualitative inquiry and research design (2 ${ }^{\text {nd }}$ ed.). Thousand Oaks, CA: Sage Publications.

Cronin, S., Curran, J., Iantorno, J., Murphy, K., Shaw, L., Boutcher, N., \& Knott, M. (2013). Work capacity assessment and return to work: A scoping review. Work: A Journal of Prevention, Assessment and Rehabilitation, 44(1), 37-55. doi: 10.3233/WOR-2012-01560

Dangel, T. (1998). Chronic pain management in children. Part I: Cancer and phantom pain. Paediatric Anaesthesia, 8(1), 5-10.

Data Resource Center for Child and Adolescent Health. (2007). National survey of children's health. from http://childhealthdata.org/browse/survey 
Desha, L. N., \& Ziviani, J. M. (2007). Use of time in childhood and adolescence: A literature review on the nature of activity participation and depression. Australian Occupational Therapy Journal, 54(1), 4-10.

Docherty, S., \& Sandelowski, M. (1999). Focus on qualitative methods: Interviewing children. Research in Nursing \& Health, 22(2), 177-185. doi: 10.1002/(SICI)1098-240X(199904)22:2<177::AID-NUR9>3.0.CO;2-H

Dyson, S., Atkin, K., Culley, L., Demaine, J., \& Dyson, S. (2012). School ethos and variation in health experience of young people with sickle cell disorder at school. Diversity \& Equality in Health \& Care, 9(1), 33-34.

Evans, S., Moieni, M., Taub, R., Subramanian, S. K., Tsao, J. C., Sternlieb, B., \& Zeltzer, L. K. (2010). Iyengar yoga for young adults with rheumatoid arthritis: Results from a mixed-methods pilot study. Journal of Pain and Symptom Management, 39(5), 904-913. doi: 10.1016/j.jpainsymman.2009.09.018

Ford, C., English, A., \& Sigman, G. (2004). Confidential health care for adolescents: Position paper of the Society for Adolescent Medicine. Journal of Adolescent Health, 35(2), 160-167. doi: http://dx.doi.org/10.1016/j.jadohealth.2004.03.002

Forgeron, P. A., King, S., Stinson, J. N., McGrath, P. J., MacDonald, A. J., \& Chambers, C. T. (2010). Social functioning and peer relationships in children and adolescents with chronic pain: A systematic review. Pain Research and Management, 15(1), 27-41.

Gallo-Silver, L., \& Weiner, M. (2006). Suvivors of childhood sexual abuse diagnosed with cancer: Managing the impact of early trauma on cancer treatment. Journal of Psychosocial Oncology, 24(1), 107-134. 
Gibson, A., D'Cruz, L., Janda, M., Beesley, V., Neale, R., \& Rowlands, I. (2015). Beyond survivorship? A discursive analysis of how people with pancreatic cancer negotiate identity transitions in their health. Journal of Health Psychology, 1-12.

Giese, T. (2005). Complementary and alternative medicine (CAM) position paper. American Journal of Occupational Therapy, 59(6), 653-655.

Gil, K. M., Carson, J. W., Porter, L. S., Ready, J., Valrie, C., Redding-Lallinger, R., \& Daeschner, C. (2003). Daily stress and mood and their association with pain, health-care use, and school activity in adolescents with sickle cell disease. Journal of Pediatric Psychology, 28(5), 363-373. doi: 10.1093/jpepsy/jsg026

Goodman, J. E., \& McGrath, P. J. (1991). The epidemiology of pain in children and adolescents: A review. Pain, 46(3), 247-264.

Harris, S., Morley, S., \& Barton, S. B. (2003). Role loss and emotional adjustment in chronic pain. Pain, 105(1-2), 363-370. doi: 10.1016/s0304-3959(03)00251-3

Hawtin, H., \& Sullivan, C. (2011). Experiences of mindfulness training in living with rheumatic disease: An interpretative phenomenological analysis. British Journal of Occupational Therapy, 74, 137-142.

Hills, A. P., Dengel, D. R., \& Lubans, D. R. (2015). Supporting public health priorities: recommendations for physical education and physical activity promotion in schools. Progress in Cardiovascular Diseases, 57(4), 368-374. doi: 10.1016/j.pcad.2014.09.010

Holtzman, S., \& Beggs, R. T. (2013). Yoga for chronic low back pain: A meta-analysis of randomized controlled trials. Pain Res Manag, 18(5), 267-272. 
Hunfeld, J., Perquin, C., Duivenvoorden, H., Hazebroek-Kampschreur, A., Passchier, J., van Suijlekom-Smit, L., \& van der Wouden, J. (2001). Chronic pain and its impact on quality of life in adolescents and their families. Journal of Pediatric Psychology, 26(3), 145-153. doi: 10.1093/jpepsy/26.3.145

Husserl, E. (1931). Ideas: General introduction to pure phenomenology. Evanston, IL: Northwestern University Press.

Irwin, L., \& Johnson, J. (2005). Interviewing young children: Explicating our practices and dilemmas. Qualitative Health Research, 15(6), 821-831. doi: $10.1177 / 1049732304273862$

Jaser, S., \& White, L. E. (2011). Coping and resilience in adolescents with Type 1 diabetes. Child: Care, Health \& Development, 37(3), 335-342. doi: 10.1111/j.1365-2214.2010.01184.x

Kaczynski, K. J., Claar, R. L., \& Logan, D. E. (2009). Testing gender as a moderator of associations between psychosocial variables and functional disability in children and adolescents with chronic pain. Journal of Pediatric Psychology, 34(7), 738748. doi: 10.1093/jpepsy/jsn113

Karoly, P., \& Ruehlman, L. S. (2006). Psychological "resilience" and its correlates in chronic pain: Findings from a national community sample. Pain, 123(1-2), 90-97. doi: 10.1016/j.pain.2006.02.014

Kennedy, H. (1979). The role of insight in child analysis: A developmental viewpoint. Journal of the American Psychoanalytic Association, 27S, 9-28.

Konijnenberg, A., Uiterwaal, C., Kimpen, J., van der Hoeven, J., Buitelaar, J., \& de Graeff-Meeder, E. (2005). Children with unexplained chronic pain: Substantial 
impairment in everyday life. Archives of Disease in Childhood, 90(7), 680-686. doi: 10.1136/adc.2004.056820

Kortesluoma, R.-L., Hentinen, M., \& Nikkonen, M. (2003). Conducting a qualitative child interview: Methodological considerations. Journal of Advanced Nursing, 42(5), 434-441. doi: 10.1046/j.1365-2648.2003.02643.x

Kuttner, L., Chambers, C. T., Hardial, J., Israel, D. M., Jacobson, K., \& Evans, K. (2006). A randomized trial of yoga for adolescents with irritable bowel syndrome. Pain Research and Management, 11(4), 217-223.

Kvillemo, P., \& Branstrom, R. (2011). Experiences of a mindfulness-based stressreduction intervention among patients with cancer. Cancer Nursing, 34(1), 24-31. doi: 10.1097/NCC.0b013e3181e2d0df

Langer, E. (2009). Mindfulness versus positive evaluation. In S. Lopez \& C. Snyder (Eds.), Oxford handbook of positive psychology (2nd ed., pp. 279-293). New York, NY: Oxford University Press, Inc.

Law, M. (1991). The environment: A focus for occupational therapy. Canadian Journal of Occupational Therapy, 58, 171-179.

Law, M. (2002). Participation in the occupations of everyday life. American Journal of Occupational Therapy, 56(6), 640-649.

Law, M., Cooper, B., Strong, S., Steward, D., Ribgy, P., \& Letts, L. (1996). The personenvironment-occupation model: A transactive approach to occupational performance. Canadian Journal of Occupational Therapy, 63(1), 9-23.

Law, M., Dunn, W., \& Baum, C. (2005). Measuring participation. In M. Law, C. Baum \& W. Dunn (Eds.), Measuring occupational performance: Supporting best practice 
in occupational therapy (2nd ed., pp. 107-128). Thorofare, NJ: SLACK Incorporated.

Lazarus, R., \& Folkman, S. (1984). Stress, appraisal, and coping. New York, NY: Springer.

Leavy, P. (2009). Methods meets art: Arts-based research practice. New York, NY: The Guilford Press.

Leigh, S. (1992). Myths, monsters, and magic: Personal perspectives and professional challenges of survival. Oncology Nursing Forum, 19(10), 1475-1480.

Lincoln, Y. S., \& Guba, E. G. (1985). Naturalistic inquiry. Beverly Hills, CA: Sage Publications.

Liptan, G., Mist, S., Wright, C., Arzt, A., \& Jones, K. D. (2013). A pilot study of myofascial release therapy compared to Swedish massage in fibromyalgia. Journal of Bodyworks and Movement Therapy, 17(3), 365-370. doi: 10.1016/j.jbmt.2012.11.010

Logan, D., \& Scharff, L. (2005). Relationships between family and parent characteristics and functional abilities in children with recurrent pain syndroms: An investigation of moderating effects on the pathway from pain to disability. Journal of Pediatric Psychology, 30, 698-707.

Logan, D., Simons, L., \& Carpino, E. (2012). Too sick for school? Parent influences on school functioning among children with chronic pain. Pain, 153(2), 437-443. doi: 10.1016/j.pain.2011.11.004 
Lynch, A. M., Kashikar-Zuck, S., Goldschneider, K. R., \& Jones, B. A. (2006).

Psychosocial risks for disability in children with chronic back pain. Journal of Pain, 7(4), 244-251. doi: 10.1016/j.jpain.2005.11.001

Lynch, A. M., Kashikar-Zuck, S., Goldschneider, K. R., \& Jones, B. A. (2007). Sex and age differences in coping styles among children with chronic pain. Journal of Pain Symptom Management, 33(2), 208-216. doi:

10.1016/j.jpainsymman.2006.07.014

Lyons, K. D. (2006). Occupation as a vehicle to surmount the psychosocial challenges of cancer. Occupational Therapy in Health Care, 20(2), 1-16. doi: doi:10.1080/J003v20n02_01

Mac Cobb, S. (2013). Mobility restriction and comorbidity in vision-impaired individuals living in the community. British Journal of Community Nursing, 18(12), 608-613.

Martin, A. L., McGrath, P. A., Brown, S. C., \& Katz, J. (2007a). Anxiety sensitivity, fear of pain and pain-related disability in children and adolescents with chronic pain. Pain Research and Management, 12(4), 267-272.

Martin, A. L., McGrath, P. A., Brown, S. C., \& Katz, J. (2007b). Children with chronic pain: Impact of sex and age on long-term outcomes. Pain, 128(1-2), 13-19. doi: 10.1016/j.pain.2006.08.027

McCracken, L. (1998). Learning to live with the pain: Acceptance of pain predicts adjustment in persons with chronic pain. Pain, 74, 21-27.

McCracken, L. (2005). Social context and acceptance of chronic pain: The role of solicitous and punishing responses. Pain, 113(1-2), 155-159. 
McCracken, L., \& Eccleston, C. (2003). Coping or acceptance: What to do about chronic pain? Pain, 105(1-2), 197-204.

Meyer, I. H. (2003). Prejudice, social stress, and mental health in lesbian, gay, and bisexual populations: Conceptual issues and research evidence. Psychological Bulletin, 129(5), 674-697. doi: 10.1037/0033-2909.129.5.674

Morrow, S., \& Smith, M. (2007). A grounded theory study: Appendix D. In J. Creswell (Ed.), Qualitative inquiry and research design: Choosing among five approaches (pp. 285-308). Thousand Oaks, CA: Sage Publications.

Moustakas, C. (1994). Phenomenology research methods. Thousand Oaks: Sage Publishing.

Munhall, P. L. (2007). A phenomenological method. In K. Sullivan (Ed.), Nursing Research: A Qualitative Perspective (4th ed., pp. 143-210). Sudbury, MA: Jones and Bartlett Publishers.

Nambi, G. S., \& Shah, A. A. (2013). Additional effect of Iyengar yoga and EMG biofeedback on pain and functional disability in chronic unilateral knee osteoarthritis. International Journal of Yoga, 6(2), 123-127. doi: 10.4103/09736131.113413

National Center for Complementary and Alternative Medicine. (2013). Complementary, alternative, or integrative health: What's in a name? Retrieved from http://nccam.nih.gov/health/whatiscam

Palermo, T., \& Eccleston, C. (2009). Parents of children and adolescents with chronic pain. Pain, 146(1-2), 15-17. doi: 10.1016/j.pain.2009.05.009 
Palermo, T., Putnam, J., Armstrong, G., \& Daily, S. (2007). Adolescent autonomy and family functioning are associated with headache-related disability. Clinical Journal of Pain, 2007(23), 458-465.

Patton, M. (2002). Qualitative research and evaluation methods (3rd ed.). Thousand Oaks, CA: Sage Publications.

Peachey-Hill, C., \& Law, M. (2000). Impact of environmental sensitivity on occupational performance. Canadian Journal of Occupational Therapy, 67(5), 304-313.

Peloquin, S. M., \& Ciro, C. A. (2013a). Population-centered life skills groups:

Perceptions of satisfaction and engagement. American Journal of Occupational Therapy, 67(5), 594-600. doi: 10.5014/ajot.2013.008425

Peloquin, S. M., \& Ciro, C. A. (2013b). Self-development groups among women in recovery: Client perceptions of satisfaction and engagement. American Journal of Occupational Therapy, 67(1), 82-90. doi: 10.5014/ajot.2013.004796

Perquin, C., Hazebroek-Kampschreur, A., Hunfeld, J., Bohnen, A., van Suijlekom-Smit, L., Passchier, J., \& van der Wouden, J. (2000). Pain in children and adolescents: A common experience. Pain, 87(1), 51-58.

Persson, D., Andersson, I., \& Eklund, M. (2011). Defying aches and revaluating daily doing: Occupational perspectives on adjusting to chronic pain. Scandinavian Journal of Occupational Therapy, 18(3), 188-197. doi: doi:10.3109/11038128.2010.509810

Persson, E., Rivano-Fischer, M., \& Eklund, M. (2004). Evaluation of changes in occupational performance among patients in a pain management program. 
Journal of Rehabilitation Medicine (Taylor \& Francis Ltd), 36(2), 85-91. doi: $10.1080 / 16501970310019142$

Petrenchik, T., \& King, G. (2011). Pathways to positive development: Childhood participation in everyday places and activities. In S. Bazyk (Ed.), Mental health promotion, prevention, and intervention with children and youth (pp. 71-94).

Bethesda, MD: American Occupational Therapy Association.

Petrenchik, T., King, G., \& Batorowicz, B. (2011). Children and youth with disabilities: Enhancing mental health through positive experiences of doing and belonging. In S. Bazyk (Ed.), Mental health promotion, prevention, and intervention with children and youth (pp. 189-205). Bethesda, MD: AOTA Press.

Rabizadeh, S., \& Dubinsky, M. (2013). Update in pediatric inflammatory bowel disease. Rheumatic Disease Clinics of North America, 39(4), 789-799. doi: 10.1016/j.rdc.2013.03.010

Ripat, J., \& Becker, P. (2012). Playground usability: What do playground users say? Occupational Therapy International, 19(3), 144-153. doi: 10.1002/oti.1331

Roley, S. S., DeLany, J. V., Barrows, C. J., Brownrigg, S., Honaker, D., Sava, D. I., . . . Youngstrom, M. J. (2008). Occupational therapy practice framework: Domain \& practice, 2nd edition. American Journal of Occupational Therapy, 62(6), 625-683.

Roth-Isigkeit, A., Stoven, H., Schwarzenberger, J., \& Schmucker, P. (2005). Pain among children and adolescents: Restrictions in daily living and triggering factors. Pediatrics, 115(2), e152-162. 
Schanberg, L. E., Anthony, K. K., Gil, K. M., Lefebvre, J. C., Kredich, D. W., \& Macharoni, L. M. (2001). Family pain history predicts child health status in children with chronic rheumatic disease. Pediatrics, 108(3), E47.

Schwartzman, A. J., Atler, K., Borg, B., \& Schwartzman, R. C. (2006). Fueling the engines: A role for occupational therapy in promoting healthy life transitions. Occupational Therapy in Health Care, 20(1), 39-59. doi: doi:10.1080/J003v20n01_03

Silva, F., Sampaio, R., Mancini, M., Luz, M., \& Alcântara, M. (2011). A qualitative study of workers with chronic pain in Brazil and its social consequences. Occupational Therapy International, 18(2), 85-95. doi: 10.1002/oti.302

Smith, B. W., \& Zautra, A. J. (2008). Vulnerability and resilience in women with arthritis: Test of a two-factor model. Journal of Consulting and Clinical Psychology, 76(5), 799-810. doi: 10.1111/1464-0597.00062.

Smorti, M. (2012). Adolescents' struggle against bone cancer: An explorative study on optimistic expectations of the future, resiliency and coping strategies. European Journal of Cancer Care, 21(2), 251-258. doi: 10.1111/j.1365-2354.2011.01271.x

Spee, L. A., Lisman-Van Leeuwen, Y., Benninga, M. A., Bierma-Zeinstra, S. M., \& Berger, M. Y. (2013). Prevalence, characteristics, and management of childhood functional abdominal pain in general practice. Scandinavian Journal of Primary Health Care, 31(4), 197-202. doi: 10.3109/02813432.2013.844405

Steward, M., \& Steward, D. (1996). Interviewing young children about body touch and handling. Monographs of the Society for Research in Child Development, 61(4-5), $1-248$. 
Strong, S., Rigby, P., Stewart, D., Law, M., Letts, L., \& Cooper, B. (1999). Application of the person environment-occupation model: A practical tool. Canadian Journal of Occupational Therapy, 66(3), 122-133.

Sturgeon, J., \& Zautra, A. (2010). Resilience: A new paradigm for adaptation to chronic pain. Current Pain and Headache Reports, 14(2), 105-112. doi: 10.1007/s11916010-0095-9

Sullivan, M., Rodgers, W., \& Kirsh, I. (2001). Catastrophizing, depression, and expectations for pain and emotional distress. Pain, 91, 147-154.

Tsao, J., Meldrum, M., Kim, S., Jacob, M., \& Zeltzer, L. (2007). Treatment preferences for CAM in children with chronic pain. Evidenced-Based Complementary and Alternative Medicine, 4(3), 367-374. doi: 10.1093/ecam/nel084

Tsao, J. C., Meldrum, M., Kim, S. C., \& Zeltzer, L. K. (2007). Anxiety sensitivity and health-related quality of life in children with chronic pain. Journal of Pain, 8(10), 814-823. doi: 10.1016/j.jpain.2007.05.011

Turk, D. C., \& Wilson, H. D. (2010). Fear of pain as a prognostic factor in chronic pain: Conceptual models, assessment, and treatment implications. Current Pain and Headache Reports, 14(2), 88-95.

United States Census Bureau. (2010). State and county quick facts. from http://quickfacts.census.gov/qfd/states/39/3916000.html

United States Census Bureau. (2011). Age distribution of the population by sex and region: 2011. Retrieved from http://www.census.gov/population/age/data/2011comp.html 
Van Huet, H., Innes, E., \& Stancliffe, R. (2012). Occupational therapists perspectives of factors influencing chronic pain management. Australian Occupational Therapy Journal, 60, 56-65.

van Kaam, A. (1966). Application of the phenomenological method. Existential foundations of psychology. Lanham, MD: University Press of America.

Van Manen, M. (1990). Researching lived experience: Human science for an action sensitive pedagogy. London, Ontario: The University of Western Ontario.

Varni, J. W., Rapoff, M. A., Waldron, S. A., Gragg, R. A., Bernstein, B. H., \& Lindsley, C. B. (1996). Chronic pain and emotional distress in children and adolescents. Journal of Developmental and Behavioral Pediatrics, 17(3), 154-161.

Vervoort, T., Goubert, L., Eccleston, C., Bijttebier, P., \& Crombez, G. (2006). Catastrophic thinking about pain is independently associated with pain severity, disability, and somatic complaints in school children and children with chronic pain. Journal of Pediatric Psychology, 31(7), 674-683. doi: 10.1093/jpepsy/jsj059

Viane, I., Crombez, G., Eccleston, C., Devulder, J., \& De Corte, W. (2004). Acceptance of the unpleasant reality of chronic pain: Effects upon attention to pain and engagement with daily activities. Pain, 112(3), 282-288. doi:

http://dx.doi.org/10.1016/j.pain.2004.09.008

Villarruel, F., \& Luster, T. (Eds.). (2006). The crisis in youth mental health (Vol. 2). Westport, CT: Praeger Publishers.

Vlaeyen, J. W. S., \& Morley, S. (2004). Active despite pain: The putative role of stoprules and current mood. Pain, 110(3), 512-516. doi: 10.1016/j.pain.2004.04.037 
Wilhelm, K., Wedgwood, L., Parker, G., Geerligs, L., \& Hadzi-Pavlovic, D. (2010). Predicting mental health and well-being in adulthood. Journal of Nervous \& Mental Disease, 198(2), 85-90.

Woodgate, R., \& Kristjanson, L. (1996). My hurts: Hospitalized young children's perceptions of acute pain. Qualitative Health Research, 6, 184-201.

Yeung, E., Arewasikporn, A., \& Zautra, A. (2012). Resilience and chronic pain. Journal of Social \& Clinical Psychology, 31(6), 593-617. doi: 10.1521/jscp.2012.31.6.593 


\section{Appendix A}

\section{CCF IRB Approval}

\section{E] Cleveland Clinic}

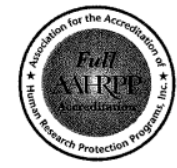

October 30, 2014

Ryan Suder, M.S

RE: IRB \#14-1269: The Lived Experience of Adolescents with Chronic Pain: A Phenomenological Study

Dear Mr. Suder:

Your response dated $10 / 22 / 2014$ to the prior review of your new study is acceptable. Your new study is now approved for the period $10 / 28 / 2014$ to $10 / 27 / 2015$

You are approved to begin this research with the use of New Study Application and Protocol 10/10/14, NOVA IRB Approval and Approved Consent and Assent Documents, Data Use Agreement and Recruitment Flyer. The Cleveland Clinic IRB has approve the use of an assent document for adolescents and a consent document fo permission of the parent. The consent interview should indicate the research is being conducted as part of a degree requirement and $\mathrm{Mr}$. Sudar is functioning as a researcher.

The stamp-approved Informed Consent, Assent and Flyer are available online under the Stamped Documents tab.

The IRB has classified this research as pediatric category \#2 under additional Protections for children involved as subjects in research. This level constitutes minimal risk with no direct benefit to the child but necessary in order to yield generalizable knowledge. You are responsible for obtaining the assent of the children capable of providing assent and the permission of at least one parent.

Any changes or amendments require IRB review and approval prior to implementation. Unanticipated problems including adverse events and deviations are to be reported in accordance with IRB Policy 60: Adverse Events and IRB Policy 70: Unanticipated Problems.

This study may not continue beyond the approved expiration date. Submit a renewal application up to 30 days prior to expiration to allow sufficient time for IRB review or a completion report for closure.

Sincerely,

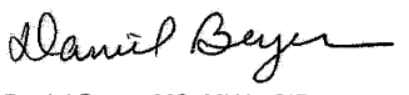

Daniel Beyer, MS, MHA, CIP

Executive Director, IRB and Human Research Protections

DB:II

Expiration Date: 10/27/2015

A signed version of this letter is available online under the Correspondence tab 


\title{
Appendix B
}

\section{Nova Southeastern University IRB Approval}

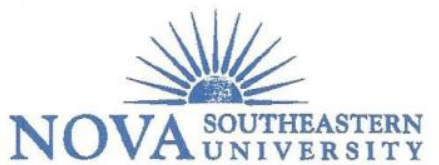

MEMORANDUM

\author{
To: $\quad$ Ryan Suder, M.S. \\ HPD - College of Health Care Sciences \\ From: David Thomas, M.D., J.D. RO for $\theta$. \\ Date: $\quad$ September 11, 2014 \\ Re: $\quad$ The Lived Experience of Adolescents with Chronic Pain: A Phenomenological Study- \\ NSU IRB No. 08041403Exp.
}

I have reviewed the revisions to the above-referenced research protocol by an expedited procedure. On behalf of the Institutional Review Board of Nova Southeastern University, The Lived Experience of Adolescents with Chronic Pain: A Phenomenological Study is approved in keeping with expedited review category \#6 and \#7. Your study is approved on September 11, 2014 and is approved until September 10, 2015. You are required to submit for continuing review by August 10, 2015. As principal investigator, you must adhere to the following requirements:

1) CONSENT: You must use the stamped (dated consent forms) attached when consenting subjects. The consent forms must indicate the approval and its date. The forms must be administered in such a manner that they are clearly understood by the subjects. The subjects must be given a copy of the signed consent document, and a copy must be placed with the subjects' confidential chart/file.

2) ADVERSE EVENTS/UNANTICIPATED PROBLEMS: The principal investigator is required to notify the IRB chair of any adverse reactions that may develop as a result of this study. Approval may be withdrawn if the problem is serious.

3) AMENDMENTS: Any changes in the study (e.g., procedures, consent forms, investigators, etc.) must be approved by the IRB prior to implementation.

4) CONTINUING REVIEWS: A continuing review (progress report) must be submitted by the continuing review date noted above. Please see the IRB web site for continuing review information.

5) FINAL REPORT: You are required to notify the IRB Office within 30 days of the conclusion of the research that the study has ended via the IRB Closing Report form.

The NSU IRB is in compliance with the requirements for the protection of human subjects prescribed in Part 46 of Title 45 of the Code of Federal Regulations (45 CFR 46) revised June 18, 1991.
Cc: Dr. Cathy Peirce
Dr. M. Samuel Cheng
Mr. Randy Denis


Appendix C

CCF IRB Amendment

View Letter

Page 1 of 1

Cleveland Clinic Institutional Review Board (IRB) Federalwide Assurance (FWA 00005367)

\section{E] Cleveland Clinic}

May 22, 2015

Ryan Suder, M.S

RE: IRB\# 14-1269: The Lived Experience of Adolescents with Chronic Pain: A Phenomenological Study

Dear Mr. Suder:

Your submission on $5 / 20 / 2015$ of the request to use drawings the children complete in the program that depict their pain was approved under expedited review on 5/22/2015.

The study expiration date of 10/27/2015 remains unchanged.

Sincerely,

Bridget toward

Bridget Howard, J.D.

Executive Director, IRB and Human Research Protections

BH:If

Expiration Date: 10/27/2015

This letter is available online under the Correspondence tab 
Appendix D

\section{Nova Southeastern University IRB Amendment}

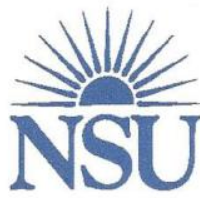

NOVA SOUTHEASTERN UNIVERSITY

Institutional Review Board

\section{MEMORANDUM}

To:

Ryan Suder, MS

HPD - College of Health Care Sciences

From:

Matthew Seamon, Pharm.D., JD

Chair, Institutional Review Board

Whts for Dr. Seamm

Date:

June 5, 2015

Re:

The Lived Experience of Adolescents with Chronic Pain: A Phenomenological StudyNSU IRB No. 08041403Exp.

I have reviewed the amendments to the above-referenced research protocol by an expedited procedure. On behalf of the Institutional Review Board of Nova Southeastern University, the following amendments to The Lived Experience of Adolescents with Chronic Pain: A Phenomenological Study are approved:

- PI will show scanned copies of participants drawings during a portion of their oral defense

Please note that this does not affect the continuing review date for this protocol.
Cc: Dr. Cathy Peirce
Dr. M. Samuel Cheng
Mr. William Smith




\section{Appendix E}

\section{Nova Southeastern University IRB Renewal}

\section{MEMORANDUM}

To:

Ryan Suder, MS

HPD - College of Health Care Sciences

From:

Cristina Garcia-Godoy, D.D.S., M.P.H., C.
$2^{\text {nd }}$ Vice Chair, Institutional Review Board

Date:

August 31, 2015

Re:

The Lived Experience of Adolescents with Chronic Pain: A Phenomenological StudyNSU IRB Protocol No. 08041403Exp.

I have reviewed the above-referenced research protocol in keeping with Continuing Review requirements by an expedited procedure. On behalf of the Institutional Review Board of Nova Southeastern University, The Lived Experience of Adolescents with Chronic Pain: A Phenomenological Study is approved. Your study is approved on August 28, 2015 and is approved until August 27, 2016. You are required to submit for continuing review by July 27, 2016. As principal investigator, you must adhere to the following requirements:

1) ADVERSE EVENTS/UNANTICIPATED PROBLEMS: The principal investigator is required to notify the IRB chair of any adverse reactions that may develop as a result of this study. Approval may be withdrawn if the problem is serious.

2) AMENDMENTS: Any changes in the study (e.g., procedures, new recruitment, investigators, etc.) must be approved by the IRB prior to implementation.

3) CONTINUING REVIEWS: A continuing review (progress report) must be submitted by the continuing review date noted above. Please see the IRB web site for continuing review information.

4) FINAL REPORT: You are required to notify the IRB Office within 30 days of the conclusion of the research that the study has ended via the IRB Closing Report form.

The NSU IRB is in compliance with the requirements for the protection of human subjects prescribed in Part 46 of Title 45 of the Code of Federal Regulations (45 CFR 46) revised June 18, 1991.

Cc: Dr. Cathy Peirce

Dr. M. Samuel Cheng

Mr. William Smith

3301 College Avenue • Fort Lauderdale, Florida 33314-7796 


\section{Appendix F}

\section{Recruitment Flyer}

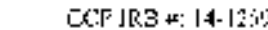

A

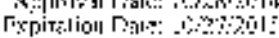

Lecrudtum Finger

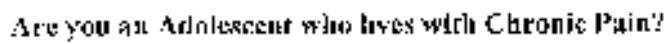

Lotsing for volputecer:

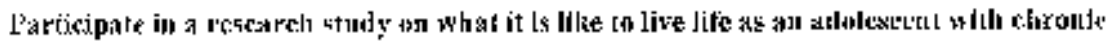
juin

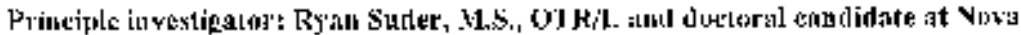

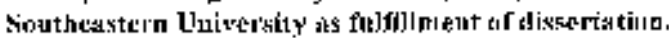

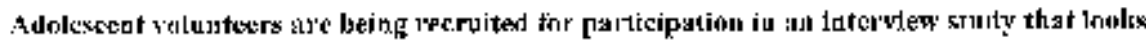

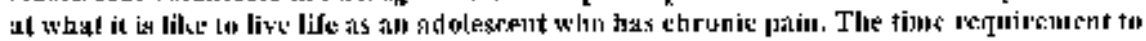

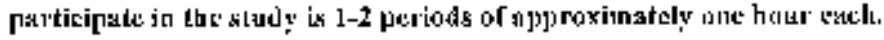

Thute will be und cost to you us part ar the study.

Pos sihlo participates te ligibility recpuirements are:

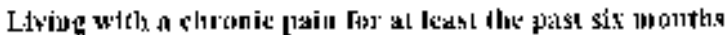

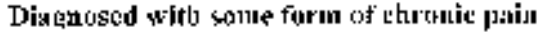

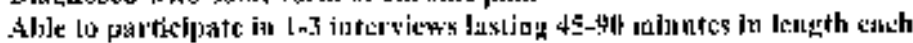

Belwe lles ases of 13 and 1 ?

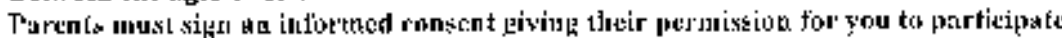

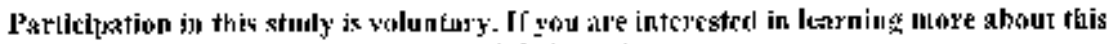
study, plestse unalie contagt to tha printiple invesilizalur at:

Lyan Suder, Rexearch F'rirutron levestigator

21 hi-448-64no ut- anderrig; 


\section{Appendix G}

\section{Parent/Guardian Consent Form}

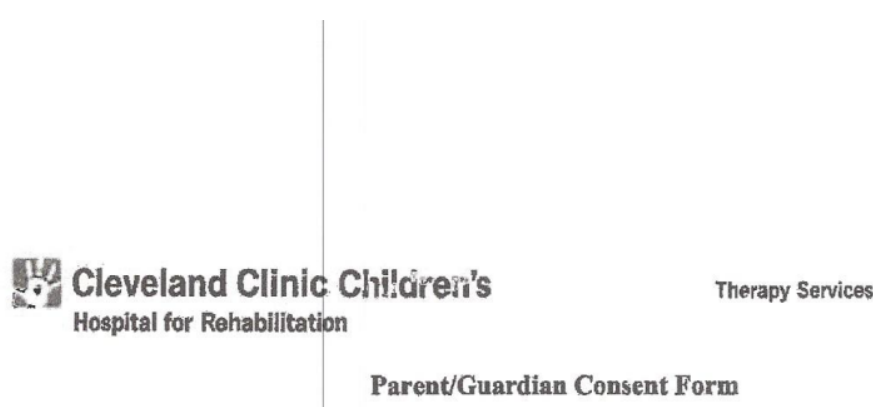

Parent/Guardian Consent Form for participation in the research study entitled "The Lived Experience of Adolescents with Chronic Pain: A. Phenomenological Study"

Funding Source: None

IRB protocol \#: $08041403 \mathrm{Exp}$

Principal investigator(s): Ryan C Suder

Degree: Master's of Science, Occupational Therapy and candidate for $\mathrm{Ph}$. . in Occupational Therapy at Nova Southeastern University

Address: 2801 MLK Jr. Drive, Cleveland, OH 44104

Contact phone number: $216-448-6400$

Committee Chair name and contact:

Dr: Cathy Peirce

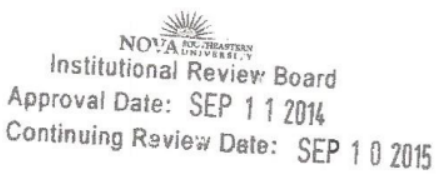

Nova Southeastern University

3200 S. University Drive

Darie, FL 33328

Ph: $954-202-1223$

Email: cpeirce@nova.edu

Cleveland Clinic Mentor

Dr. Ethan Benore

Phone: 216-448-6400

For questions/concerns about your research rights, cuntact

Human Research Oversight Board (Institutional Review Board or IRB)

Nova Southeastern University

(954) 262-5369/Toll Free: 866-499-0790

IRB(@),nsu.nova.edu

Or

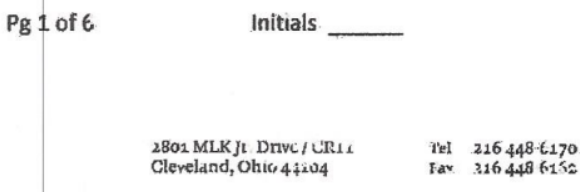


Institutional Review Board of Cleveland Clinic 216-444-2924 or IRB@ccf.org

Site Information

Cleveland Clinic Children's, Hospital for Rehabilitation

2801 MLK Jr Drive

Cleveland, $\mathrm{OH} 44104$

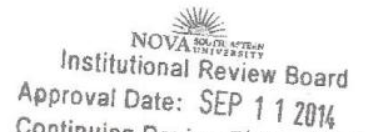

Continuing Review Date: SEP 182015

Your child is being invited to participate in a research study. A research study is designed to answer specific questions about new ways to prevent, detect, and treat disease. Being in a research study is different from being a patient. The purpose of this document is to provide a written summary of the discussion and exchange of research information you had with the research team. It is also for use as a reference during the study.

This research study has been approved by the Institutional Review Board (IRB). The IRB is a committee that reviews human research studies to ensure the safety and welfare of research volunteers are protected in accordance with federal human subject regulations and ethical principles

Please note:

- Your child is being asked to participate in a research study

- Ask as many questions as needed so you can make an informed decision.

- Carefully consider the risks, benefits, and alternatives of the research

- Your decision for your child to participate is completely voluntary and will have no effect on the quality of your medical care if you choose not to participate. You can also withdraw your child from the study at anytime.

What is the research about?

Your child is being asked to participate in a research study to look at what it is like to live a life as an adolescent with chronic pain. Your child is being asked to participate in the study because you have been living with chronic pain and might have insight into what it is like to live a life with pain on a day-to-day basis. This research could provide helpful information to occupational therapists who treat adolescents with chronic pain. The study will include around 10 adolescents who have been living with chronic pain for at least six months.

\section{What will I be doing?}

This research study will involve one to three interviews of each adolescent depending on how much follow-up the researcher needs with each adolescent. The interviews will last approximately 45-90 minutes and will be audio taped to ensure accurate depiction of the results for the researcher. Topics that will be included in the interviews are: day-to-day life living with chronic pain, activities the adolescent participates in and how chronic pain affects that
Pg 2 of 6
Initials 


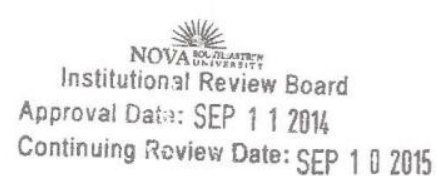

participation, and challenges faced living with chronic pain. With all research, there are minimal risks associated with participation. In this study, proper protections will be in place to reduce any associated risks to pain or distress associated with interviews. Some protections put in place are raw data access is limited to the researcher and institutional review board from either Cleveland Clinic Foundation or Nova Southeastern University (in limited cases for review) along with having access to medical and psychological referrals, if needed.

\section{Audio recording disclosure}

This research project will include audio recordings of each interview with the participants. These audio recordings will be available to be heard by the researcher, the IRB, and Dr. Ethan Benore. The recording will be transcribed by the researcher Ryan Suder. The recording will be kept securely in a locked cabinet only being accessed by the researcher at Cleveland Clinic Children's, Hospital for Rehabilitation. The recording will be kept for 60 months and destroyed after that time by Iron Mountain private health information services provided by Cleveland Clinic. Because your voice will be potentially identifiable by anyone who hears and sees the recordings, confidentiality for things you say or do on the recording cannot be guaranteed although the researcher will try to limit access to the tape as described in this paragraph.

\section{What risks are there for your child to participate in this study?}

All studies involving human subjects have some degree of risks. This research study has potential risks associated with participating in interviews and observations with the researcher. It is important for you to understand all risks associated with this study prior to your child participating.

Some risks that are associated with research are:

1. The possible stress and anxiety the interviews could produce.

2. The interviews also have time requirements for both the parent and adolescent. These are also possible risks to both parties.

3. Breach of confidentiality with any components of the data including loss of data. All safeguards will be taken including encryption of data, limited access of data including data being locked in protected cabinet and only accessed by researcher, research assistant, researcher's committee, and IRB.

If you have any questions about the research or your research rights, or you have a researchrelated injury, please contact Ryan Suder, principle investigator or committee chair, Dr. Cathy Peirce. Contact information is located on pg 1 of this document. You may also contact the IRB at the numbers indicated above with questions as to your research rights."

$\mathrm{Pg} 3$ of 6

Initials 


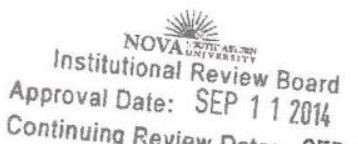

Continuing

Continuing Review Date: SEP 102015

What good things might come about for you or your child?

Research with human participants is completed to discover new information. In this study, there is no foreseeable direct benefit of either the child or parent. Future indirect benefits are possible for other adolescents who live with chronic pain.

What alternatives are there to participating in this research?

Alternative treatment to participating in this study involve, but are not limited to the pediatric pain rehabilitation program, outpatient therapy services, psychological services, and medical services. Please contact your child's medical provider for additional assistance, if needed. If your child is currently enrolled in the pediatric pain rehabilitation program, no changes to their current plan of care will occur if they participate in this research program.

\section{Do I have to pay for anything?}

There are no costs for you to participation in this study.

\section{Will I or my child get paid?}

There are no payments made for participating in this study.

\section{FIPAA Authorization (Privacy and Confidentiality)}

Cleveland Clinic and Nova Southeastern University have rules and procedures to protect information about you. Federal and State laws also protect your privacy.

The research team working on the study will collect information about you and your child. This includes your child's health information, data collected for this research study and personal identifying information which may include you or your child's name, address, date of birth and other identifying information.

Generally, only people on the research team will know your identity and that you are in the research study. However, sometimes other people at Cleveland Clinic may see or give out your information. These include people who review research studies including the Institutional Review Board and Research Compliance, their staff, lawyers, or other Cleveland Clinic staff.

People outside Cleveland Clinic may need to see you or your child's information for this study. Examples include committee members at Nova Southeastern University. Cleveland Clinic will do our best to ensure your information is kept confidential and that only the health information which is minimally required to conduct the study is used or disclosed to people outside Cleveland Clinic; however, people outside Cleveland Clinic who receive your information may not be covered by this promise.

$$
\operatorname{Pg} 4 \text { of } 6
$$

Initials 


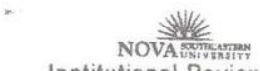
Institutional Review Board Approval Date: SEP 112014

Continuing Review Date: SEP 102015

You do not have to give this permission to use and give out your information; however you will not be able to participate in this research study without providing this permission by signing this consent form. The use and disclosure of your information has no expiration date.

You may cancel your permission to use and disclose your information at any time by notifying the Principal Investigator in writing, Ryan Suder, Cleveland Clinic Children's, Hospital for Rehabilitation, 2801 MLK Jr Dr, Cleveland, OH 44104. If you do cancel your permission to use and disclose your information, your child's participation in this study will end and no further information about your child will be collected. Your cancellation would not affect information already collected in the study.

\section{CONFLICT OF INTEREST}

This researcher and his team have no conflict of interests with this research study.

What if $I$ do not want my child to be in the study or my child does not want to be in the study?

You have the right to refuse for your child to participate or withdraw your child at any time. Your child may also refuse to participate or withdraw. If you do withdraw your child, or your child decides not to participate, neither you nor your child will experience any penaity or loss of services that you have a right to receive. If you choose to withdraw your child, or he/she decides to leave, any information collected about your child before the date of withdrawal will be kept in the research records for 60 months from the conclusion of the study and may be used as a part of the research.

\section{Other Considerations:}

If significant new information relating to the study becomes available, which may relate to your willingness to continue to participate, this information will be provided to you by the investigator.

Who do you call if you have any questions or problems?

If any questions or concerns arise during participation in this study, please contact the Primary Investigator, Ryan Suder at 216-448-6400 and ask him to be paged. He can be reached 24 hrs per day. 
Voluntary Consent by Participant:

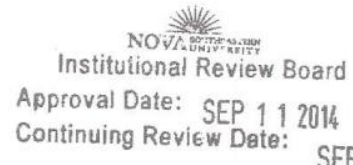

Continuing Review 112014

By signing below, you indicate that

- this study has been explained to you

- you have read this document or it has been read to you

- your questions about this research study have been answered

- you have been told that you may ask the researchers any study related questions in the future or contact them in the event of a research-related injury

- you have been told that you may ask Institutional Review Board (IRB) personnel questions about your study rights

- you are entitled to a copy of this form after you have read and signed it

- you voluntarily agree for your child to participate in the study entitled "The Lived Experience of Adolescents with Chronic Pain: A Phenomenological Study".

\section{Signatures}

\section{Statement of Participant}

I have read and have had verbally explained to me the above information and have had all my questions answered to my satisfaction. I understand that my child's participation is voluntary and that I may stop his/her participation in the study at any time. Signing this form does not watve any of my legal rights. I understand that a copy of this consent will be provided to me. By signing below, I agree for my son or daughter to take part in this research study.

\section{Permission of Parent/Legal Guardian}

You and your child have had the above research study explained to you and your child in language that you and your child can undersiand, and you give permission for your child's participation.

\begin{tabular}{l|l}
\hline Parent Name & \\
\hline Parent Name & \\
\hline Parent/Guardian Signature & Date \\
\hline Parent/Guardian Signature & Date \\
Pg 6 of 6 & \\
\end{tabular}




\section{Appendix $\mathrm{H}$}

\section{Child Assent Form}

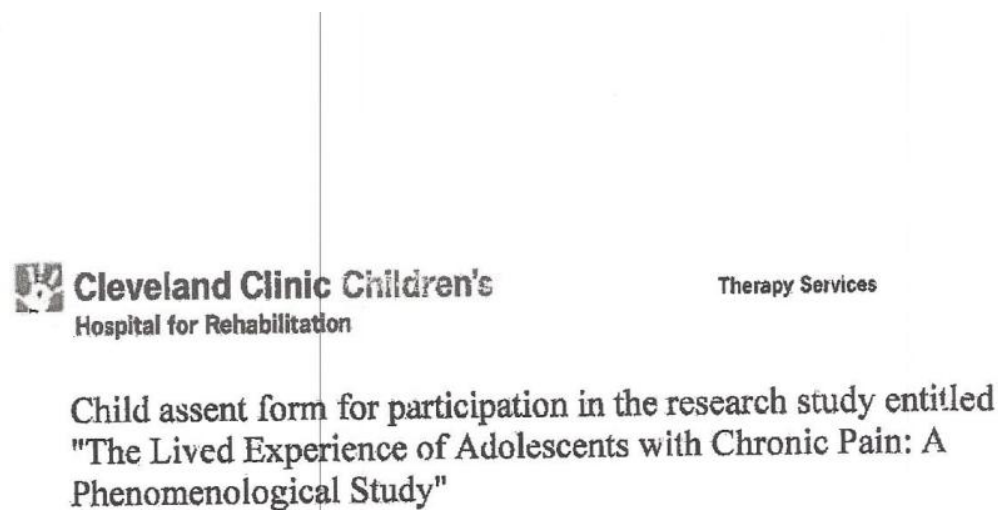

IRB protocol \#: 08041403 Exp.

Principal investigator(s): Ryan C Suder

Degree: Master's of Science, Occupational Therapy and candidate for Ph.D. in

Occupational Therapy at Nova Southeastern University

Address: 2801 MLK Jr. Drive, Cleveland, OH 44104

Contact phone number: $216-448-6400$

Cleveland Clinic Mentor

Dr. Ethian Benore

Phone: 216-448-6400

For questions/concerns about your research rights, contact:

Human Research Oversight Board (Institutional Review Board or IRB)

Nova Southeastern University

(954) 262-5369/Toll Free: 866-499-0790

IRB@nsu.nova.edu

Or

Institutional Review Board of Cleveland Clinic

216-444-2924 or IRB(@)cc,org

Site Information

Cleveland Clinic Children's. Hospital for Rehabilitation

2801 MLK Jr Drive

Cleveland, $\mathrm{OH} 44104$
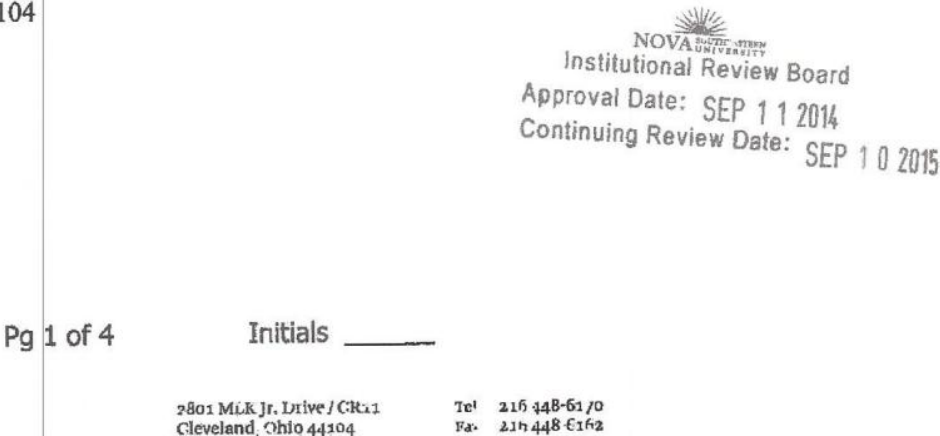


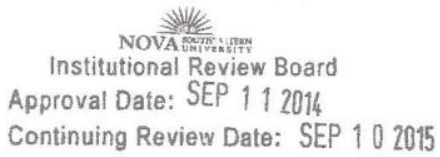

What is a research study?

Continuing Review Date: SEP 102015

Ryan Suder, researcher, is asking you to be in a research study. Research is a way to help us learn new things. Only people who decide they want to help will be in the study. He will tell you about the study and then you should take time to make your decision. You should talk to your parents or your guardian before you decide.

\section{Why is this study being done?}

This study's purpose is to understand more about what life is like as an adolescent living with chronic pain. The information learned in the study could benefit occupational therapists who work with adolescents with similar conditions. The study could also benefit other adolescents who live with chronic pain.

\section{What will happen to me?}

You will be involved in 1-3 interviews with Ryan that will last between $60-90$ minutes each. The interviews will ask questions about your life living with chronic pain. More specifically, the questions will ask about day-to-day life living with chronic pain and difficulties that you may face due to your condition. This will give you the opportunity to tell your story and inform others about the challenges and opportunities to make adolescent's lives that live with similar conditions better.

What are the good things about being in this study?

There are two good things that might happen.

1. Participating in the study may be a good opportunity to inform professionals about what life is like living with chronic pain. This may help other adolescents living with chronic pain in the future.

2. Participating in the study may lead to future research that will provide better treatment for adolescents with chronic pain.

\section{Will being in the study hurt me?}

There is no foreseeable physical risk for participating in this study. There is a potential risk of suffering discomfort from discussing living with chronic pain. There can be an emotional response to discussing your life. This response can be very individualized and hard to determine the degree of pain that could occur.

\section{How long will I be in the study?}

The study involves 1-3 interviews that each last $60-90$ minutes in length. Once the interviews are all completed, there is no other obligation to participate in the study.

$\operatorname{Pg} 2$ of $4 \quad$ Initials 


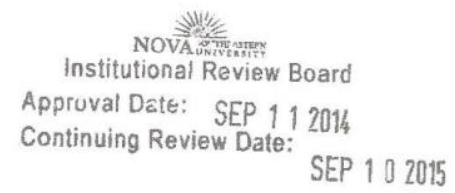

Do I have other choices?

There are no other alternatives to participating in the study. You may continue with your current level of treatment, whether outpatient therapy or chronic pain rehabilitation program.

\section{Will people know that I am in the study?}

Only the researcher and one person who helps him will see the questions that you answered. The researcher won't use your name when telling other people about the best way to help children like you.

\section{Who can I ask questions?}

If you have any questions you can ask Ryan Suder, researcher. Remember, you should also talk with your parents or your guardian about this study.

Is it OK if I say "No, I don't want to be in the study"?

You do not have to be a part of this study if you don't want to. No one will be mad or upset. There will also be no consequences of not participating and will not interfere with your current treatment you receive.

If you change your mind, you can decide during the study to stop being in the study.

If you ask not participate following conclusion of interviews and data analysis, the researcher will keep the information that he got while you were in the study.

$\mathrm{Pg} 3$ of $4 \quad$ Initlals 


\section{Do you understand and do you want to be in the study?} I understand. All my questions were answered.

I want to be in the study.

I don't want to be in the study.

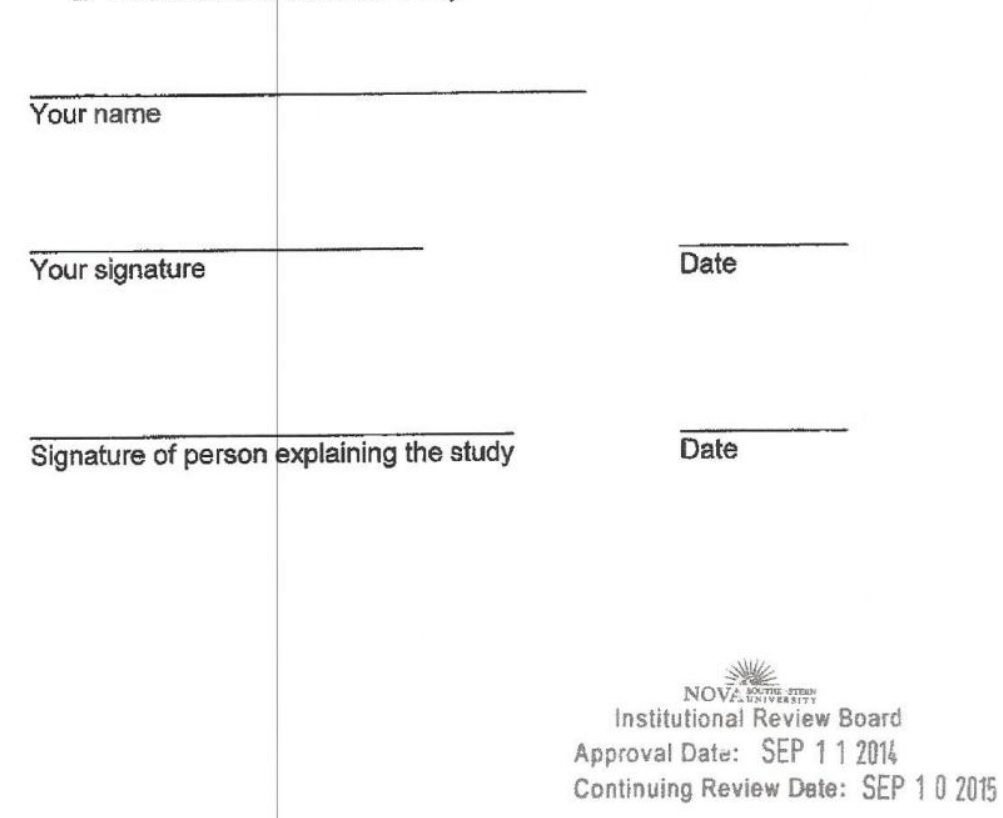

$\mathrm{Pg} 4$ of 4

Initials 


\section{Appendix I}

\section{Interview Guide}

Interview Guide:

1. Please introduce yourself and tell me about yourself.

2. Please tell me about how your chronic pain started.

3. What is the first thing that comes to mind when you think about living with chronic pain?

4. Please describe the experience of living life with chronic pain as an adolescent. What is it like living day-to-day with chronic pain?

Probe: What stands out about that experience?

5. Which characteristics best describe you as a person who lives with chronic pain?

6. What feelings or thoughts stand out to you in describing this experience of living with chronic pain?

7. Which activities or occupations help give you identity or meaning in your life? Has chronic pain changed your involvement in those occupations?

Probe: Out of school recreation, social participation, work, sleep

8. Tell me about any positive opportunities that you have experienced while living with chronic pain?

9. Are there certain places or people that have helped or hindered your ability to remain active?

10. What are some challenges that you face living with chronic pain?

Probe: How do those challenges shape your life? How do they affect your participation in leisure, work, school activities?

11. What other relevant information should I know in understanding the essence of what life is like as an adolescent with chronic pain? 